\title{
DHRS 2009
}

\section{Proceedings of the}

Ninth Danish Human-Computer Interaction Research Symposium. Aarhus, Denmark, December 14, 2009

Olav W. Bertelsen

Anne Marie Kanstrup (eds.)

DAIMI PB - 591

December 2009

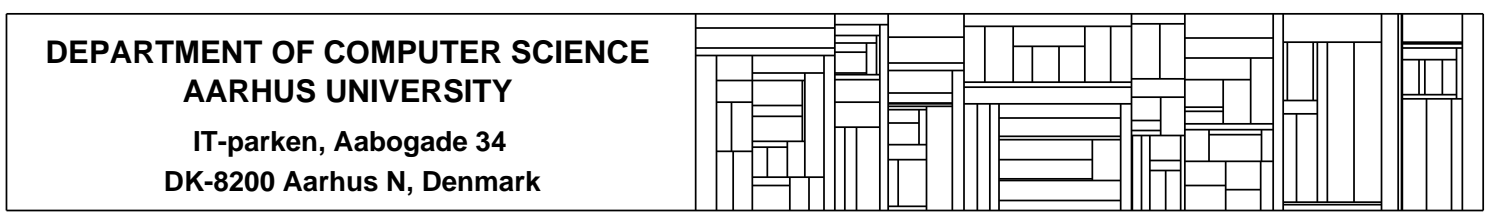





\title{
DHRS 2009
}

\section{Proceedings of the}

Ninth Danish Human-Computer Interaction Research Symposium.

\author{
Aarhus, Denmark, December 14, 2009
}

Olav W. Bertelsen

Anne Marie Kanstrup (eds.)

DAIMI PB - 591

December 2009

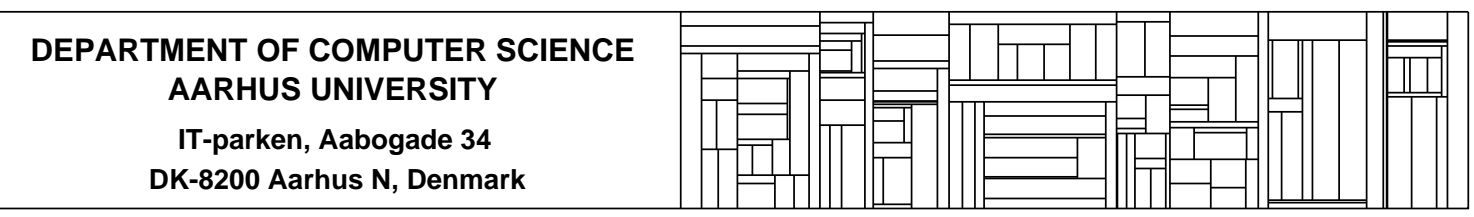





\section{Preface}

Since 2001 the annual Danish Human-Computer Interaction Research Symposium has been a platform for networking, and provided an opportunity to get an overview across the various parts of the Danish HCI research scene. This year's symposium was about to be cancelled, but we decided that we could not just let the tradition evaporate. Therefore, we took on the arrangement and decided that it could take place in Aarhus, so that we could manage the practicalities, and a month later than normal, so that the community would have time to submit papers.

For this years symposium we received a record number of 18 submissions; after review we accepted 16 papers. The accepted papers included in the proceedings present work in progress as well as summaries of resent work. In addition to the paper presentations the symposium features a keynote lecture by Charles Ess, who is a visiting professor at Aarhus University.

We would like to thank all contributors, who at short notice submitted papers for the symposium. We would also like to thank the Department of Computer Science for administrative, and other support.

The Danish HCI Research symposium is organized in collaboration with SIGCHI.dk.

Olav W. Bertelsen, Aarhus University Anne Marie Kanstrup, Aalborg University

December 2009 


\section{Table of Contents}

4

5

10 Participating in CUE-8, Comparative Usability Evaluation Anders Bruun, Janne Jul Jensen, Mikael Skov, Jan Stage

14 Design for Reasoning

Ellen Christiansen

18 Two perspectives on mobile television: Consumption in a social context and Collaborative/competitive behaviors

Alexandre Fleury, Jakob Schou Pedersen, Lars Bo Larsen

22 Vestibular rehabilitation in the home: Design challenges

Erik Grönvall, Rikke Aarhus, Simon B. Larsen

26 Interacting with Software Architectures - An Experiment with Interface Criticism of Software Architectures Klaus Marius Hansen

30 Which Is the Better Prompt in Thinking-Aloud Studies, "What Are You Trying to Achieve?" or "Keep Talking"?

Morten Hertzum, Kristin D. Hansen, Hans H. K. Sønderstrup-Andersen

34 History of User Interfaces: A Mahoneyan Perspective

Anker Helms Jørgensen

$38 \quad$ Wild Rabbits in Living Lab Skagen

Anne Marie Kanstrup

42 Methodological Reflections on Working with Young Children

Matthias Korn

45 How to design security

Niels Raabjerg Mathiasen

48 ClickDrop - a fast interaction technique on large touch displays

Thomas Riisgaard Hansen

51 Use of Sense-Making Methodology in a Requirement Process

Georg Strøm

55 Designing technology for spectator experiences - Beyond the passive spectator Rune Veerasawmy

$59 \quad$ Utilizing Social Network Services for Enhanced Communication with Elderly Living at Home Stefan Wagner

63 Experiencing Democracy - a Research Proposal

Pär-Ola Zander, Morten Bohøj 


\title{
Keynote Lecture
}

\section{"Culture" - Does It Matter Anymore?}

\author{
Charles Ess \\ Aarhus University \\ Department of Information and Media studies \\ http://www.drury.edu/ess/ess.html \\ imvce@hum.au.dk
}

\begin{abstract}
The biennial conference series on "Cultural Attitudes towards Technology and Communication" (CATaC - see $<$ www.catacconference.org $>$ ) began in 1998 with what was then a relatively novel observation: most of the Anglophone, especially then U.S. dominated discourse regarding the Internet and the $\mathrm{Web}$, rested on a technological instrumentalism that presumed that these technologies were somehow "just tools," i.e., neutral instruments disconnected from any culturally-variable factors (including values, practices, beliefs and communicative preferences). For those of us able to travel and communicate across national and cultural boundaries, however, it was becoming quickly obvious that the explosive diffusion of the once U.S.-centered web brought in its train a number of "cultural collisions" in which the cultural-specific values and communicative preferences in fact built into these technologies clashed in one or more ways with the values and preferences of local, "target" cultures.
\end{abstract}

The CATaC conferences brought together a wide range of increasingly sophisticated culturally-oriented research and reflection, demonstrating first of all that, indeed, cultural values and communicative preferences profoundly shape the design, implementation, and use of ICTs - and hence, designers who wished to avoid "computer-mediated colonization" (i.e., the imposition of one set of values and preferences upon those holding different values and preferences) would need to take cultural differences into account.

On the one hand, this approach to HCI and related design fields has become gradually more mainstream. At the same time, however, more recent work highlighted at the CATaC conferences has radically critiqued not only the prevailing frameworks used in cultural analyses for the sake of a more "culture-aware" approach to design (most importantly, those developed by G. Hofstede and E.T. Hall) - but, more fundamentally, the very concept of 'culture' itself.

In my lecture, I will provide an overview of these three phases of scholarship and research, i.e., (1) examples (1998-2006) of how culturally-variable beliefs, practices, and communicative preferences manifest themselves in the design, implementation, and reactions to ICTs; (2) emerging critiques (2004-2008) of Hall, Hofstede, and the very notion of 'culture' itself; and (3) emerging suggestions for HCI and design that seek to avoid cultural colonization, but now on the basis of concepts and analytical frameworks that intend to go beyond Hall, Hofstede, and 'culture' as such. 


\title{
Timelines as a Collaborative Planning Tool
}

\author{
Morten Bohøj \\ Alexandra Institute \\ Åbogade 34, DK-8200 Århus N \\ bohoej@cs.au.dk
}

\begin{abstract}
This paper presents timelines as a collaborative planning tool. This paper briefly presents how we used timelines as a tool for planning parental leave in connection with the project eGovt. Work on generalising our timeline prototype to a general framework is then presented along with the first initial use of this framework.
\end{abstract}

\section{Keywords}

Collaboration, planning, timelines, visualization,

\section{INTRODUCTION}

In this article I will present the use of timelines as a collaboration object. Our initial work with timelines as collaborative objects began with our work with parental leave in connection with the eGov+ project in the fall of 2008.

In Denmark parents are granted 52 weeks of subsidised parental leave to share. The legislation surrounding this parental leave is very complex and allows for many different compositions of parental leaves. The 52 weeks are split into four different types, four weeks of pregnancy leave held by the mother prior to the birth, two weeks of paternal leave held by the farther and 14 weeks of maternal leave held by the mother, both held directly following the birth, and finally 32 weeks of parental leave to share between the mother and the father. Parents may also choose to save some of the leave to be held at a later time. The leave may be used the first nine years of the child's life.

The flexibility of the legislation is good for the citizen and allows for planning the parental leave to fit many different needs, but it also makes the planning more difficult. When planning their leave, many parents call the municipality to get advise on how to structure their leave and here the flexibility makes every case unique for the caseworker to handle and requires a lot of time.

Here the timeline functioned as a way of planning and applying for parental leave and used for collaboration between citizens and municipal caseworkers. The challenge of planning and applying for parental leave formed the basis for our idea of using timelines as a collaborative planning tool. The idea is that timeline allows the parents to drag and drop the different types of leave periods on to the timeline, creating a visual impression of how the leave as a whole unfolds over time. The timeline is web based and collaborative by allowing several people manipulating the same timeline at the same time. Changes made by one are propagated to others manipulating the same timeline. The manipulation of the timeline is done by direct manipulation. Periods and events can be dragged onto the timeline and manipulated in size by dragging the ends and also moved around the timeline. As pointed out in [7] "in an information-rich environment (...) the critical property of information is that it is available at-a-glance". This availability at-a-glance is one of our goals with the timeline concept for parental leave, both creating an overview for the parents and caseworkers.

In order to visualize the timeline concept, both mock-ups and working prototypes were constructed. A screenshot of the working prototype is available in Figure 1. Highlighted are some of the important aspects of the prototype. Events are shown in the top of the timeline (label 1), with the periods below (label 2). Each colour period represents a type of parental leave. The focus of the timeline is between label 3 and 4, and by changing the dates at either end of the focus, one can zoom and change focus. The prototype is described in more detail in [1] and later I will describe how this working prototype has formed the basis for a generalisation of the timeline concept into a timeline framework.

\section{RELATED WORK}

Time plays an important role in a collaborative setting, as most collaboration takes place over time and/or place. The role of time in collaboration is present both when working in a hospital [7] or collaborating in school [3], where timelines were used to show activity. In [6] timelines are introduced to present criminal youth records and argued to be useful alternatives in governmental settings.

Timelines have also been introduced to the web where $[4,9]$ and others have developed timeline-based interaction, mainly to summarize personal web history.

Timelines are mainly used as visualisation of information, to give an overview. The information is mostly manipulated elsewhere, such as by search results [8] or through other interfaces, as in [6] where the information is edited with forms. 
Manipulation of data through timelines is well known from multimedia programs such as Macromedia Flash, GarageBand or Windows Movie Maker, where the timeline is used to place media events in relation to each other and to organise the media flow.

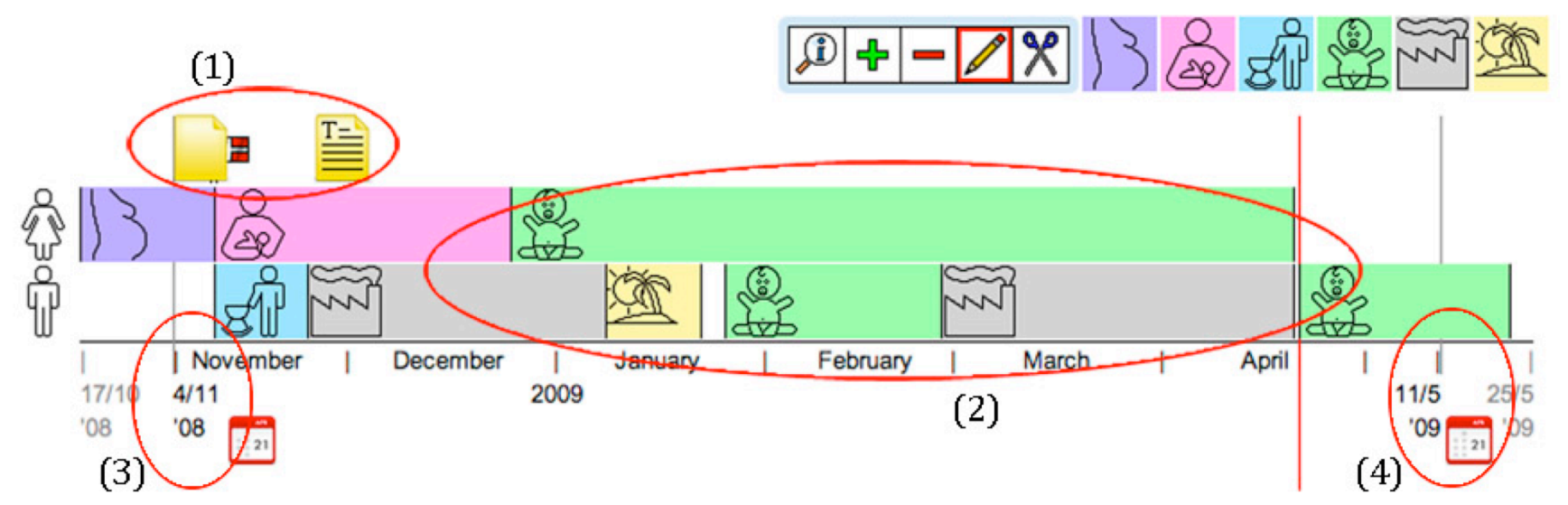

Figure 1 - Parental leave working prototype

\section{GENERALISATION}

During the work with the parental leave prototype, thoughts on how the timeline could be used to visualize casework information in general and support collaboration in general, began to emerge. Initially the ideas surrounded other parts of the services provided by the municipality, in order to better visualize the administrative procedures and make the process more clear and understandable to the citizen, but later the ideas embraced collaboration and planning in general. The first idea outside the governmental context was the planning of the course of a $\mathrm{PhD}$, such as half-year evaluations, courses and stay abroad. The plan for a $\mathrm{PhD}$ involves at least two people, namely the PhD student and the supervisor. Sometimes there can be more than one supervisor and there may also be administrative people at the faculty involved. All these people could then share the same timeline to get an overview for the remainder of the $\mathrm{PhD}$. Administrative people and supervisors may be involved with more than one $\mathrm{PhD}$, and here the timeline may also help to get a quick overview of the status.

\section{Implementation}

As the prototype for the parental leave was just a rough implementation of the timeline idea and was very minded towards the parental leave concepts, a new implementation was needed. I have been working on this general implementation during the fall of 2009 and used the things we learned during the first prototype implementation.

The initial prototype also had some limitations as for functionality of the interaction. Not all the functionality regarding drag and drop manipulation was implemented at first, and some of the functionality, meant as direct manipulation, was replaced by tools allowing this manipulation. The new generalisation has skipped tools completely the periods now allow for movement on the timeline and resizing by dragging either end of the period. Deleting a period is done by dragging the period from the timeline and onto the garbage icon. Periods available for a particular timeline are, as with the first prototype, available above the timeline to drag onto the timeline.

The user tests conducted with the initial prototype also revealed some difficulties with way one would zoom in and out and change the focus of the timeline. This confusion has led to a complete redesign of the timeline and another way of zooming and changing focus. Zooming is now done by clicking magnifying glasses above the timeline. Zooming in halves the distance between the first and the last visible date, and zooming out doubles the distance. Panning the timeline is now simply done by dragging the scale indicators at the top, left or right, where you previously had to change the two dates at either end of the timeline to achieve the same thing.

The idea of using evaluators to determine whether or not a period could be change on the timeline, was already a part of the initial prototype, but has evolved with the new prototype. Because the framework should be very flexible and able to handle periods and events of all kind, these evaluators are also very additional manipulation of periods, to respond to direct manipulation, can be done. This additional manipulation could be things such as maintaining a list of manipulators or handling the correct reference to a document sitting elsewhere.

Another change to the general framework is the ability to customize some of the interaction. It is possible to configure the timeline to allow or disallow manipulation and to allow or disallow collaboration. By disallowing manipulation, the timeline may be used as a tool for visualisation only.

As an initial test of the new implementation, the parental leave context was reimplemented to fit the new structure. A screenshot of the new implementation, for the parental leave, can be seen in Figure 2. 


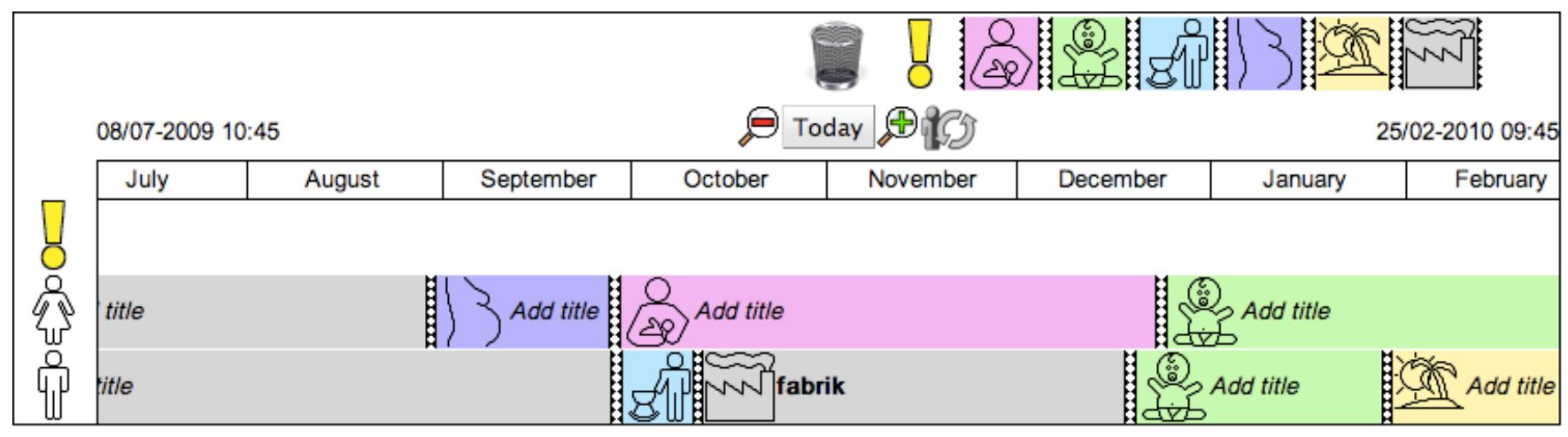

Figure 2 - New implementation

\section{BSCW Timeline}

During a stay with the Fraunhofer Institute (FIT), I used the general framework for another test. In collaboration with Wolfgang Prinz, I tried to use the timeline to visualise activity in a BSCW workspace. BSCW is a web-based shared workspace tool that allows for collaboration on documents and other artefacts. The test was a follow up to a previous test [5] done to create activity awareness. Activity awareness is always required when collaborating [2] and BSCW tries to provide some awareness by sending out daily reports by email, generated by activity in a workspace. This email lists the activities as a list showing, by artefact, the activity and user performing the activity. The idea is to use the show the activities on the timeline when the activity occurs, order by user. The ordering by user means that all activity of this user is located in the same layer on the timeline. Events are further coloured to reflect the target artefact.

The visualisation contains several different views of activity, and thereby giving more options than the static activity email. Clicking an event will change view and only show the events for this artefact, still ordered by user, and clicking a user will only show events generated by this user, ordered by artefact. Users can access artefacts directly in BSCW via links.

The BSCW timeline configures the timeline framework to disallow manipulation and collaboration and thereby function only as a visualisation. A screenshot of the BSCW timeline is shown in Figure 3.

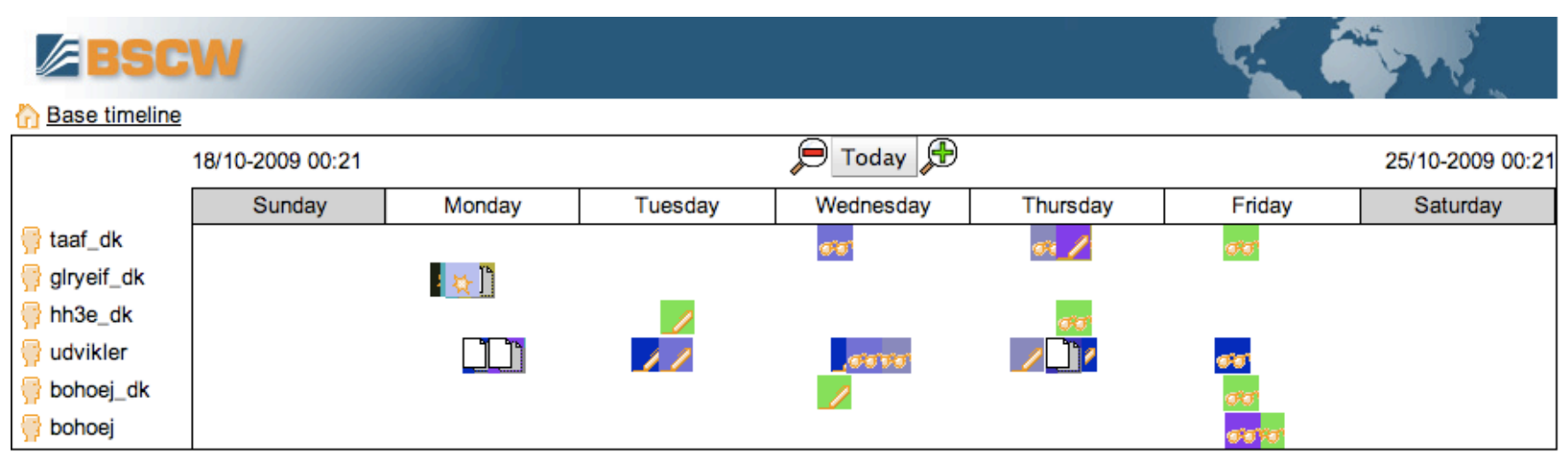

Figure 3 - BSCW timeline

For testing of the visualisation compared to the auto generated emails, interviews with four test users were conducted. The users were all used to using BSCW and the activity emails. The users were presented with the timeline view of activity and the emails generated from the same activities, and asked to compare the two and give examples of when one option would be better than the other. They were also asked to evaluate on the interaction with the timeline.

The users found the timeline reasonably easy to navigate, when first trying it. Most users did however expect to be able to scroll the timeline be dragging the entire timeline and not just using the scale indicators at the top. When comparing the timeline to the emails, users found that this would be better when trying to get an overview over a longer period, such as coming back from holiday or just joining a project, but found the list in the email a better choice when looking at day to day activity. The reason was mainly down to familiarity with the email. The timeline was highlighted as a way to get a quick overview and to see which users were active and to see if collaboration going on, by seeing if more than one person was editing the same document. An initial conclusion is that the timeline is a good supplement to existing awareness tools, and gives reason for further investigation. 


\section{FUTURE WORK}

Based on the work with the original parental leave timeline prototype and the initial experiments with the reimplemented prototype, the idea of using timelines as a collaboration object is promising. More work is obviously needed and as the next experiment, I will implement the $\mathrm{PhD}$ planning mentioned earlier, and try out the more collaborative aspects of the timeline.

On the functional side, more implementation is still needed, such as some performance enhancement, when working with many periods and events (more than 1000). I will also look into basing the evaluators on external rules, such as from xml-files.

\section{REFERENCES}

1. Bohøj, M. and Bouvin, N.O. (2009). Collaborative Time-based Case Work. Proceedings of Hypertext 2009.

2. Dourish, P. and Bellotti, V. (1992). Awareness and Coordination in Shared Workspaces. CSCW '92: Proceedings of the 1992 ACM conference on Computersupported cooperative work, pp. 107-114

3. Ganoe, C.H., Somervell, J.P., Neale, D.C., Isenhour, P.L., Carroll, J.M., Rosson, M.B. \& McCrickard, D.S. (2003). Classroom BRIDGE: using collaborative public and desktop timelines to support activity awareness. Proceedings of UIST'03, pp. 21-30

4. Gyllstrom, K (2009). Chronicling users' information interaction history by recording when and what they read. IUI, pp. 147-156.

5. Pankoke-Babatz, U., Prinz, W. \& Schäfer, S. (2004) Stories about Asynchronous Awareness. Cooperative systems design: scenario-based design of collaborative systems, pp. 23-38.

6. Plaisant, C., Milash, B., Rose, A., Widoff, S., \& Schneiderman, B. (1996). Lifelines: Visualizing personal histories. In Proceedings of CHI'96, New York, NY: ACM Press, pp. 221-227.

7. Reddy, M. \& Dourish, P. (2002) A finger on the pulse: temporal rhythms and information seeking in medical work. Proceedings of CSCW 2002, pp. 344-353.

8. Ringel, M., Cutrell, E., Dumais, S. \& Horvitz, E. (2003) Milestones in Time: The Value of Landmarks in Retrieving Information from Personal Stores. Proceedings of INTERACT'03.

9. Shirai, Y., Yamamoto, Y. \& Nakakoji, K. (2006). A history-centric approach for enhancing web browsing experiences. CHI Extended Abstracts, pp. 1319-1324. 


\title{
Participating in CUE-8, Comparative Usability Evaluation
}

\author{
Anders Bruun, Janne Jul Jensen, Mikael Skov \& Jan Stage \\ Department of Computer science \\ Aalborg University \\ Selma Lagerlöfs Vej 300 \\ DK-9220 Aalborg East \\ \{ bruun, jjj, dubois, jans\}@cs.aau.dk
}

\begin{abstract}
This paper reports on the usability evaluation conducted for the participation in the eighth Comparative Usability Evaluation (CUE-8). It elaborates on the history of the CUE series, then reports in detail on the usability evaluation conducted and the results of it. Finally the overall results of the CUE- 8 workshop are explored and the lessons learned from the workshop are presented.
\end{abstract}

\section{Keywords}

Usability measurement, comparative usability evaluation, time-on-task, satisfaction rating, success rate, quantitative data analysis, SUS, TLX

\section{INTRODUCTION}

Traditional usability evaluations are a series of moderated sessions involving a user and a test leader, and it generates both quantitative and qualitative data. This type of qualitative test is the most common usability test. However, usability practitioners find themselves having to accommodate managers who prefer measurements over qualitative data [2] in order to be able to benchmark and measure progress. The ISO 9241-11 [1] standard defines usability in terms of effectiveness, efficiency, and satisfaction and provides examples of metrics to measure them. Most commonly used by practitioners are success rate, time-on-task, satisfaction rating, and error rate. This became the focus of the eighth CUE workshop in which 15 teams participated. The website chosen for evaluation was budget.com, a car rental service website.

\section{BACKGROUND}

For eight years running, Rolf Molich has organised a reoccurring workshop on comparative usability evaluation, often referred to as the CUE-workshops [3]. Each year these workshops include a number of professional usability teams that volunteer their skills to evaluating a chosen product or service applying the methods, tools, techniques and procedures they would normally use for a similar evaluation. This generates a large amount of empirical data that is otherwise rarely available creating an ideal basis for comparison of results.

In 2009 the eighth CUE workshop took place at the Usability Professionals' Association (UPA) Conference in Portland, OR, USA on June $9^{\text {th }}$ 2009. Molich had found that there is no general agreement on what best practice in usability task measurement is [4]. Thus, the purpose of this year's CUE workshop was to discuss the state-of-the-art in usability task measurement based on the results gathered from each teams' evaluation of a particular website and compare practical approaches to usability task measurement based on the assumption that "you can't manage what you can't measure". This differed from previous years' CUE workshops as they have been focusing on qualitative evaluations, rather than quantitative.

Ahead of the workshop each of the 15 participating teams were asked to conduct a usability evaluation of the car rental service website budget.com. The tasks were fixed and the same for all teams although comments and changes were possible on drafts beforehand. Each team was asked to carry out an independent evaluation parallel with the other teams, using the methods, tools, techniques and procedures they would normally use for a similar evaluation. Each team was, however, encouraged to measure efficiency (e.g. time-on-task) effectiveness (e.g. completion rate and errors) and satisfaction (e.g. post-task and post-test ratings). The System Usability Scale (SUS) was suggested as a post-test questionnaire if a team was unfamiliar with measuring post task and post test satisfaction. Each team was also expected to be willing to spend 10-30 hours on the evaluation and preparation of a report before the workshop.

Upon completing the evaluation, each team was asked to produce an anonymised usability report containing their results to the organizers ahead of the workshop. These reports would then form the basis of the workshop. 


\section{OUR CONTRIBUTION TO CUE-8}

Our evaluation of budget.com took place on May $19^{\text {th }} 2009$ in our usability lab. It involved 10 users, two test leaders and two loggers.

\section{Procedure}

The usability evaluation was carried out by the authors of this paper.

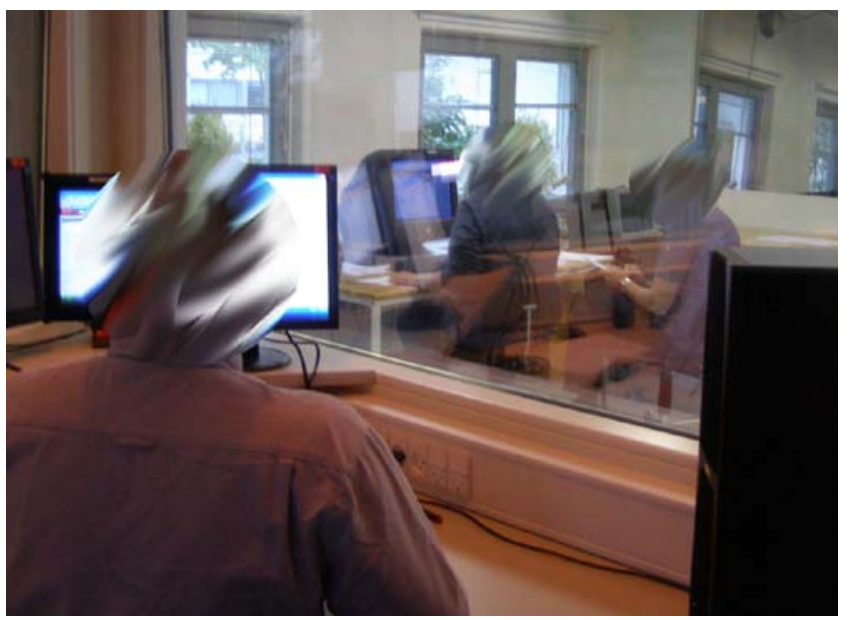

Picture 2: The evaluation setup seen from within the observation room.

The participants were assigned a 45 minute slot each in a test plan and two of the authors were assigned as alternating test leaders, while the two others would operate the data collection equipment. The participants were asked to think aloud to supply an insight into their train of thought during their task solving. Upon completing their task solving, each of the participants were subjected to a NASA TLX test to measure their mental workload during the evaluation.

\begin{tabular}{|c|c|c|c|c|c|}
\hline & 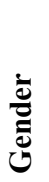 & $\sum_{\pi}^{80}$ & 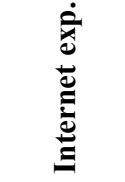 & 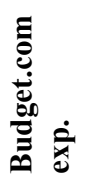 & 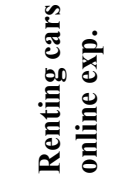 \\
\hline TP1 & $\mathrm{F}$ & 41 & Every day & Never & 1 time \\
\hline TP2 & $\mathrm{F}$ & 45 & Every day & Never & $10+$ times \\
\hline TP3 & $\mathrm{F}$ & 35 & Every day & Never & 0 times \\
\hline TP4 & $\mathrm{F}$ & 34 & Every day & Never & 2-10 times \\
\hline TP5 & $\mathrm{F}$ & 28 & Every day & Never & 0 times \\
\hline TP6 & $\mathrm{M}$ & 30 & Every day & Never & 0 times \\
\hline TP7 & $\mathrm{M}$ & 28 & Every day & Never & 2-10 times \\
\hline TP8 & $\mathrm{M}$ & 27 & Every day & Never & 1 time \\
\hline TP9 & $\mathrm{M}$ & 26 & Every day & Never & 2-10 times \\
\hline TP10 & $\mathrm{M}$ & 23 & Every day & Never & 0 times \\
\hline Avg. & -- & 31.7 & Every day & Never & -- \\
\hline High & -- & 45 & Every day & Never & $10+$ times \\
\hline Low & -- & 23 & Every day & Never & 0 times \\
\hline
\end{tabular}

Table 1: Demographic data of the participants.

\section{Participants}

The evaluation included ten participants. All participants were employees in our organization or spouses of the evaluators. As the website should appeal to a wide demographic profile we chose participants of differing age, differing job profile and an even number of males and females. Each participant was given a bottle of wine for their participation. Their demographic data can be seen in table 1.

\section{The Evaluation}

All ten evaluation sessions were carried out in the usability laboratory of our organization (See figure 1).

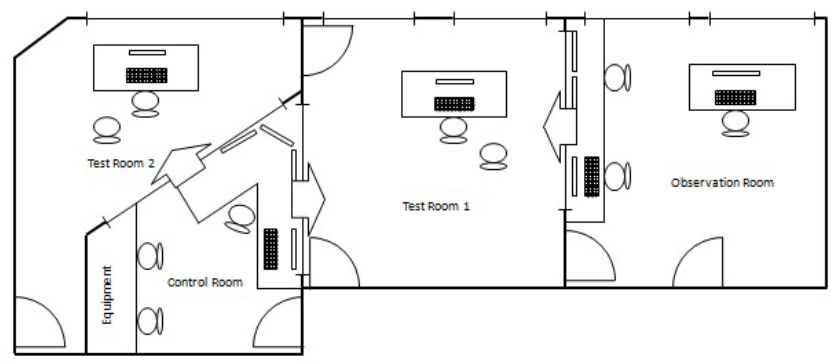

Figure 1: The layout of the laboratory used.

After greeting and briefing each participant, they were placed by the PC and given the tasks one by one always in the same order. They were asked to clearly state when they felt they had completed the task. The test leader would only help in case the participant got stuck.

After each task, the participant was asked to answer the corresponding question in a SUS-questionnaire. The evaluation was stopped if this exceeded the assigned 45 minutes by more than five minutes (happened once). Upon completion of the evaluation, the participants answered the rest of the SUS questionnaire.

Each session was completed by having the participant fill out a questionnaire regarding their demographic data.

\section{RESULTS OF OUR EVALUATION}

Our results address the three categories of the ISO: Efficiency, effectiveness and satisfaction. We furthermore also compiled a problem list and the results of the NASA TLX test, the results of which will not be presented in this paper.

\section{Efficiency (Time)}

The participants were rather diverse in terms of efficiency. On average, they spent almost 1600 seconds ( $\sim 26$ minutes) on task completion. However, they were rather different on task completion with one participant using only 997 seconds (16 minutes) and another using 2719 seconds ( $\sim 5$ minutes). See table 2 for further details.

Our results seem to challenge the statement on the front page of budget.com where it is claimed that you can rent a car in 60 seconds. All our participants spent more than 4 minutes on this task.

Task 2 had a relatively high task completion time for a task that to some degree was a repetition of task 1 . It could be 
expected that the completion time would reflect some learning from task 1 but this seems minimal.

\begin{tabular}{ccccccc} 
TP1 & 277 & 137 & 160 & 352 & 540 & 1466 \\
TP2 & 328 & 158 & 141 & 160 & 210 & 997 \\
TP3 & 395 & 236 & 822 & 268 & 198 & 1919 \\
TP4 & 279 & 176 & 161 & 307 & 165 & 1088 \\
TP5 & 243 & 317 & 391 & 208 & 220 & 1379 \\
TP6 & 585 & 486 & 419 & 318 & 283 & 2091 \\
TP7 & 615 & 437 & 154 & 404 & 275 & 1885 \\
TP8 & 1012 & 496 & 302 & 909 & -- & 2719 \\
TP9 & 356 & 176 & 105 & 145 & 304 & 1086 \\
TP10 & 417 & 231 & 230 & 171 & 253 & 1302 \\
\hline Avg. & 450.7 & 285 & 288.5 & 324.2 & 272 & 1593.2 \\
High & 1012 & 496 & 822 & 909 & 540 & 2719 \\
Low & 243 & 137 & 105 & 145 & 165 & 997 \\
\hline
\end{tabular}

Table 2: Task completion time for the participants. Gray italic numbers indicate that the task was not solved or that the test leader provided extensive help, while two dashes indicates that the participant was asked to proceed by the test leader.

\section{Effectiveness (Task Completion)}

We measured effectiveness from task completion. Four participants never fully completed two tasks (task 1 and 5). Either they realized they could not complete the task, e.g. find specific information, or they simply failed to provide a correct answer to the question specified in the task.

Our strong focus on usability problem identification (as the primary result of our evaluation) results in very few noncompleted tasks: Encouraging the participants to continue trying to solve the tasks usually provides more insight into the problems of the application. However, this also often means that the participants manage to finish tasks they would otherwise not have finished, working on their own, as they would simply have given up earlier.

Satisfaction (System Usability Scale, SUS)

All participants filled in a System Usability Scale (SUS) questionnaire as a measure for satisfaction.

\begin{tabular}{|c|c|c|c|}
\hline \multicolumn{4}{|c|}{ SUS scored (1-100) } \\
\hline TP1 & 63 & TP6 & 48 \\
\hline TP2 & 90 & TP7 & 63 \\
\hline TP3 & 73 & TP8 & 32 \\
\hline TP4 & 58 & TP9 & 70 \\
\hline TP5 & 33 & TP10 & 53 \\
\hline & & & \\
\hline & & & \\
\hline
\end{tabular}

Low

32

Table 3: The SUS scored on a scale from 1 to 100.

Looking at the SUS questions after each task (table 4), we can see that the participants perceived the first task as relatively easy (2.8). This is somewhat surprising as they spent considerable more time on this task than anticipated. On the other hand, they were more negative towards task 4 (3.8) where they have to find information about insurance. This task caused several problems for more of the participants.

\begin{tabular}{cccccc}
\hline & Task 1 & Task 2 & Task 3 & Task 4 & Task 5 \\
\hline TP1 & 1 & 2 & 3 & 5 & 7 \\
TP2 & 5 & 1 & 2 & 3 & 2 \\
TP3 & 2 & 2 & 7 & 1 & 2 \\
TP4 & 3 & 2 & 2 & 4 & 1 \\
TP5 & 1 & 1 & 6 & 3 & 2 \\
TP6 & 4 & 4 & 4 & 4 & 4 \\
TP7 & 2 & 5 & 1 & 6 & 4 \\
TP8 & 6 & 4 & 2 & 4 & -- \\
TP9 & 2 & 3 & 2 & 3 & 5 \\
TP10 & 2 & 2 & 3 & 5 & 2 \\
\hline Avg. & 2.8 & 2.6 & 3.2 & 3.8 & 3.2 \\
High & 6 & 5 & 7 & 6 & 7 \\
Low & 1 & 1 & 1 & 1 & 1 \\
\hline
\end{tabular}

Table 4: The SUS rating of each task from each participant on a scale from 1 to 7,1 being easiest, 7 being hardest.

\section{THE CUE-8 WORKSHOP}

The results of our evaluation were compiled into a usability report which was submitted to the organizers of the CUE-8 workshop. The organizers had before the workshop produced some comparison results derived across all of the reports submitted and these results were presented at the workshop. Each team would present their results and based on the reports and the presentations, an extensive discussion of the results took place.

Based on the workshop the following overall lessons learned were derived:

Lesson 1: Unmoderated usability evaluations are only more cost effective than moderated usability evaluations when the sample size is large: Surprisingly unmoderated evaluations proved to have a lot of overhead compared to moderated evaluations with small sample sizes. This was attributed to the extra work of cleaning up the data of the evaluation.

Lesson 2: It is advisable to use recognized questionnaires rather than to make your own: Own brand questionnaires tend to be less regular and may not discriminate between the tremendous variety there is between users, thus causing warped when doing the statistical analysis afterwards. 
Lesson 3: Cleaning contaminated data from unmoderated usability evaluations poses serious challenges: The data of unmoderated evaluations often contain flawed data in the form of unrealistically high or low time-on-task or low error rate. This is usually dealt with through a cleaning procedure setting some thresholds. However, multiple teams found that with these procedures there were outliers being discarded that were valid and inliers that were erroneous and should have been discarded but were not. Thus, unmoderated evaluations come at a cost.

Lesson 4: Using mean and median for time-on-task should be done carefully: Often mean and median are used for reporting the average time on task in a usability evaluation. However, as time-on-task is not normally distributed, the mean is a poor indicator of the centre of a distribution. The median may be used instead but it censors data or discards extreme observations instead. An uneven distribution can be handled with the right statistical tools, but unfortunately it rarely is.

Lesson 5: Confidence intervals are valuable for describing the location and precision of the results: Often however, these are not computed and reported. This could be a valuable addition to a field that mostly takes a qualitative approach to usability evaluation. Eight of the 15 teams did not report confidence intervals for their data.

Lesson 6: Reproducing results between teams is possible to some extent: Six of the 15 teams agreed on all five tasks within a 95\% confidence interval. Two more teams agree with the six teams for all tasks except task 1. Two teams agree with the majority for three tasks. On the other hand, five teams mostly report diverging results. Two teams consistently diverge from the other teams.

\section{CONCLUSION}

Usability metrics expose the weaknesses in usability evaluation methods (recruiting, task definitions, userinteractions, task success criteria, etc) that likely exist with qualitative testing but are less noticeable in the final results.
With qualitative data it is difficult to compute the reproducibility of the results due to their qualitative nature. This in return prevents us from assigning confidence intervals, which can be a valuable metric.

Unmoderated measurements are attractive from a resource point of view with large sample sizes; however, data contamination is a serious problem and it's not always clear what you are actually measuring. Furthermore cleaning the data poses a number of challenges not trivially overcome. We recommend further studies of how data contamination can be prevented and how contaminated data can be cleaned efficiently.

\section{ACKNOWLEDGMENTS}

We wish to thank Rolf Molich for the possibility of participating in the CUE- 8 workshop. We also wish to thank the participants of our usability evaluation, as it would not have been possible without them.

\section{REFERENCES}

1. ISO (1998) ISO Standard 9241-11. Guidance on Usability, International Organization for Standardization.

2. Molich, R., Kirakowski, J., Sauro, J. \& Tullis, T. (2009) Comparative Usability Task Measurement (CUE-8) Instructions. Retrieved on December 1, 2009 from http://www.dialogdesign.dk/cue-8.htm.

3. Molich, Rolf (2009) CUE - Comparative Usability Evaluation. Retrieved on December 1, 2009 from http://www.dialogdesign.dk/CUE.html

4. Usability Professionals' Association (2009) Comparative Usability Task Measurement (CUE-8). Retrieved on December 1, 2009 from https://www.usabilityprofessionals.org/upa_conference/ app/schedule/show_detail/10176/for:2009 


\title{
Design for Reasoning
}

\author{
Ellen Christiansen \\ Dept. of Communication, Aalborg University \\ Krogsstraede 1, DK 9220 Aalborg Ø \\ ech@hum.aau.dk \\ $+4528582167$
}

\begin{abstract}
The aim of this paper is to position interaction design and information architecture in relation to design of interfaces to ICT applications meant to serve the goal of supporting users' reasoning, be it learning applications or self-service applications such as citizen self-service. Interaction with such applications comprises three forms of reasoning: deduction, induction and abduction. Based on the work of Gregory Bateson, it is suggested that the disciplines of interaction design and information architecture are complementary parts of information processes. To show that abduction, induction and deduction play together in an information process, the paper reviews three examples: Plato's Socratic dialogues, the sociology of inscriptions, the practice of police investigation. All three examples illustrate the main point of the paper: that interaction design and information architecture are different, complementary, and indispensible for the information processes, and that design of sense making can not need both disciplines.
\end{abstract}

\section{Author Keywords}

Reasoning, interaction design, information architecture

\section{INTRODUCTION}

Students from a graduate study program in Information Architecture, where I teach, often ask about the relationship between information architecture and interaction design: How to get to grips with differences and similarities between what in the professional literature often presents itself as two distinct professional disciplines? For example did Jonathan Korman in 2005, in a piece on web-design, suggest a clarification [7] implying that interaction design means defining system behavior, which meet users' desire for action, while Information Architecture means finding ways to help users can find the information they want. By Korman's definitions you may get the impression that Interaction Design and Information Architecture are phenomena not much older than the Internet. This is, however, not the case. Both are anthropological primitives, as old as the human habit of making and reading inscriptions. The inscriptions themselves existed since the invention of written language: an architect organized the structure of the medium of communication - even if in stone. The Ten Commandments were organized numerically, and their order reflects the hierarchy of life issues of their time and location.
Throughout the Middle Ages information architectures were developed to reflect the structural relationships of the order of society. In fact, within the domains of religion, law, and accounting, professions emerged around interaction design and information architecture thousands of years ago. Today the Internet-activities have lifted these competencies from the background to the foreground, and also into university teaching. Hence, we in Academia need to discuss the content and relationship of information architecture and interaction design with respect to supporting reasoning.

This discussion furthermore spills over to my research in design of citizen self-service in the area of e-government, currently in the eGovPlus project http://www.egovplus.dk/index.php?id=2234 . In this project, instead of having the User in the form of personas as foundation for design, a timeline of case handling is explored. This can in fact be seen as a shift from interaction design to information architecture, hence also a challenge to clear up the relationship between the two.

Vygotsky [11], in his work on developmental psychology, suggested that in order to understand behavior, we have to go back to the historical roots of the activity, or to what Engeström [6], building on Vygotsky, has called 'germ cell activity'. I here take information process as the germ cell activity of reasoning, from which interaction design as well as information architecture originate. Going trough three examples I try - if not to prove, then at least to support this viewpoint.

\section{INFORMATION PROCESS}

Intuitively, we tend to think of information in line with data as some 'thing', a material, which can be stored, manipulated and retrieved. Seen in the perspective of learning and sense making - in a humanistic perspective that is - this intuition fails to grasp the original meaning of the Latin root of the word 'information', which is a verb, 'informare'. Informare means shaping, creating or giving form to - reasoning. In the occidental culture, reasoning is assumed to be based in logic, as the semiotician Thomas Sebouk has vividly described [10]. Humans, when faced with a puzzle, work from intuition, trying to sense relationships, further towards induction, where overwhelming empirical evidence is the convincing factor, leading to a generalization of rules, 
and theory, which in turn is applied through deduction, and then a new circle can begin, where novices start their development of professional competence as described by Dreyfus \& Dreyfus in their 5-step model [5] by applying rules free of context. This whole chain is driven by a drift towards information - the recognition of a difference, which makes a difference as suggested in Gregory Bateson's famous definition [2, p. 315]. According to Bateson, differences are perceived in communication, in the learning process, where living organisms interact and learn how to best adapt to and develop into the environment.

The purpose of the process of informing (informare) is survival, and humans have a talent for endlessly complicating and nuancing this process, which makes us good survivors as a species. Bateson, from his practice as an anthropologist, in his 1936 epilogue to his and Margaret Mead's monograph on the culture of the Iatmul people of New Guinea, "Naven"[ 3], found, that any piece of behavior has a structure, and a function, and is conducted with style, a personal touch that is, which Bateson chooses to call 'ethos', a term that brings Aristotle and his Poetics to mind. Structure, function and ethos are, according to Bateson, 'labels for points of view from which all behavior may be seen' [3, p.265].

Philosophers of language, and linguists, too, have suggested that the act of informing is an act of making and utilizing relationships of linguistic nature. They have provided theories of grammar, semantics, and pragmatics, which map to the Naven insight of Bateson's. I see a congruency between grammar and structure, and between semantics and function, and maybe even between pragmatics and ethos which indicates a potential congruency between the ways in which we understand language and the way we may understand behavior. The same elements: structure, functional rules, and rhetoric are all going into both abduction, induction and deduction, but in different blends.

Bateson's thinking builds on what he himself calls 'syllogisms of grass'. He adopted Jung's distinction between Pleroma and Creatura - two different levels of seeing reality, pointing out, that the map is not the territory, and a thing is not it's name. Instead of the Peircian triangulation of a symbol at the same logical level, Bateson suggests layers of understanding, the basic one being that of object and symbol, which at another level can be tagged into a relationship of symbol and meta-symbol. Patterns are enabling the leap from one level to the next.

Ecological psychologist R.G. Barker [1], in his 20 years of thorough studies of the social life in the small town Midwest, worked out patterns for a combination of functional rules and information architecture of behavior, into a system of 'behavioral settings'.

Hence, across philosophy, linguistics, semiotics, anthropology and ecological psychology it is possible to find researchers, who bring evidence that reasoning, which lead people to see a difference, which makes a difference, con- sists of rules of functioning, and structures where to apply these rules.

The third element in informational processes belongs not to the language as such, but to the language user. This we find acknowledged from Aristole's poetics onwards to our own Grundtvig, who wrote (what rimes in Danish) that you never get wise on a subject unless you fall in love with it. Believing and trusting comes before reasoning, and paves the way for understanding.

Following this line of thought changes focus from the differences between interaction design and information architecture to the intertwinedness and complementarity of these disciplines.

\section{EXAMPLES}

In what follows I present three examples of reasoning, one, where the purpose is deduction, one, where the purpose is induction, and one, where the purpose is abduction.

The examples show that despite the different goals for the outcome, abduction, induction and deduction are all part of the process of reasoning, which leads to information. In the first example the difference, which makes a difference, is that the slave boy realizes how to construct multiples of squares. In the second example the difference, which makes a difference is that the Maecenas says: "Yes! This trip seems worth my money", and in the third example information is that the police investigators get a hunch of to how to solve a crime.

\section{Deduction - Getting to apply a rule}

Mortensen [9] has analyzed Plato's Socratic dialogue, Meno, where the point for Socrates is to teach the slave how to apply mathematical rules - a form of deduction that is. You reason by applying a rule to a case. Thing Mortensen found that interaction with a modeling device for the sake of the argument takes 12 structuring acts. Socrates makes the slave boy realize how to construct a square twice the size of a given square utilizing 12 acts, which according to Mortensen are 1. making an object; 2 . insert or remove it; 3 . alining objects; 4 . inverting the object; 5. moving the object according to a certain rule; 6 . stating a border and transcending it; 7. undo/redo; 8. repeat action; 9. present two options and choose; 10 . relating two objects with a link; 11. give and return an object from one person to the other; 12. posing a condition. We can divide this list of moves into two: one of structure, and one of rules of function:

- making an object, 5. moving the object according to a certain rule; 9. present two options and choose; 11. give and return an object from one person to the other; 12. posing a condition are all rules of function.

- $\quad$ insert or remove; 3. aligning objects; 4. inverting the object; 6 . stating a border and transcending it; 
7. undo/redo; 8. repeat action; 10. relating two objects with a link are all about structure.

Mortensen's analysis shows that structure and function are complementary, you can not have the one without the other: You can not move an object without having created it, on the other hand you can not formulate rules for how to create and move the object without having lines along which creating and movement can take place.

The goal in Meno is to teach the form of reasoning called deduction - application of a rule that is. But we see how Socrates begins with an abduction: lets us say that so and so were the case, and how he proceeds through induction, having the slave boy to go back and forth collecting empirical evidence. The rules 1-12 serve both abduction, induction, and deduction.

\section{Induction - Getting overwhelming empirical evidence}

Latour, in his paper on the sociology of inscriptions and inscribing 'Drawing things together' [8], points out, how in the old days adventurous travelers, who went on expensive journeys to foreign parts of the world, had to bring back tokens to convince their Maecenas that the trip was worth funding. Latour outlines how it was not perception, which was the problem of visualization and cognition, but mobilization. You have to go and come back with the 'things' should your moves not be considered a waste. But you could not bring back the 'things' if not in a form that could withstand the return trip without withering away, and furthermore, the 'things' had to be presented to convince those who did not go. This was when objects were invented, which were mobile, but also immutable, presentable, readable, and combinable with one another [8]. This characterization goes for empirical evidence that serves the reasoning process of induction in general. But as Latour unfolds the situation, where a travelers brings back his tokens and present them to the Maecenas, we realize that before this happens the Maecenas has made an abduction - witnessing the presentation has made him alert - something new and interesting is going to happen, and when he was confronted with the incriptions, he at first applied his own rules of understanding, and then gradually he was moved to go into a new understanding and a new form of sense-making based on a new form of explanation - geo-maps, for example. So, although the goal of this exercise, and the medium chosen, was to convince by means of overwhelming empirical evidence, abduction and deduction were also part of the act of reasoning.

\section{Abduction - Getting a hunch}

Seboeck [10] has pointed out that the crucial matter of police investigation is abductive thinking. I did [4] a study within the flying squad of the Danish national police, which supports this point, but which on the other hand also demonstrates that induction and abduction are important parts of the reasoning of police investigation as well. In those days, and in the context of my study, investigation of a homicide began with the head of homicide squad receiving a notice and forming a number of teams, each with their own resort: A. the notice, B. technical evidence, c. medical evidence, D information about the victim, E. interrogation in the area, F. special items, G. the suspects. Eventually more teams would be formed. Case-material was indexed according to this structure. Being more or less the same from investigation to investigation, this structure formed the backbone of the investigators' shared reasoning. The investigators interacted with reference to this structure during morning briefing, where first team $\mathrm{A}$, then team $\mathrm{B}$ etc would have the word. Each team would have a file, named A, B, C etc, where other teams would go and look up information, and once the final case report for court was written it's chapters would follow in this same order. There is a historical root to this specific schema, namely the formula stated by Cicero for how to present a case to court, the modus operandi scheme, which is also part of the working knowledge of the policemen, I interviewed. There were specific rules for how to engage with the work within each team, and for how to work out reports within each category, all of which was part of the investigators competence.

Getting a hunch in police investigation is a matter of applying rules correctly, following the structure systematically, collecting empirical data in this format, and through this getting ideas; in other words, progress goes from deduction through induction to abduction.

\section{CONCLUSION}

All three examples bring to bear on the main point of this paper: that human reasoning requires a well-designed structure, and rules of functioning, and that deduction, induction and abduction is involved in information processes. It is the seeing of differences, which enables people to learn what they want to know, and for that to happen, both structure and functionality must feed each other. Interaction design and information architecture are complementary, and does not suffices without also taking rhetoric and ecology into account. I have tried to draw attention to the classical roots of interaction design and information architecture, because these crafts is related to the basic human activity of externalizing and communicating experience about the world from generation to generation, from community to community, but also - by the same token - to exclude some fellow human beings from coming to understand. By one and the same token they are pedagogical projects and power games.

If we take design of citizen self-service in the area of egovernment as a case of support of reasoning, imagining that the citizen has the goal of getting, say a permission, but without knowing what steps it may actually take, depending on prior experience the interaction will start with abduction or deduction, but the middle part will have the form of reasoning about the overwhelming amount of information present of the site. Both the interaction and the architecture shape the information process all the way through. 


\section{ACKNOWLEDGEMENTS}

Without the Information Architecture students' constant questioning of the content of the information architecture study program, this paper would not have been written. I hope that the students will continue to grant me the favor of sharing their critical reflections.

\section{REFERENCES}

1. Barker, R.G. (1968) Ecological psychology. Stanford University Press

2. Bateson, G. (1972/2000) Steps to an ecology of mind. The universioty of Chicago Press

3. Bateson, G. (1958) Naven. Stanford University Press

4. Christiansen, E. (1995) Tamed by a Rose in: Nardi (ed.) Context and Consciousness. MIT Press

5. Dreyfus, H.L. \& S.E. Dreyfus (1986) Mind over Machine. Basil Blackwell

6. Engeström, Y. (1987). Learning by expanding. OrientaKonsultit Oy
7. Korman, J. ( 2005). The web, Information Architecture, and Interaction Design,

http://www.cooper.com/journal/2005/09/the_web_infor mation architectu.html

8. Latour, B. (1990). Drawing Things Together. In M. Lynch and S. Woolgar (Eds.) Representation in Scientific Practice. Cambridge, Mass, MIT Press

9. Mortensen, Arne Thing (1992) Sprogligt Håndværk. Essays om Beskrivelser og Kognition (Linguistic Crafts. Essays on Description and Cognition), Filosofi og Videnskabsteori på Roskilde Universitetscenter, 2. række

10. Sebeok, T. (1981) "You Know My Method." In Sebeok, T. "The Play of Musement." Bloomington, IA: Indiana.

11. Vygotsky, L. (1978) Mind in society. Harvard University Press 


\section{Two perspectives on mobile television: Consumption in a social context and Collaborative/competitive behaviors}

\author{
Alexandre Fleury \\ Aalborg University \\ Niels Jernes vej 12 \\ DK-9000 Aalborg Denmark \\ amf@es.aau.dk
}

\author{
Jakob Schou Pedersen \\ Aalborg University \\ Niels Jernes vej 12 \\ DK-9000 Aalborg Denmark \\ jsp@es.aau.dk
}

\author{
Lars Bo Larsen \\ Aalborg University \\ Niels Jernes vej 12 \\ DK-9000 Aalborg Denmark \\ lbl@es.aau.dk
}

\begin{abstract}
This paper describes two user studies aiming at uncovering two distinct aspects of end user experience with mobile television. The first experiment assessed the acceptability of using mobile TV services in a public context, while the second experiment investigated the test users' collaborative and competitive behavior as a possible motivation factor to encourage user contribution. The results from the first study suggest that users would feel comfortable watching mobile TV in a social environment, especially when combined with earplugs. The second study uncovered challenges to tackle in order to achieve mobile collaboration and that the trustworthiness of mobile services is of primary importance for users willing to contribute with content.
\end{abstract}

\section{Keywords}

User studies, situated test, panel discussion, mobile tv, social environment, collaboration, competition

\section{INTRODUCTION}

\subsection{Context of the study}

The work reported in this paper takes place in the context of the Converged Advance Mobile Media Platforms (CAMMP) project $^{1}$ and addresses the convergence of media services with mobile technologies. In this purpose, CAMMP merges $3 \mathrm{G}$ mobile technologies with Internet, digital $\mathrm{TV}$ and radio and investigates the potential of this new infrastructure which combines traditional media and user-generated content.

\subsection{Motivations}

The CAMMP project offers a unique opportunity to design, implement and test new mobile rich media services. Especially because the project is still in its early phase, it is crucial to identify the target population, its willingness to use such services and its expectations towards it. This is the aim of the first part of the work presented in this paper. It investigates one of the first contexts of use for mobile TV to be thought of, namely a social environment where the user has to deal with more than what happens on the screen of the device. Additionally, the population recruited for the test is composed of "early adopters", which includes the first end users of new technology and services.

The main motivation for conducting the second part of the study comes from the lack of literature in the areas of mo-

\footnotetext{
${ }^{1}$ http://www.cammp.aau.dk/
}

bile collaboration and competition. Human collaborative and competitive behaviors have been extensively studied in many contexts and from various approaches, but the available research does not appear to focus much on mobile settings. It is therefore interesting to investigate firstly how users perceive these two notions put in a mobile context and secondly if these behaviors could be used to motivate user-generated content creation. Moreover, research on motivation factors for user contribution has primarily focused on online services accessed from fixed platforms. Therefore, only some of the conclusions might apply to mobile online services.

\subsection{Outline}

Section 2 presents previous research work conducted within the topics covered by the presented studies. Then, the two test activities of interest, namely the social interaction study and the conceptual evaluation are detailed in sections 3 and 4 , respectively. The main findings for each activity are presented in the according section. Finally, Section 5 concludes on the paper's contribution and opens for further research.

\section{RELATED WORK}

The related research referred to in this section should be seen not only as an introduction for the work presented later in the paper but also as a grounding material for future research in the areas discussed.

\subsection{Consumption contexts}

When dealing with the consumption of mobile media in a social context, the study reported in [1] identifies the following classification of social motivations for watching videos on mobile devices:

- Individual Viewing

- Managing solitude

- Disengaging from others

- Managing transitions between spaces

- Coordinating mobile experiences with family life

- Juggling commitments

- Coordinating content with family

- Watching at home

- Sharing the experience

- Watching together

- Showing video to others 
- Owning and exchanging content

- Getting content onto the devices

The social interaction study presented in this paper focused on practices related to "individual viewing" and "sharing the experience".

\subsection{Competitve behavior}

Analyses of human competitive behavior have been carried out by many researchers, a number of whom focused on gender issues. For instance the authors of [2] investigated the differences in behavior between women and men when choosing a payment scheme. The results show that men are more likely to choose a competition-based payment scheme (where the highest benefits go to the best performer) than women, who are influenced by their degree of risk aversion. Men on the other side compete more against other men than against women. Furthermore, Rizza and Reis focused on women's competitive nature and presented in [3] a study on how competition impacts school girls in their academic and personal lives. The interviewees reported a negative perception of the term competition and preferred to use "comparison" instead. However, in this particular setting competition as such was perceived as achieving both positive or negative sociocultural results.

When it comes to using this competitive behavior as a motivation factor for online user contribution, von Ahn presented in [4] the principles of "games with a purpose", which consists in creating games which solve computational problems that cannot be solved by electronic systems. This approach has been named "human computation" and is introduced in [5]. For instance [4] introduces two examples of small online games which use this principle. The first game, called the "ESP Game"2 serves the purpose of image labeling while the second game, "Peekaboom" addresses exhaustive image description through locating objects in pictures.

\subsection{Collaborative behavior}

As for its competitive counterpart, the study of human collaborative behavior can be carried out from various perspectives. For instance Semmann documents in [6] his research on human cooperative behavior in a large group of unknown individuals. He demonstrates that humans naturally cooperate only under certain circumstances such as reputation building. Despite this rather negative conclusion, Semmann demonstrated that optional participation could sometimes promote voluntary and anonymous participation.

In another study, Tyler and Blader reported in [7] that the main antecedent for cooperating in a social group is the notion of identity. Maintaining a favorable image of oneself and of the group appears of primary importance and influences the group members' behavior.

Furthermore, motivational factors have been described in various setups with existing services. For instance [8] and [9] investigated the practice of tagging pictures using webbased photo sharing platforms like Flickr. While Ames and Naaman defined a taxonomy of tagging motivations along

\footnotetext{
${ }^{2}$ www.espgame.org
}

the sociality and function axes [8], Nov et al. report that the motivation to tag for the general public or oneself is positively correlated to the number of tags, whereas it is not the case when it comes to tagging for family and friends $[9]$.

Finally, [10] assesses social psychology theories as a driving tool for encouraging user participation in online communities. Reminding the contribution's uniqueness to their creator as well as assigning challenging goals seem to be an efficient way of ensuring user contribution.

\section{SOCIAL INTERACTION STUDY 3.1 Presentation}

The purpose of this activity was to investigate how users handle the consumption of rich media in a social context. We carried out this investigation through a situated testing approach in which test users were observed while consuming rich media in a live and natural context (e.g. while situated in a canteen). Immediately after, they were debriefed via semi-structured interviews.

\subsection{Test setup}

The evaluation took place in one of the canteen areas at Aalborg University, between morning and early afternoon (roughly between 10.30 and 13.30) i.e. when there were other people in the canteen. All participants were interviewed for approximately 30 minutes each. The tasks performed by the participants were carried out on Nokia N77 phones, receving a DVB-H signal from a local broadcast setup. The test environment is illustrated in Figure 1.

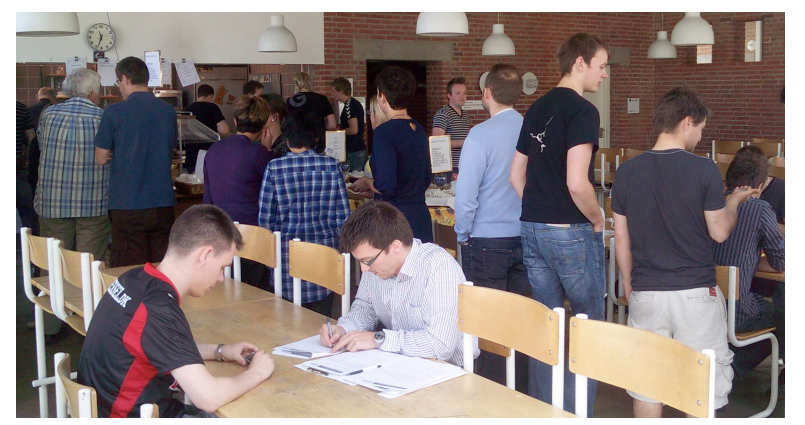

Figure 1: The canteen as test environment for the social interaction study

\subsubsection{Tasks to be carried by test participants}

During the test session, each participant carried out the following set of tasks, while being asked a set of related questions.

- Start up the TV-player application on the device.

- Surf the available channels.

- Tune in on the news channel and watch two full news stories; also pay attention to a textual news ticker located at the bottom of the screen.

\subsubsection{Participants}

In total 26 participants were recruited (3 females and 23 males). As means of compensation, all participants received a food-voucher to be used in the canteen. The participants 
were recruited among students and staff from Aalborg University. The participants were 24.2 years old in average, among who 21 expressed a high level of IT literacy. Four reported a moderate level, while only one reported a low level (although this participant reported being more comfortable with mobile phones than with computers).

\subsection{Main findings}

Interviewed users reported a strong willingness to watch mobile TV in social contexts, especially outside the home in situations of static mobility (e.g. public transports). Commuting hours and evening were the most envisioned time of usage. News was clearly the most cited type of content to be watched, in order not only to stay up-to-date but also to kill time. Most participants reported foreseeing to be comfortable when watching mobile TV in a public context, especially among strangers, although they would use earplugs when doing so. Furthermore, it has been repeatedly reported by test participants that the practice of watching TV in such context is similar and comparable to the practice of reading the newspaper or listening to music. For what concerns their experience with the mobile TV solution on the Nokia N77, they reported a very positive first opinion, especially with the image resolution. Complaints were however reported concerning long delays when switching channels.

\section{CONCEPTUAL EVALUATION}

\subsection{Presentation}

The purpose of this activity was to investigate the concepts of competition and collaboration which are involved by the use of rich media services in a social mobile context. Informal panel discussions were used for elucidating these issues. Each panel discussion started with a brief introduction of the CAMMP project and its scope, which was followed by the illustration of the two concepts of focus (collaboration and competition) through real-world examples. A selection of scenarios were used as examples of possible concrete applications where collaboration and/or competition are involved. In these scenarios, the collaboration scheme is to be interpreted as an implicit behavior: users collaborate with each other mainly through the use of the service, in opposition to direct collaboration where users would team up prior to interacting with the service. Additionally, a realistic collaboration-oriented scenario was acted out by the participants themselves. The scenario required the group to identify a preferred movie from a selection of video clips. Gathering the participants' input was be done through notes taken by the test facilitators as well as video recording of the test session.

\subsection{Test setup}

For the panel discussions, three groups of three, three and five participants were formed. The sessions took place in the afternoon and lasted approximately two hours each. All participants were paid in form of cinema tickets. The test setup is illustrated in Figure 2.

\subsubsection{Participants}

In total, 11 participants (10 males and 1 female) took part in the conceptual evaluation. The participants had an average age of 25 years and were, according to themselves, either moderately or highly skilled within IT (Moderately:

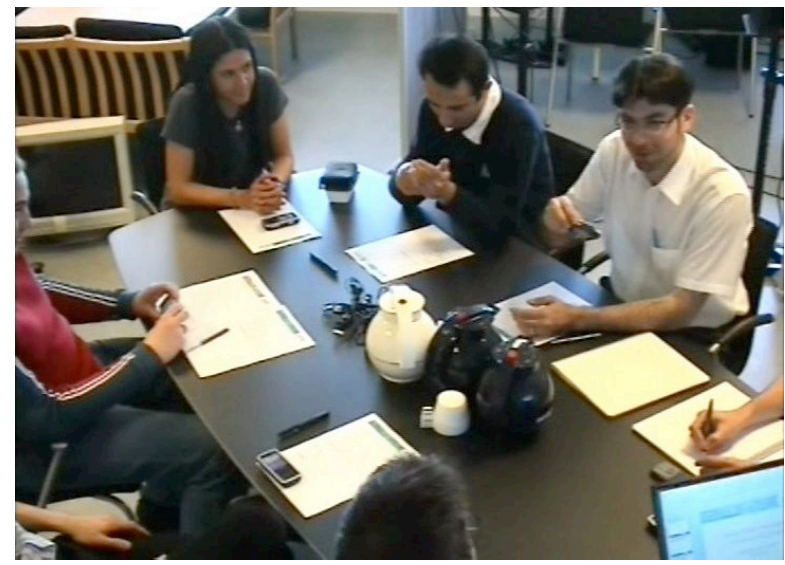

Figure 2: A meeting room as test environment for the conceptual evaluation

6, highly: 5). Based on questionnaires filled out by the participants prior to the conceptual evaluation, $72 \%$ of the participants tend to display collaborative behavior as belonging either to the group of "Creators" or "Critics" (according to Forrester's online consumer segmentation model [11]). It could therefore be speculated that almost $3 / 4$ of the participants would be likely to contribute either with data to a platform based on user-generated content or with comments, ratings, reviews etc. to such a setup. It should however be noted that this tendency may be coupled to the relatively high IT-literacy of the participants.

\subsection{Results}

Two thirds of the interviewed users displayed, through a collaboration scenario, explicit collaborative behavior involving verbal communication. The users reported that during such explicit collaboration involving mobile devices, issues such as omnidirectional sound and synchronization between sound/video as well as between devices could by quite annoying. The general quality of the tested handsets (Nokia N77) as well as video content broadcast via DVB-H was however praised. It was furthermore stated that while discounts/micro rewards may motivate some users to contribute with data it would potentially also open for abuse and lead to situations of untrustworthy information. It was suggested that a high level of quality in the information available may motivate users to contribute with additional data and that feedback to contributions may be highly motivating. For what concerns driving forces for competition it was indeed found that high score functionalities would be important, especially when among friends. In order for users to be willing to use competitive services it was in addition argued that user settings should be centralized in order to make for instance gaming on various devices as convenient as possible. Also, the interoperability between all kinds of mobile terminals should be guaranteed for the same reason.

\section{CONCLUSION AND FUTURE WORK}

\subsection{Contribution}

This paper presents two user studies dealing with specific aspects of the user experience with mobile rich media services, namely the use of mobile television in a social envi- 
ronment and the perception and application of collaborative and competitive behaviors with mobile rich media.

The findings from these studies suggest that early adopters have no problem neither watching informative and entertaining television programs on their mobile device in a public context, nor dealing (consciously or not) with the concepts of collaboration and competition when applied to mobile setups.

\subsection{Future work}

With regard to the context of use, the answers from the interviewed users could be mapped to the classification scheme introduced by O'Hara et al. in [1]. Furthermore, later studies could complement this initial mapping and provide a more complete and reliable model of the targeted population's habits in terms of mobile media consumption.

These further studies could be integrated into CAMMP's next test iteration, which will include a large scale field trial. It is envisioned to provide compatible mobile phones to a large representative segment of the Danish population and record their usage over a period of several months. This will validate the initial results concerning the context of use of mobile TV.

Foreseen future user tests include:

1. Determining the acceptability of channel switching delays. It is to be assessed how tolerant users are when it comes to channel switching delays.

2. Further investigating motivational factors for contribution. It is to be further established how end users can be encouraged to produce multimedia content as well as ratings, comments and/or reviews.

Building on the preliminary results presented in this paper, this last test would provide a better understanding of how to encourage end users to participate in the mobile TV community through user generated content. Beyond this, it would also inform future service designers on the users' inner motivations for using a particular service. Indeed, it has been recurrently discussed during the conceptual evaluation that the added value to mobile media services such as mobile TV are community-like practices such as reviews, comments and ratings. Therefore, understanding the motivational factors for user generated content should be integrated to future mobile media services.

\section{References}

[1] K. O'Hara, A. S. Mitchell, and A. Vorbau, "Consuming video on mobile devices," in CHI '0\%: Proceedings of the SIGCHI conference on Human factors in computing systems. New York, NY,
USA: ACM, 2007, pp. 857-866. [Online]. Available: http://docs.google.com/fileview?id=F.68338d345642-4f1a-bd59-fe0eff306e62

[2] M.-C. Villeval, N. D. Gupta, and A. Poulsen, "Male and female competitive behavior - experimental evidence," Groupe d'Analyse et de Théorie Economique (GATE), Centre national de la recherche scientifique (CNRS), Université Lyon 2, Ecole Normale Supérieure, Working Papers 0512, Dec. 2005. [Online]. Available: http://ideas.repec.org/p/gat/wpaper/0512.html

[3] M. G. Rizza and S. M. Reis, "Comparing and contrasting: Stories of competition," Gifted Child Quarterly, vol. 45, no. 1, pp. 54-62, 2001.

[4] L. von Ahn, "Games with a purpose," Computer, vol. 39, no. 6 , pp. 92-94, June 2006.

[5] — - "Human computation," in K-CAP '07: Proceedings of the 4th international conference on Knowledge capture. New York, NY, USA: ACM, 2007, pp. 5-6.

[6] D. Semmann, "Human cooperative behavior," Ph.D. dissertation, Christian-Albrechts-Universität, Kiel, Germay, February 2004. [Online]. Available: http://edoc.mpg.de/112197

[7] T. R. Tyler and S. L. Blader, "Identity and cooperative behavior in groups," Group Processes Intergroup Relations, vol. 4, no. 3, pp. 207-226, 2001. [Online]. Available: http://gpi.sagepub.com/cgi/content/abstract/4/3/207

[8] M. Ames and M. Naaman, "Why we tag: motivations for annotation in mobile and online media," in $\mathrm{CHI}$ '07: Proceedings of the SIGCHI conference on Human factors in computing systems. New York, NY, USA: ACM, 2007, pp. 971-980.

[9] O. Nov, M. Naaman, and C. Ye, "What drives content tagging: the case of photos on flickr," in CHI '08: Proceeding of the twenty-sixth annual SIGCHI conference on Human factors in computing systems. New York, NY, USA: ACM, 2008, pp. 1097-1100.

[10] G. Beenen, K. Ling, X. Wang, K. Chang, D. Frankowski, P. Resnick, and R. E. Kraut, "Using social psychology to motivate contributions to online communities," in CSCW '04: Proceedings of the 2004 ACM conference on Computer supported cooperative work. New York, NY, USA: ACM, 2004, pp. 212-221.

[11] C. Li, J. Bernoff, R. Fiorentino, and S. Glass, "Social technographics - mapping participation in activities forms the foundation of a social strategy," Forrester Research, Tech. Rep., April 2007. 


\section{Vestibular rehabilitation in the home: Design challenges}

\author{
Erik Grönvall, Rikke Aarhus \\ Aarhus University \\ Department of Computer Science \\ Aarhus, 8200 DENMARK \\ \{gronvall,raa\}@cs.au.dk
}

\author{
Simon B. Larsen \\ Alexandra Institute \\ Aarhus, 8200 DENMARK \\ simon.larsen@alexandra.dk
}

\begin{abstract}
Vestibular dysfunction is a balance disorder, causing dizziness that provokes discomfort and fall situations. This paper discusses early results from a project aiming to support a home-based rehabilitation regime for elderly affected by Vestibular dysfunction. This paper will introduce diverse requirements existing in home-based Vestibular Rehabilitation (VR) and depict some of peculiarities related to home-based rehabilitation and care.
\end{abstract}

\section{Keywords}

Vestibular dysfunction, elderly, rehabilitation, home-based healthcare, assistive technology, design, HCI

\section{INTRODUCTION}

In our project, we like to support elderly affected by Vestibular dysfunction in their home-based rehabilitation programme. A part from the home-training, all patients also visits a fall-clinic at the hospital twice a week, to train together with other elderly and two physiotherapists also involved in the project.

Current trends within the healthcare sector reposition the patient from being passive to becoming an active actor in a variety of care scenarios. Patients spend less time at the hospital while treatment is centralized at bigger hospitals. As hospitals becomes centralized, so do in a large extent healthcare expertise [1]. This development challenges the patient, family and home, as well as care organizations. Indeed, the home is not built as a place for care. To support patients in home-based care scenarios, technology has been identified as an enabler. A range of tele-care solutions exists that for example assist patients with diabetic foot ulcers [2] and rehabilitation after a hip-replacement operation [3]. However, the home as a care environment provides challenges not existing in professional care settings. For example people mentally attribute different values and roles to themselves in a hospital compared with a home setting. At the hospital, the patient only has to care about being 'a patient', while at home, 'the patient' shall also be the husband/wife, the worker, the sportsman [4].

\section{Vestibular dysfunction}

Vestibular dysfunction can relate from an inner-ear problem or a cerebral damage. Some patients are affected by one of these two conditions, while others have both. In common, both forms of Vestibular dysfunction cause dizziness. Elderly with these symptoms run a risk of falling and to isolate themselves due to fear of falling when for example going outside; this can lead to a negative trend where the symptoms of the vestibular problem get worse. The body shall be exposed to the very things that cause dizziness to be able to handle, or suppress, the effects of Vestibular dysfunction. Indeed, the rehabilitation practice is to a large extend based upon the continuous exposure to the very things that trigger dizziness.

\section{Vestibular rehabilitation}

Today, patients visit a rehabilitation centre at the hospital twice a week, to attend a rehabilitation programme together with trained physiotherapists. Before admitted to the rehabilitation program, each patient undergoes a screening process to understand if they are suitable for the programme. For example the elderly must not demonstrate symptoms of dementia and other cognitive problems. Patients train two types of exercises; 1) Special head and eye movements together with balance training to provoke dizziness and 2) general condition and fitness training. The eye-training is based upon different gaze exercises. For example follow an object with the head and eyes back and forth (Figure 1).

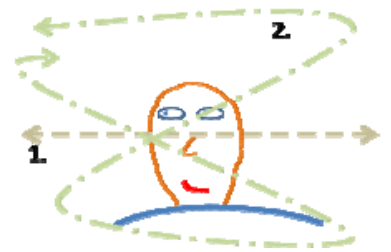

Figure 1: 1) Horizontal eye-movement or 2) combined horizontal and vertical eye-movement

However, training two times a week is not sufficient. Training should be carried out on a day-to-day basis to have full impact on the patient's recovery process. Therefore, the physiotherapists promote home-based training. Patients follow the hospital-based training but there are examples of adherence-problems in the homebased training. Our studies indicates e.g. that some patients do not understand the importance of the home-based training, they experience the exercises diffuse or 'hard to relate to' or they might not consider themselves having the time to engage in VR activities at home. Furthermore, the 
training is tiresome - continuously provoking dizziness and little progress is perceived the first 12 weeks of rehabilitation training making it hard to always find the motivation. Today's home-based training is supported through written instructions on an A4 paper. Some patients in our study that do train cannot satisfactory follow these instructions. Misunderstandings can emerge or there are perceived problems how-to perform the instructions in the home. The supervised training in the centre also provides 'randomness' in the different exercises, e.g. the physiotherapists always make small variations in gazedirections during the eye-training so the elderly never know where to look next. The elderly have expressed a lack of this randomness in the home-based training, since they decide themselves where to look. A part from the written instructions, no other tools exists today that support the elderly in remembering and carrying out the exercises in a correct manner. Finally, today the physiotherapists also lack tools to monitor patients progress at home and to understand what activities creates problems and what activities works well. We like to support the patients in their home-based training and at the same time create support for a dialogue between patients and the therapists around the home-based training, bridging the physical distance between the fall clinic and the homes.

\section{Pre-conditions for VR in a home setting}

Safety is of outmost importance. The user shall lay down, sit or stand while performing the rehabilitation exercises at home depending on the level of vestibular dysfunction. If standing, the elderly are instructed to place themselves in a corner with a chair in front of them to provide fallprotection. The elderly cannot be expected to be big consumers of technology and the setup and maintenance must be 'non-existing' or handled by a care-provider. Initial studies have indicated motivational and lifestylepriority aspects as reasons for why the exercises are not carried out sufficiently. A lack of understanding in the importance of the exercises and how they shall be performed are other identified issues creating nonadherence or low-quality training. These are examples of issues that must be handled in home-based VR

\section{Early outcomes}

Now a brief walkthrough of some of the diverse concepts and ideas we have developed and tried out together with the elderly and physiotherapists at home and at the fall clinic will be presented. They have all in different ways driven the design work forward to our current concept related to flowers that will be presented in the next section.

\section{Infrared goggles system}

We developed and tried out a system composed by a TV, IR-goggles, a Wii-mote and a 'videogame'-software. The user wears goggles containing four infrared Leds and position herself in front of the TV. Instructions are given on the TV-screen where the user shall look (e.g. up-left, right or down-right). The IR-camera in the Wii-mote, placed above the TV registers the IR-Leds and calculates the gaze direction of the user. Since the screen is too small to create an angle sufficiently big for the rehabilitation, the instructions on the TV indicate points outside of the actual TV-screen (see figure 2, left).

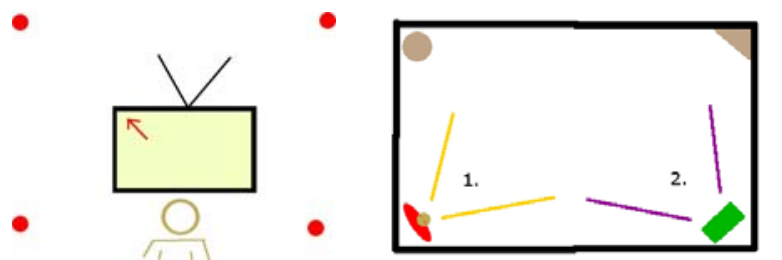

Figure 2: (left) A TV with 'spots' indicating where to look and (right) a room with (1) line of sight for elderly and (2) possible viewing-angle for the TV.

\section{Design feedback:}

The elderly do not seem to any have problems with the technology as such, or the rather geek-looking goggles. They are kind of interested in the 'gaming'-aspects of the system. However, the therapists pointed out a risk with to much focus on competition rather than the quality aspects of the exercises. These trails were however conducted in a controlled environment and still offered challenges from a usability-perspective. We experienced problems related to the positioning of the Wii-mote, calibration of distance and height between the Wii-mote and the IR-Leds on the goggles. Furthermore, the system depended on 'dots' outside of the screen to guide the users' vision. This adds complexity to the home-based configuration and setup of the system. Most of these challenges could potentially be handled by more advanced algorithms in software, but a main disadvantage was the TV. To use existing technology within the home has been pointed out as a possibility in similar settings, but in our particular case the TV did risk not to match certain aspects of the training. The user shall preferably stand in a corner, with a chair in-front of her. It is hard to foresee that most homes will have a TV placed in a visible angle from the training corner (figure 2, right).

\section{Infrared points}

A simplify version of the IR goggle system without the TV and the 'videogame'. A simple mock-up was built, composed by 3 units. An IR-sender, to be used on the users head, placed on a goggle or similar. This sender broadcasts continuously an infrared beam. This beam could be picked up by two receivers that were placed on different locations in the room. When the user looked at one of the receivers, it picked up the IR-signal and provided feedback by turning on a visible Led. These receivers can be built so small, that they easily can be attached to objects, like lamps or picture-frames existing in the home, almost unnoticed when not looked at with the IR-sender. The user should hence look at the different 'spots' in a room, equipped with 
a receiver, before looking at the next spot. One can imagine audio-feedback to guide the exercise, instead of the TV.

\section{Design feedback}

Even if this system would not need to be calibrated for distance to, or height of, the user like the previous example other implications exist. An audio-guiding system or equivalent must be made for each home, depending on where the receivers are placed. If the user like to change position of the receivers (e.g. placing them further apart, as the user becomes better) the audio files also requires updates. Placing active components distributed in a homeenvironment provides challenges related to the powerconsumption of these devices. Shall they all be connected to the power grid by cable, or run on batteries, and if so, who will change batteries? If the positioning of the receivers is done by the elderly themselves, can the therapists be sure they are placed in a way that answers to the existing rehabilitation requirements?

\section{DVD}

Different instructional videos have been demonstrated for the elderly and the physiotherapists. The elderly liked a video where you could see the physiotherapists guiding an exercise from a 'first-person'-perspective.

\section{Design feedback}

The elderly indicated that instructions of how to perform the exercises were not that important. However, they did like the 'surprise'-element since they did not know where the therapist on the DVD would like them to look. If this positive feeling of 'randomness' would disappear after many playbacks of the DVD is unknown to us. If a DVD based system is equipped with some sort of feedback system, and it is not limited to the size of the TV-screen, it could be of interest. However, the use of the TV screen affords sitting down in front of it, and contains the same problem space as illustrated in figure 1, right.

\section{Wall projections}

New micro-projectors exist, that can project e.g. pictures and computer-generated output on a wall. We have elaborated different ideas to use a complete wall for projections, to overcome limitations of for example a small TV-screen. We have tried to 'project' moving dots on a wall using a flashlight, to get a feeling of the feasibility of such ideas.

\section{Design feedback}

Due to bad sight of many elderly and overcrowded walls not suitable for projections the light source must be rather strong to have a good effect. The modern, small microprojectors are not suitable for the task, ranging from 10-50 lumens (light-power) in respect to normal size projectors having lumens of above 1000 .

\section{Dart}

One idea that came from the therapists was an augmented dart game. They found the throwing of an object challenging for the balance and eye-coordination. We performed Wizard of $\mathrm{Oz}$ game-scenarios of different difficulty levels with the elderly and the physiotherapists. The games ranged from hitting a fixed target, to hit a target that moved between each throw, to positions that provoked dizziness. We also added a complexity-level by making the elderly move between each throw. This challenged their vestibular system since they had to look down on the floor to locate the new spot where to stand, move there and then look up again before the next throw.

\section{Design feedback}

As with the Infrared goggle system, the elderly liked the 'gaming' aspects of the dart system. It made some of them not to perceive the exercises as training or something hard, but as something fun. However, people not good at dart, did not experience this in the same extent. The dart board we used in our WoO sessions was received rather well as an artefact, not being an object signalling e.g. sickness. On the other hand, one elderly expressed fear that the Velcroballs used as 'arrows' would damage things in the home, even if these balls were made out of plastic (this was also a user that was not skilled in the dart game). Negative feedback of this concept related to the need to pick up the 'arrows' that did not hit the target since many of the elderly has difficulties in 'bending down' to pick up objects. This could be handled by e.g. attaching a string to the ball, using virtual 'arrows' or having a bigger target-area. We discussed the possibility to use 'smart-fabric', like a drapery that could be used to display moving target-areas and sense hits. However, we experienced difficulties to implement this solution in private homes, in an easy to manage and non-intrusive manner.

\section{Surround Sound}

We tried out 5.1surround sound enabled headphones; to understand how sound could be used to guide the elderly in their exercises.

\section{Design feedback}

Even if our elderly users could hear if the sound came from the right or left and in some cases from the back or from the front, it is not enough from a VR perspective. They must be able to identify a fixed coordinate in a $3 \mathrm{D}$ soundroom for the technology to be useful. This is not possible with the technology we tried out.

\section{The Flower Concept}

Feedback from the diverse concepts described above and other feedback and requirements from the elderly and physiotherapists have inspired a concept of flowers, currently under development. A main challenge has been to verify that the user actually do carry out the exercises and not only 'turns on' the system to make the physiotherapists happy and that the user actually do the correct movements and exercises. We have experienced positive response to game-kind activities and a need to make an assistive technology that do not occupy too much space and that 
blend into a wide range of different homes and lifestyles. Our design shall provide motivational cues, be easy to use and not be 'a big machine'. The flower concept tries to answer to these and other requirements emerging from our heterogeneous users and settings.
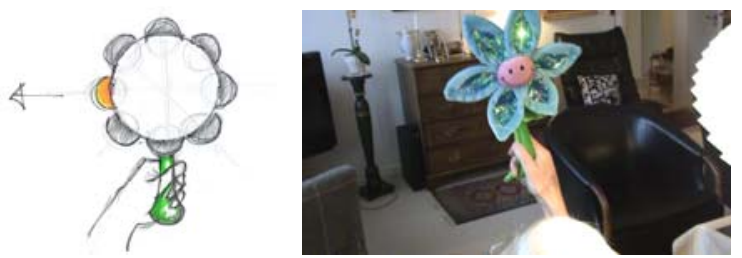

Figure 3: Early drawing and lo-fi prototype used in WoO sessions

The basic system is composed by an abstract flower (figure 3 ) and a flowerpot. The flowerpot holds the flower when not in use, acting as a docking station for the flower providing charging and internet connectivity. Hence, the flower is always fully charged and ready to be picked up and used as a rehabilitation instrument. The flower contains a wireless connection to the 'flower-pot', a Led in each petal, accelerometer to measure speed, direction and angle to earth, speaker, special purpose sound chips and a microcontroller. The microcontroller executes the program, or 'game' and this can be remotely updated by the therapists.

The basic activity supports patients laying down, sitting or standing up. The user holds the flower in front of her. A petal lights up indicating a direction similar to a compass. The user now moves the flower in that direction, until a new petal (i.e. direction) light up. The user shall now move the flower in the new direction. This can only be accomplished if the user actually do look at the flower, noticing the change of activated petal and is therefore an indication of correct use in respect to the rehabilitation protocol. The activity can be supported by short voice instructions saved on small integrated circuits, each able to store a number of short audio files. We have done trails utilizing a low-fi version of the flower. This version is built around a toy-flower made out of fabric. We have augmented the flower with a Led in each petal. These Leds can be individually controlled by a purpose-made remote controller communicating with the flower wirelessly. Through the WoO technique, the early flower concept is currently under evaluation, both at private homes of elderly and at the fall clinic.

\section{Design feedback}

Early feedback has been mostly positive. Aesthetically, people seem to accept even our early 'toy-flower' in a higher extent then our other concepts. The interaction modality do not discriminate people with less skills, as the speed and other parameters can be adjusted to suit each patient. However, some weak patients have demonstrated problems moving the flower due to back or arm-pain. Here further work is needed. Maybe a bouquet of flowers, with different characteristics could be used to complement each other. To target the elderly with limited possibility to move their bodies, we also consider objects that do not need to be moved by hand. However, they will contain moving elements or get bigger to provide a wide sight or gaze angle for the user.

\section{Discussion}

This paper has presented different design concepts for supporting home based VR. They have all informed the design process and helped in creating a wider understanding of the requirements that can exist when developing assistive technologies for home use. Our work shows that acceptance or motivational aspects to engage in technology use as part of a home-based care programme is important, but complex in nature. Elderly represent a heterogeneous group with diverse requirements on supportive technology that has to be understood. Introducing assistive technology for home-based VR, enables the development of support-tools also for the physiotherapists. They can get tools to understand individual progress and problems related to the home-based training. This data can become a mediator in the dialogue between patient and therapist, something they in a high degree lack in current practice. The fall clinic represents a controlled, supervised professional setting where technology acceptance mostly is based upon functional requirements, while the home and its inhabitants challenge the design of rehabilitation technologies also from nonfunctional requirements.

\section{ACKNOWLEDGMENTS}

We would like to thank the elderly and the physiotherapists who participate in this ongoing project.

\section{REFERENCES}

1. Grönvall, E., Aarhus, R., Larsen, S.B., Pervasive healthcare in the home : Supporting patient motivation and engagement, Proc. Pervasive Health 2010. 2010: Munich, Germany.

2. Clemensen, J., Larsen, S.B., Kirkevold, M., Ejskjaer, N., Treatment of diabetic foot ulcers in the home: video consultations as an alternative to outpatient hospital care. Int. J. Telemedicine Appl., 2008: p. 1-6.

3. Aarhus R., Gjerlufsen T., Hohn T., Vesterby M., Telemedicine for healthy patients, 2 nd Int. Workshop on Infrastructures for Health Care:Connecting practices across institutional and professional boundaries, 2009, Copenhagen, Denmark: p 5-7.

4. Alonzo, A., Everyday illness behavior: a situational approach to health status deviations. Soc. Sci. \& med., 1979. 13(4): p. 397. 


\title{
Interacting with Software Architectures - An Experiment with Interface Criticism of Software Architectures
}

\author{
Klaus Marius Hansen \\ University of Iceland \\ kmh@hi.is
}

\begin{abstract}
Software architectures have user interfaces too. Through APIs, documentation, IDEs users (developers) interact with software architectures. While significant research has been done on the influence of software architecture on the interface to users of software, little consideration has been given to the software architecture as an interface to developers of software. In this paper, we argue that interaction with software architecture is important and investigate the use of the "interface criticism" approach in this context. In particular, we analyze an open source, pervasive/mobile computing software architecture (Android) and a cloud computing software architecture (Google App Engine).
\end{abstract}

\section{INTRODUCTION AND MOTIVATION}

"Software architecture" may be defined as

The software architecture of a computing system is the structures of the system, which comprise software elements, the externally visible properties of those elements, and the relationships among them [2].

Take the Android ${ }^{1}$ mobile (phone) operating system as an example. From a static point of view, the software elements include Java packages and classes that a developer needs to use to create Android application. The relationships among the elements include dependencies among packages including that an Android application will need to inherit from Android-specific classes. In this way, the software architecture influences externally visible properties of the applications in that the portability Android applications to other platforms (such as a Java ME-based mobile phone) is hindered whereas the buildability of Android systems is enhanced.

In addition to static structures, it is common to also distinguish runtime structures (e.g., which objects or

\footnotetext{
${ }^{1}$ http://www . android.com/
}

Permission to make digital or hard copies of all or part of this work for personal or classroom use is granted without fee provided that copies are not made or distributed for profit or commercial advantage and that copies bear this notice and the full citation on the first page. To copy otherwise, or republish, to post on servers or to redistribute to lists, requires prior specific permission and/or a fee.

DHRS 2009, December 14, 2009, Aarhus, Denmark. components are running in the application and how) and allocation structures (e.g., on which device is an application being deployed). Software architecture is important since it gives developers a fundamental and manegeable understanding of the system and enables or inhibits a large number of system quality attributes such as performance, modifiability, or availability $[3,7]$

We are here interested in how users/developers interact with software architectures and define the "interface" of a software architecture as

An interface of a software architecture is a means by which a software architecture can be used by a developer

As another example, consider Google App Engine (GAE) ${ }^{2}$ platform for "cloud computing" [8]. Cloud computing can be seen as a combination of providing software as (Web) services (as is done, e.g.,in GMail) and computing resources (e.g., CPU cycles or network data transfer) as a utility (i.e., as a potentially unlimited resource that may be bought). A developer (a "cloud user") interacts with the static structure of the GAE through the use of software code, i.e., classes, methods, APIs etc. The allocation structure at Google (a "cloud provider") consists of a vast number of servers/virtual machines. The interface a developer has to this software architecture is the ability to create a Web service (in Python or Java) that the GAE may then distribute on multiple servers.

Since software architecture is deciding for many quality attributes, it is important that software architecture can be understood, learned, realized etc. by developers. In the following, we review work on software architecture and usability and report from the application of an interaction evaluation method applied to software architecture.

\section{RELATED AND PREVIOUS WORK}

Previous work has investigated the relationship of software architecture and the quality/externally visible property of usability [3]. Bass and John [2003] investigated to which extent usability is an architectural system quality attribute, i.e., to which extent architectural design decisions and usability are related. A typical exam-

\footnotetext{
${ }^{2}$ http://code.google.com/appengine/
} 
ple is the support for undo/redo in user interfaces: the availability of undo/redo commands in a user interface arguably enhances usability and a decision to support undo/redo most has architectural impact in that, e.g., the Command pattern [6] needs to be designed into the system.

To our knowledge, little or no work has been performed on the usability of software architectures in themselves. Quality attributes such as "modifiability" and "buildability" are related to usability of the software architecture by developers [2] but only in so far as specific requirements can be implemented using the architecture in a timely fashion.

Inspiration for evaluating the interface of software architectures may be drawn from "traditional" humancomputer interaction (HCI) evaluation methods. Bødker [5] discerns three "waves" of HCI: A first wave with focus on human factors and with evaluation methods such as controlled laboratory tests, cognitive walkthroughs, and guidelines; a second wave with focus on "human actors" doing collaborative work [1] and evaluation methods such as participatory design workshops, prototyping, and contextual inquiry; and finally a third wave in which the use of computers has extended beyond work situations to other aspects of human life with a focus on, e.g., culture and experience.

While evaluation methods from all three waves of HCI may be relevant to software architecture, software architecture use (and focus) can historically be seen as parallelling the evolution of HCI: from single-organization software architecture, over open source software architectures, to software development (and software architecture) becoming increasingly pervasive and commonplace $[9,10]$. For an initial investigation of software architecture interface evaluation, we chose a third generation evaluation method, "interface criticism". The next section reports from our application of this method.

\section{A SOFTWARE ARCHITECTURE CRITIQUE EXPERIMENT}

Bertelsen and Pold [4] defined the concept of "interface criticism" as part of a re-orientation of HCI as an aesthetic field, one argument being that issues such as design for unanticipated use of design of cultural interfaces. In line with the historical evolution of software architecture, we attempt to apply interface criticism "as-is" to software architecture by applying the interface criticism guide, exemplifying using the Android and GAE architectures. For each perspective of the guide, the perspective questions are repeated.

\section{Stylistic References}

Analyze stylistic references in the interface (e.g., Mac OS vs. X11, renaissance vs. baroque) [4]

Software architecture styles are most often codified in "(software) architectural styles" [11]. These software architectural styles present different trade-offs of qual- ity attributes, but more importantly, in our context, a software architectural style also create expectations of, e.g., conventions observed. In GAE, for example, a "client/server" architectural style is used in multiple ways: First, in Java, developers create "Servlets" that are later deployed on a Web server as a server while end user Web browsers act as clients. Secondly, in Java the IDE used acts as a client to Google's GAE infrastructure of physical servers.

As remarked by Bertelsen and Pold, style can also be analyzed historically. The Android platform rejects the common way of architecting Java-like platforms for mobile devices that add mobile variants of standard Java features. While this embellishing can in a sense be seen as a baroque style, Androids reimplementation and redefinition of the standard Java platform and API be seen as neoclassical.

\section{Standards}

Identify the use of standards and the conformance to tradition [4]

While GAE adheres to the standards of HTTP and Java, Android deviates from the Java standard. Breaking with the tradition of Java ME and similar, Android's software architecture interface is on the surface indistinguishable to a Java SE API. However, the Android architecture is fundamentally different from standard Java: only a subset of libraries are implemented and an idiosyncratic virtual machine (Dalvik) is used. This effectively means that Android breaks with traditions and that developers cannot expect all APIs needed to be available (or reused from another "Java" implementation).

\section{Materiality and remediation}

Consider the materiality of the interface (e.g., code, algorithms, pixels) and disucss how it is used

Consider how the interface draws on the materiality of other media (e.g., text pages, photography, cinematic language, control panels)

Discuss immediacy and hypermediacy in the interface [4]

For GAE the main representation that developers work with is that of the Servlet, a Java class that implements a server response to an HTTP request. The architecture attempts to seamlessly scale developer applications both up and down as end user requests vary. Thus GAE attempts to achieve transparency/immediacy in the sense of hiding the intricacies of the Google cloud platform. However, developer use of GAE is subject to payment leading to an interest in knowing how much needs to be paid, is the budget about to be exceeded etc. Some mediation of payment (and scaling) appears necessary and some architectural variant of "hypermediacy" could/should support this. Other cloud platforms (such 
as Amazon $\mathrm{EC}^{3}$ make the deployment structure fully transparent, allowing developers to work directly on a virtual machine (representation) rather than (more) indirectly on a Servlet representation of the same resource.

\section{Genre}

Identify and consider various genres in the interface [4]

The "genre" of the Android platform pertains to the "reference architecture" it embodies [2]. While not formalized as a single reference architecture, Android comprises a common set of architectural patterns/styles including Model-View-Controller for structuring user interface, layering for separating programming abstractions, and an event system/implicit invocation for communication/coordination among programs (through "Intents").

GAE (and related cloud platforms) may be seen as establishing a new genre (in terms of similarities in form, style, subject, and expectations that developers can make): developers may create applications following "traditional" styles, expecting "the cloud" to manage these applications in a scalable way.

\section{Hybridity}

Discuss the interface as a hybrid between the functional (control interface) and the cultural interface [4]

While the primary means of interaction with software architecture is through its "control interface" in that interacting with software architecture is mostly a matter of getting work (development) done using the software architecture. However, open source projects (such as Android) establish large groups of developers, establishing a culture based on the projects. While it may be hard to distinguish a particular experience-based interaction with software architecture, open source software architecture (elements) definitely have a cultural interface in that specific attitudes and behavior is expected when producing and using components.

\section{Representations}

Identify representational techniques and analyze how they work (e.g., realistic and naturalistic representations vs. symbolic and allegorical representations) [4]

One interesting aspect of representation in GAE is that Web server elements have two different static representations: either as a Java class (a Servlet) or as a Python class (a "RequestHandler"). Obviously both of these are symbolic (in the sense that the deployment structure is not realistically represented).

\footnotetext{
${ }^{3}$ http: //aws.amazon. com/ec2/
}

\section{Challenges to Expectations \& Development Potentials}

Identify challenges to users' expectations

Consider the developmental potentials. How is development in use supported? How may the interface support the development of unanticipated use? [4]

We have currently not performed any form of empirical evaluation and thus do not have data on challenges (as experienced by users/developers) of the Android or GAE software architecture. Apart from direct interaction/observation of developers, one interesting way of obtaining such data would be to mine the defect databases of the projects. One example is Android issue 3691: "Allow root access through Android Debug Bridge". If realized, this would fundamentally break with that the Android platform in that this would allow developers to completely change or even remove Android from a mobile phone. The issue may be seen as a symptom of that it is challenging for developers to control fundamental functionality of phones (such as the call functionality).

Development in use is furthermore an aspect of software architecture that is seldomly stressed: both Anroid and GAE (and most other architectures that we are aware of) provide a single, "true" software architecture that does not support learning, e.g., going from a developer wanting to just deploy simple Servlet to a developer wanting (and able) to control scalability parameters of Servlet deployment.

\section{DISCUSSION}

We have argued that software architecture is important and that an important aspect of a software architecture from the point of view of a developer is the interface of a software architecture and how it is possible to interact with the software architecture.

We gave two examples of software architectures (and their interfaces), Android and Google App Engine, and used a "third way" HCI evaluation method, "interface criticism", to analyze the software architectures. While the analysis is superficial, it still points to the utility of an aesthetic approach in analyzing software architectures in particular and the potential of using HCI evaluation methods on software architectures in general.

The use of interface criticism brought forward points that were not obvious to us before doing the analysis including that: i) the concept of "genre" may be relevant and useful for software architectures (and that a specific "cloud genre" may be forming), ii) that Android simultaneously mimics and breaks standards in a way that may be both an advantage and a disadvantage to developers, and iii) the general lesson that developmentin-use and learning may need to be addressed (better) in software architecture interfaces. Having said this, for the specific technique of "interface criticism" to be immediately applicable in a software architecture (in- 
terface) context, it appears that guide both has to be specialized (e.g., drawing examples from architectural styles rather than user interface styles) as well as extended (e.g., by incorporating an analysis of the different modes/structures of software architectures).

\section{REFERENCES}

1. L. Bannon. From human factors to human actors: The role of psychology and human-computer interaction studies in system design. Design at work: Cooperative design of computer systems, pages 25-44, 1991.

2. L. Bass, P. Clements, and R. Kazman. Software architecture in practice. Addison-Wesley Professional, 2 edition, 2003.

3. L. Bass and B.E. John. Linking usability to software architecture patterns through general scenarios. The Journal of Systems $\&$ Software, 66(3):187-197, 2003.

4. Olav W. Bertelsen and Søren Pold. Criticism as an approach to interface aesthetics. In NordiCHI '04: Proceedings of the third Nordic conference on Human-computer interaction, pages 23-32, New York, NY, USA, 2004. ACM.

5. Susanne Bødker. When second wave hci meets third wave challenges. In NordiCHI '06: Proceedings of the 4th Nordic conference on Human-computer interaction, pages 1-8, New York, NY, USA, 2006. ACM.
6. E. Gamma, R. Helm, R. Johnson, and J. Vlissides. Design patterns: elements of reusable object-oriented software. Addison-wesley Reading, MA, 1995.

7. Klaus Marius Hansen, Kristján Jónasson, and Helmut Neukirchen. An empirical study of open source software architectures' effect on product quality. In The Second Workshop on Empirical Assessment in Software Architecture (EASA'09), Cambridge, UK, September 2009. To Appear.

8. Brian Hayes. Cloud computing. Commun. ACM, 51(7):9-11, 2008.

9. E.M. Maximilien, A. Ranabahu, and S. Tai. Swashup: situational web applications mashups. In Companion to the 22nd ACM SIGPLAN conference on Object-oriented programming systems and applications companion, page 798 . ACM, 2007.

10. C. Scaffidi, M. Shaw, and B. Myers. Estimating the numbers of end users and end user programmers. In Proceedings of the 2005 IEEE Symposium on Visual Languages and Human-Centric Computing, pages 207-214. Citeseer, 2005.

11. M. Shaw and P. Clements. Toward boxology: Preliminary classification of architectural styles. In Foundations of Software Engineering, pages 50-54. ACM New York, NY, USA, 1996. 


\section{Which Is the Better Prompt in Thinking-Aloud Studies, "What Are You Trying to Achieve?" or "Keep Talking"?}

\author{
Morten Hertzum \\ Computer Science \\ Roskilde University \\ 4000 Roskilde, Denmark \\ mhz@ruc.dk
}

\author{
Kristin D. Hansen \\ Computer Science \\ Roskilde University \\ 4000 Roskilde, Denmark \\ kdh@ruc.dk
}

\author{
Hans H. K. Sønderstrup-Andersen \\ National Research Centre for \\ the Work Environment \\ 2100 Copenhagen, Denmark \\ hsa@nrcwe.dk
}

\begin{abstract}
Thinking aloud is widely used for usability evaluation but generally in a relaxed way that conflicts with the prescriptions of the classic model for obtaining valid verbalizations of thought processes. We investigate whether participants that think aloud in the classic or relaxed way behave differently compared to performing in silence. Results indicate that whereas classic thinking aloud has little or no effect on behaviour apart from prolonging tasks, relaxed thinking aloud affects behaviour in multiple ways. During relaxed thinking aloud participants took longer to solve tasks, spent a larger part of tasks on general distributed visual behaviour, issued more commands to navigate both within and between the pages of the web sites used in the experiment, and experienced higher mental workload.
\end{abstract}

\section{Keywords}

Thinking aloud, verbalization, usability evaluation

\section{INTRODUCTION}

Evaluation is an important and complex element of systems development, and effective and valid evaluation methods are, consequently, in high regard. The thinking-aloud method has become popular in practical usability evaluation as well as in usability research and is by many considered the single most valuable usability evaluation method [3, 13]. However, the possible effects of thinking aloud on the behaviour of participants in usability evaluations have only been examined in a few studies [e.g., $8,11]$. Instead, claims to validity have been adopted from studies in cognitive psychology, particularly Ericsson and Simon's [5] work on verbal reports. Descriptions of the thinking-aloud method for usability evaluation differ, however, in important respects from thinking aloud as defined by Ericsson and Simon [5, 6], particularly regarding instructions and reminders to think aloud, and these differences are likely exacerbated in practical use of the method $[1,14]$.

DHRS2009: Proceedings of the Ninth Danish HCI

Research Symposium (Aarhus, DK, December 14, 2009).
This study aims to investigate whether thinking aloud causes participants in usability evaluations to behave differently and experience a different level of mental workload compared to performing in silence. To address the variation in - and uncertainty about - what test participants are more specifically asked to do when they are asked to think out loud we distinguish between classic thinking aloud and relaxed thinking aloud. Classic thinking aloud complies with the prescriptions of Ericsson and Simon [5]. Relaxed thinking aloud complies with typical descriptions of thinking aloud in the context of usability evaluation [e.g., 4, 13]. We restrict our study to concurrent thinking aloud; that is, participants think aloud while solving tasks.

Usability evaluation has become widely practiced, not least through the uptake of lightweight, or discount, methods [e.g., 12, 13]. These methods promise to require little time, few skills, hardly any facilities, and yet to yield good results. The entire approach stands in stark contrast to the rigour of Ericsson and Simon's [5] description of thinking aloud and to their assessment of the consequences of failing to think aloud in the proper way. Ericsson and Simon [5] distinguish three levels of decreasingly valid verbalizations, each characterized by the amount of interference caused by the additional processing involved in producing the verbalizations:

Level 1 verbalization is the vocalization of thoughts and information that are already in a person's present focus of attention in verbal form. No intermediate processes are needed to report these thoughts and people need expend no special effort to communicate them. For example, when people report sequences of numbers while mentally solving math problems they are producing level 1 verbalizations because the reported numbers - that is, the intermediate results of the calculations - are directly available in the form needed to report them.

Level 2 verbalization is the explication of information that is presently in a person's focus of attention but must be recoded into verbal form before it can be reported. The explication or recoding involves additional processing but does not bring new information into the person's focus of attention. For example, images and abstract concepts must be transformed into words before they can be reported but 
as long this transformation is the only additional processing that is performed such verbalization is at level 2 .

Level 3 verbalization introduces mental processing that influences a person's focus of attention in ways beyond those occasioned by task performance. The influence on the person's focus of attention consists of requiring that present thoughts and information attended to at the moment are linked to earlier thoughts and information attended to previously. People, for example, produce level 3 verbalizations when they are asked to provide explanations of their thoughts and behaviour or to retrieve additional information from memory.

According to Ericsson and Simon [5] verbalizations at levels 1 and 2 are valid data about task performance, whereas level 3 verbalizations are not. This restricts valid verbalization to the currently heeded information; that is, the contents of short-term memory.

\section{METHOD}

\section{Participants}

Eight participants took part in the experiment. Participants' age ranged from 23 to 33 years with an average of 28.5 years. All participants were experienced computer users and indicated that they used computers daily. In addition, the participants had normal or corrected-to-normal vision and none used hard contact lenses or multi-focal glasses.

\section{Tasks}

The experimental tasks involved looking for information on four web sites - two web sites for Danish television channels and two for online bookstores. Each task was paired with another, near-identical task. The two tasks in a pair were performed on the web sites for either the two television channels or the two online bookstores. That is, the tasks in a pair were performed on similar but different web sites, thus reducing any learning effects. To further even out effects of learning, the order in which participants solved the tasks in a pair was counterbalanced across participants. Each participant performed 8 fact tasks and 8 assessment tasks. In fact tasks participants gathered information that was explicitly available on the web sites. For example, 'Which city has the highest temperature today - Copenhagen or Aarhus?' In assessment tasks participants gathered information and based on this information formed an opinion. For example, 'What is the biggest domestic news story on the front page?'

\section{Procedure}

Upon arriving at the lab, participants were introduced to the experiment and asked questions about their background. Then, participants were instructed about how to think aloud at levels 1 and 2 and practiced thinking aloud on four training tasks. The thinking-aloud instructions were copied from Ericsson and Simon [5, pp 377-379], and the three first training tasks were near identical to their training tasks. After practicing thinking aloud, participants were introduced to the task load index (TLX [9]). The preparations for the experimental tasks were completed by setting up and calibrating the eye tracker so that it accurately captured the participant's line of gaze. Participants' eye movements were recorded with a headmounted eye tracker from SMI, sampling at $50 \mathrm{~Hz}$.

The experiment consisted of two sub sessions for each participant. In the first sub session participants performed tasks in the classic thinking aloud and silent conditions. In classic thinking aloud participants performed the tasks while thinking out loud and the experimenter reminded participants to 'keep talking' when they fell silent for more than about 30 seconds. This condition corresponds to how thinking aloud is defined by Ericsson and Simon [5] as consisting of verbalization at levels 1 and 2 . In the silent condition participants performed the tasks without verbalizing their thoughts. Participants were simply instructed to solve the tasks and report their answer to the experimenter upon completion. This condition is similar to how people work when they are not enrolled in usability evaluations or other tests. The two thinking-aloud conditions in the second sub session were relaxed thinking aloud and silent. In relaxed thinking aloud participants performed the tasks while thinking out loud and the experimenter intervened with questions asking participants for explanations and comments. Examples of the questions include 'What are you trying to achieve?' and 'Did you find this easy or difficult?' This condition includes level 3 verbalization and corresponds to how thinking aloud is commonly employed in the context of usability evaluation. The silent condition was similar to the first sub session.

\section{RESULTS AND DISCUSSION}

We investigated the presence of effects with respect to correctness of task solutions, task completion times, eye movements, hand movements, and mental workload.

The correctness of task solutions was not affected by whether participants were thinking aloud or performing in silence. This was the case for both classic and relaxed thinking aloud (but was determined for fact tasks only). For relaxed thinking aloud, some previous studies [2, 16] indicate that verbalization leads to fewer errors, compared to performing in silence.

Task completion times were longer during thinking aloud than when participants performed in silence. This difference was present for classic thinking aloud as well as for relaxed thinking aloud, and it was mainly due to participants' performance on assessment tasks, see Tables 1 and 2. The extra time required during thinking aloud accords with previous studies $[5,15]$ and indicates that verbalization is a slower process than thinking.

Participants' eye movements differed in some respects but did not provide evidence of a trend indicating that marginal effects for classic thinking aloud become significant for relaxed thinking aloud. During classic thinking aloud mental activity may have been shifted slightly from the start toward the end of assessment tasks. A similar effect was not found for relaxed thinking aloud. During relaxed 
Table 1. Task completion times, classic thinking aloud

\begin{tabular}{|c|c|c|c|c|c|}
\hline \multirow{2}{*}{$\begin{array}{l}\text { Task completion time } \\
\text { (seconds/task) }\end{array}$} & & \multicolumn{2}{|c|}{ Classic } & \multicolumn{2}{|c|}{ Silent } \\
\hline & & $M$ & $S D$ & $M$ & $S D$ \\
\hline Fact tasks & & 110 & 47 & 82 & 35 \\
\hline Assessment tasks & $*$ & 303 & 92 & 217 & 41 \\
\hline
\end{tabular}

Table 2. Task completion times, relaxed thinking aloud

\begin{tabular}{|c|c|c|c|c|c|}
\hline \multirow{2}{*}{$\begin{array}{l}\text { Task completion time } \\
\text { (seconds/task) }\end{array}$} & & \multicolumn{2}{|c|}{ Relaxed } & \multicolumn{2}{|c|}{ Silent } \\
\hline & & $M$ & $S D$ & $M$ & $S D$ \\
\hline Fact tasks & & 201 & 55 & 131 & 76 \\
\hline Assessment tasks & $* *$ & 319 & 148 & 114 & 49 \\
\hline
\end{tabular}

$M-$ mean, $S D-$ standard deviation, $* * p<0.01$

thinking aloud saccades were of shorter duration for assessment tasks, the more complex type of tasks. This is often seen as an indication of decreased visual search [7]. However, in this condition participants also spent a larger part of task completion times in general distributed visual behaviour, see Table 3. This seems to indicate that participants to a larger extent needed to fixate briefly on various screen elements to assess their relevance and contribution to the tasks. Distributed visual behaviour is akin to visual search but at a level of aggregation where brief fixations intersperse an activity primarily characterized by frequent saccades between screen elements that are spatially far apart and typically also distinct in contents. One reason for the increase in general distributed visual behaviour during relaxed thinking aloud could be that verbalizing at level 3 disrupted participants' mental activities and made it more difficult for them to maintain a focus, necessitating more distributed visual behaviour to regain a focus. Another reason could be that relaxed thinking aloud made participants in doubt about their approach to solving tasks or aware of other ways of solving them, leading to more distributed visual exploration of the screen.

Table 3. Visual behaviour, relaxed thinking aloud

\begin{tabular}{|c|c|c|c|c|}
\hline \multirow{2}{*}{$\begin{array}{l}\text { Eye movements } \\
\text { (percent of task time) }\end{array}$} & \multicolumn{2}{|c|}{ Relaxed } & \multicolumn{2}{|c|}{ Silent } \\
\hline & $M$ & $S D$ & $M$ & $S D$ \\
\hline Focused: general & 23 & 8 & 21 & 7 \\
\hline Focused: text & 3 & 4 & 5 & 7 \\
\hline Focused: illustration & 3 & 3 & 2 & 2 \\
\hline Distributed: general $* *$ & 10 & 4 & 5 & 5 \\
\hline Distributed: text & 38 & 7 & 39 & 17 \\
\hline Distributed: illustration & 1 & 1 & 1 & 2 \\
\hline
\end{tabular}

$M-$ mean, $S D-$ standard deviation, $* * p<0.05$
Table 4. Hand movements, relaxed thinking aloud

\begin{tabular}{lrcccc}
\hline Hand movements & & \multicolumn{2}{c}{ Relaxed } & \multicolumn{2}{c}{ Silent } \\
\cline { 2 - 6 }$($ pr task) & $*$ & $S D$ & $M$ & $S D$ \\
\hline Mouse clicks & $*$ & 5.9 & 4.9 & 4.0 & 2.6 \\
Scrolling instances & $* *$ & 26.6 & 21.5 & 10.9 & 8.9 \\
Writing instances & & 2.4 & 1.8 & 1.9 & 1.0 \\
\hline$M-$ mean, $S D-$ std deviation, ${ }^{*} p<0.05, * * p<0.01$
\end{tabular}

Participants' hand movements revealed considerable differences in how participants interacted with the system while solving the tasks. Mouse clicks and writing instances approached significantly higher numbers during classic thinking aloud compared to the silent condition. This suggests that participants may be paying more attention to obtaining information from web pages other than the current one. During relaxed thinking aloud participants made more mouse clicks and scrolling instances compared to the silent condition, see Table 4 . This indicates that participants made more efforts to obtain information from other web pages by making more shifts between web pages, and they also explored the current web page more comprehensively by scrolling more. Hence, the increase in task completion times must be interpreted differently for classic and relaxed thinking aloud. During classic thinking

Table 5. Mental workload, classic thinking aloud

\begin{tabular}{|c|c|c|c|c|c|}
\hline \multirow{2}{*}{$\begin{array}{l}\text { TLX subscale } \\
(0-100)\end{array}$} & & \multicolumn{2}{|c|}{ Classic } & \multicolumn{2}{|c|}{ Silent } \\
\hline & & $M$ & $S D$ & $M$ & $S D$ \\
\hline Mental demand & $*$ & 41 & 26 & 31 & 17 \\
\hline Physical demand & & 20 & 22 & 14 & 13 \\
\hline Temporal demand & & 23 & 22 & 20 & 13 \\
\hline Effort & & 28 & 24 & 21 & 14 \\
\hline Performance & & 30 & 26 & 29 & 23 \\
\hline Frustration & & 26 & 19 & 18 & 13 \\
\hline
\end{tabular}

$M-$ mean, $S D$ - standard deviation, ${ }^{*} p<0.05$

Table 6. Mental workload, relaxed thinking aloud

\begin{tabular}{lccccc}
\hline TLX subscale & & \multicolumn{2}{c}{ Relaxed } & \multicolumn{2}{c}{ Silent } \\
\cline { 3 - 6 }$(0-100)$ & & $M$ & $S D$ & $M$ & $S D$ \\
\hline Mental demand & $* *$ & 30 & 15 & 19 & 10 \\
Physical demand & & 16 & 13 & 10 & 7 \\
Temporal demand & $*$ & 18 & 12 & 10 & 7 \\
Effort & $*$ & 25 & 12 & 14 & 8 \\
Performance & $*$ & 21 & 18 & 17 & 16 \\
Frustration & $*$ & 21 & 15 & 10 & 7 \\
\hline$M-$ mean, $S D-$ std deviation, $* p<0.05, * * p<0.01$
\end{tabular}


aloud the increase in task completion times was primarily a slowdown in participants' performance but during relaxed thinking aloud participants performed the tasks in a different way.

Mental workload approached higher ratings for classic thinking aloud, compared to performing in silence. For relaxed thinking aloud participants rated mental workload higher than for performing in silence. This overall picture was repeated for the individual TLX subscales. Verbalization at levels 1 and 2 added to one of the six subscales of mental workload, whereas verbalization at level 3 added to all but one of the subscales, see Tables 5 and 6 . The results for mental workload, a subjective measure, are consistent with the performance measures. Effect sizes tend to be larger for mental workload than for the performance measures, suggesting that participants may moderate performance differences by putting in extra mental effort while thinking aloud.

\section{CONCLUSION}

Thinking aloud is widely used as a method for usability evaluation. The method is, however, generally applied in a relaxed manner that conflicts with the prescriptions of Ericsson and Simon's classic model for obtaining valid verbalizations of thought processes. Descriptions of thinking aloud in the methodological literature often display a similar failure to consistently distinguish between classic thinking aloud (corresponding to verbalization at levels 1 and 2) and relaxed thinking aloud (corresponding to verbalization at levels 1 to 3 ). In this study, we have investigated the effects of thinking aloud over performing in silence for both classic and relaxed thinking aloud.

Our results confirm that classic thinking aloud has little effect on participants' behaviour and mental workload, except for prolonging tasks. Hence, valid data about the use of a system can be obtained at the price of precise instructions and minimal interaction between the user who thinks aloud and the evaluator who listens in on the user's thoughts. Conversely, relaxed thinking aloud led to longer task completion times, a larger part of tasks spent on general distributed visual behaviour, more commands issued to navigate both within and between the pages of the web sites used for solving the tasks, and higher perceived mental workload. Hence, the relaxed approach to thinking aloud threatens the validity of the method and indicates that this approach, common in practical usability evaluation, may not be the authoritative yardstick it is often assumed to be.

\section{ACKNOWLEDGEMENTS}

This paper is a summary of Hertzum et al. [10]. Please, consult the full paper for the details.

\section{REFERENCES}

1. Boren, T., and Ramey, J. Thinking aloud: Reconciling theory and practice. IEEE Transactions on Professional Communication 43, 3 (2000), 261-278.
2. Chi, M.T.H., De Leeuw, N., Chiu, M.-H., and LaVancher, C. Eliciting self-explanations improves understanding. Cognitive Science 18, 3 (1994), 439-477.

3. Dumas, J.S. User-based evaluations, in Jacko, J. and Sears, A. eds. The Human-Computer Interaction Handbook, Erlbaum, Mahwah, NJ, 2003, 1093-1117.

4. Dumas, J.S., and Redish, J.C. A practical guide to usability testing. Revised edition. Intellect Books, Exeter, UK, 1999.

5. Ericsson, K.A., and Simon, H.A. Protocol analysis: Verbal reports as data. Revised edition. MIT Press, Cambridge, MA, 1993.

6. Ericsson, K.A., and Simon, H.A. Verbal reports as data. Psychological Review 87, 3 (1980), 215-251.

7. Goldberg, J.H., and Kotval, X.P. Computer interface evaluation using eye movements: Methods and constructs. International Journal of Industrial Ergonomics 24, 6 (1999), 631-645.

8. Haak, M.J.v.d., Jong, M.D.T.d., and Schellens, P.J. Retrospective vs. concurrent think-aloud protocols: Testing the usability of an online library catalogue. Behaviour \& Information Technology 22, 5 (2003), 339351.

9. Hart, S.G., and Staveland, L.E. Development of NASATLX (task load index): Results of empirical and theoretical research, in Hancock, P.A. and Meshkati, N. eds. Human Mental Workload, North-Holland, Amsterdam, 1988, 139-183.

10.Hertzum, M., Hansen, K.D., and Andersen, H.H.K. Scrutinising usability evaluation: Does thinking aloud affect behaviour and mental workload? Behaviour \& Information Technology 28, 2 (2009), 165-181.

11.Krahmer, E., and Ummelen, N. Thinking about thinking aloud: A comparison of two verbal protocols for usability testing. IEEE Transactions on Professional Communication 47, 2 (2004), 105-117.

12.Monk, A., Wright, P., Haber, J., and Davenport, L. Improving your human-computer interface: A practical technique. Prentice Hall, New York, 1993.

13. Nielsen, J. Usability engineering. Academic Press, Boston, 1993.

14. Nørgaard, M., and Hornbæk, K. What do usability evaluators do in practice? An explorative study of thinkaloud testing, in Proceedings of the Sixth DIS Conference on Designing Interactive Systems, ACM Press, New York, 2006, 209-218.

15.Rhenius, D., and Deffner, G. Evaluation of concurrent thinking aloud using eye-tracking data, in Proceedings of the Human Factors Society 34th Annual Meeting, HFS, Santa Monica, CA, 1990, 1265-1269.

16. Wright, R.B., and Converse, S.A. Method bias and concurrent verbal protocol in software usability testing, in Proceedings of the Human Factors Society 36th Annual Meeting, HFS, Santa Monica, CA, 1992, 12201224. 


\title{
History of User Interfaces: A Mahoneyan Perspective
}

\author{
Anker Helms Jørgensen \\ IT University of Copenhagen \\ Rued Langgaardsvej 7 \\ DK-2300 Copenhagen S Denmark
}

\begin{abstract}
This paper explores the relationship between the current state of art in history of user interfaces and history of computing, drawing upon the work of the late historian Michael Mahoney. Computing only attracted the interest of professional historians in the 1980s - until then exclusively the territory of computing pioneers like Jean Sammet, Maurice Wilkes, and Herbert Goldstine. One of these historians was Michael Mahoney. From 1988 to 2008 he published a good number of papers on the topic, primarily on the historiographic aspects, such as how can history of computing learn from history of technology and how do you go about doing historical enquiries in software engineering? The present paper describes how Mahoney's papers have been inspiring and useful in my explorations in user interface history. The paper focusses on three points: genres and authorship, the tripartite nature of computing, and a palette of historiographic models. In sum, the current state of art in user interface history shares many features with history of computing twenty years ago.
\end{abstract}

\section{Keywords}

History of user interfaces, history of computing, Michael Mahoney.

\section{INTRODUCTION}

The last decades have seen a growing interest in historical aspects of user interfaces - often in the veil of HCI history. It is time to ask: What is the historical relevance of user interfaces? What is the state of art in the emerging field? What can be learned from other fields? Before embarking on these larger questions, a bit of historical background is in place.

Although the first digital computers - and calculators before them - had input/output devices such as dials, switches, plugboards, and input tables, the concept user interface only gained foothold in computing in the 1960s. The underlying theoretical foundation Human-Computer Interaction (HCI) was established in the 1970s and 1980 s. As there is some overlap between these two in the literature, let me clarify: I consider user interfaces as tangible and conceptual artefacts - such as input devices and pop-up menus - while I consider HCI as an academic field with concepts, theories, and methods as cornerstones. Hence the two differ but they are also closely related; my focus here is on user interfaces.

\section{OBJECT OF HISTORICAL ENQUIRIES}

The computer has in half a century migrated from large computer rooms in highly specialized settings to everyday, mundane objects. It is increasingly invisible, embedded, and pervasive and the user interface has come to the fore at the expense of the computer itself. Along with this migration, a number of perspectives on user interface issues have emerged in the literature that attest to the peneration and diversity of the user interface, such as usability engineering [28], utility [19], culture [15], media [26], emotions [29], persuasion [7], and aesthetics [8]. In all these books the user interface plays an important role - if not the only role. Hence the user interface has turned out to be multi-facetted enough to attract interest from many academic quarters.

To illustrate this point in a more mundane manner I have made two searches with Google Image: one for window and one for windows. The idea is that the window - an ancient, everyday artefact - is so deeply embedded in our daily lives that we hardly notice it (unless it breaks and no longer protects us from the rough climate). windows is plural of window and conveys the same meaning, but is also the name of a Microsoft operating system. What do these two searches yield? The window search ${ }^{1}$ seen in the upper part of Figure 1 shows solely traditional windows, while the windows search in the lower part solely shows the Microsoft product. In the windows search the user interface is depicted in about half of the images - most of the others are Microsoft logos.
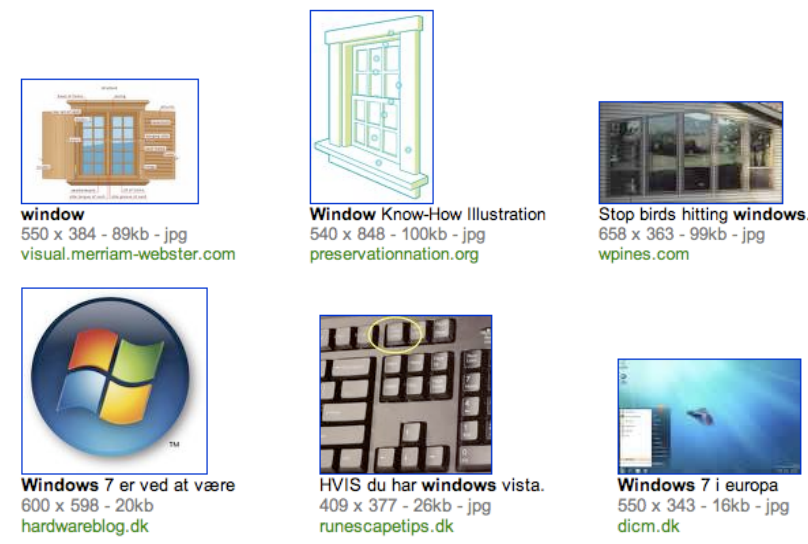

Figure 1: Google Image search for window (upper row) and windows (lower row)

This is an indication of the strength of the cultural footprint of the user interface. All in all, the user interface must be said to be a worthy object of historical inquiries.

\footnotetext{
1 The search was conducted on Oct. 12, 2009 in Denmark
} 


\section{MAHONEY'S HISTORIOGRAPHICAL WRITINGS}

In approaching history of user interfaces, it is obvious to ask if history of computing and history of technology can be helpful. Indeed - and here Michael Mahoney's papers on computer history and historiography come to mind. Among his many papers, I have found the following three most valuable: The History of Computing in the History of Technology from 1988 [23], Issues in the History of Computing from 1996 [24], and The Histories of Computing(s) from 2005 [25]. The 1988 paper [23] is particularly relevant as it was written when history of computers started to take shape. Note that the papers cover the span from the 1980s until now where history of computing could be expected to have reached a mature state. By using these papers as frame of reference I will outline the state-of-art in history of user interfaces (and $\mathrm{HCI})$.

\section{Genre and authorship}

Mahoney [23] identified three types of authors in history of computing. These types are important as their backgrounds, methods, agendas, and writings differ substantially. Firstly, we have the people involved, the computing pioneers. Several have written their memoirs: front line scientists like Maurice Wilkes [35] and Edsger Dijkstra [6], and practitioners like Lundstrom [21]. Some have even drafted a full history of computing from the Abacus, such as Herbert Goldstine [9], while others have addressed specific areas such as Jean Sammet on history of programming [32].

Secondly, journalists who have addressed the more spectacular facets of computing history. Mahoney [23] wrote " ... the computer attracted the attention of journalists ... they have an eye for the telling anecdote.... they tend to focus on the unusual and spectacular ...". Here the microcomputer has been featured abundantly, for example by [5].

Thirdly, Mahoney wrote "Finally, there is a small body of professional historical work. ... There historians stand before the daunting comlexity of a subject that has grown exponentially in size and variety, looking not so much like an unchartered ocean as like a trackless jungle. We pace on the edge, pondering where to cut in." [23]. Several historians entered the field in the 1980s, and numerous papers on selected aspects of computer history emerged. But it took almost a decade before two textbooks by professional historians attempting to paint a fuller picture emerged [3] and [4].

These three categories are reflected in the current state of art in user interface history - with a view to the literature on history of HCI. Numerous user interfaces and HCI pioneers have presented their stories: Johnson and others on Xerox Star [14], Alan Kay on the GUI [18], and Dick Pew [31] and Brian Shackel [33] on HCI history.

Mahoney's second category journalists is also at play here, not least addressing the history of the graphical interface and the work at Xerox PARC [13] and the precursors [34].

As to the third category, the professional historians, only a few works peripheral to the user interface have emerged. [1] focussed on Doug Engelbart and the invention of the mouse, while [30] address the remarkable achievements of Vannevar Bush, among these the famous Memex.

However, there is a fourth category in user interface history. Firstly, scholars in media studies and in cultural studies have addressed various aspects of user interface history such as the cultural aspects [15] and Alan Kay's endavour [2]. HCI has also fostered historical writers however hardly pioneers. One example is the acknowledged scholar Brad Myers [27] who wrote a thorough lists of "firsts" in user interface history. Another example is Jonathan Grudin's thorough contextual analyses of the development of HCI $[11,12]$.

\section{The tripartite nature of computing}

Mahoney distinguished between three "layers" of computing. Firstly, the hardware being immediate, manifest and tactile - and therefore addressed widely.

Secondly, the layer of software that in turn has two facets: a static and a dynamic aspect - the latter being teasing as Mahoney put it. Indeed anyone having done programming will attest to the tremendous difference between reading the static code and understanding the dynamic behaviour of a program. Software is far more elusive than hardware - and therefore addressed much less.

The third level is that of software production and development where professional programmers and developers create software in a organisational environment with professional practices and values - and even less addressed.

Coming from HCI, it is striking that the user and use context is not addressed by Mahoney. (To pay full justice to Mahoney's work, the 2005 paper [25] actually mentions the field of HCI and the importance of the user and use context.) After all, technology has only meaning in use and - according to constructivist thinking - is also shaped in use. Mahoney mentioned the elusive character of software and programs. Indeed, but the inclusion of human beings acting dynamically with computers and interfaces in organizational and social contexts adds even more complexity to the picture.

\section{A Palette of Models}

In the 1988 paper [23], Mahoney presents a rather comprehensive palette of models that can be invoked to describe and explain trajectories in history of computing. This is unusual - mostly historians hide their deliberations regarding historical method. The list comprises technology as systems components, mass production and mass consumption, assembly line, evolution and revolution, invention and innovation, technology determinism, and meet a need or create a need. No cookbooks exist in historical enquiries, but these models may be useful to keep in mind in approaching user interface history.

\section{MY ACHIEVEMENTS SO FAR}

In order not only to describe but also to apply the Mahoneyan framework, I will present some of my achievements, shaped around Mahoney's points.

\section{Getting an Overview}

The first step was to get an overview of the jungle [16]: A study surveying the developments over the last four 
decades. It included eight papers addressing user interface (and HCI) history at large. The study revealed that several historiographical genres were at play such as internalism, technological determinism, and Whig'ism largely exhibiting a technology-centered approach - but contextualism (favoured by historians) was also present, in particular in Jonathan Grudins extensive writings [11, 12].

\section{An early game and an unusual user interface}

Pursuing Mahoney's jungle metaphor, a colleague of mine Søren Lauesen stepped right out of the jungle and told me about an interesting game development project at Regnecentralen in Denmark in 1962-63 [17]. The game was a variant of the ancient game Nim called Nimbi, developed by the Danish inventor, designer, and poet Piet Hein in 1945. In the early 1960s games were typically played on the console via printed characters depicting the game board, but Lauesen and Hein decided to use a physical game board that mirrored the wooden Nimbi game board. This solution with a bespoke I/O device turned out to be difficult to implement: the game board was hardwired directly to the central register of the computer. In all probablility this was a prime reasons why only one computer was equipped to play the game. This implied in turn that the game was never used as intended to promote computers towards the public at public exhi-bitions and trade fairs - as other contemporary computer games like Tic-Tac-Toe and Nim.

As to the design of the user interface, the designers adhered to the important design principles mappings and consistency (having the computer representation of the real world mirror the real world). Note that these well known user interface principles were not coined at all in 1962-63 - what far-sighted designers! Hence, in the Nimbi project, good interface design had significant negative implications for use. This is an example of a facet of historians' practice: unsuccessful projects may be equally important as successful projects in order to get the right history and get the history right.

\section{The Role of IBM $\mathbf{3 2 7 0}$ in Interactive Computing}

Almost all of the stories in user interface history still need to be told. Where to start after the Nimbi story? In Mahoney's words: I pace on the jungle and wonder where to cut in. My current attempt is to cut in the jungle and explore the role of the IBM 3270 terminal in the proliferation of interactive computing in the 1970s. The terminal was produced from 1972 to 1987 and employed a communication protocol that is still widely used. The terminal has been manufactured in huge numbers by IBM - and as plug-compatible terminals by other manufacturers such as Facit in Scandinavia. Hence myriads of developers have been developing a huge number of 3270 applications that in turn have been use by even more myriads of users.

It has been said that as Henry Ford taught American citizens to use the car in the 1910s and 1920s by way of Ford T ("put America on wheels"), IBM taught American businesses to user computers in the 1960s and 1970s by way of IBM 360/370 computers. Paraphrasing this grand statement, my working hypothesis is that IBM taught employees in American organizations to use interactive applications in the 1960 s and 1970 s by way of the IBM 3270 terminals.

As to evidence on the introduction of terminals in offices and workplaces, HCI - as well as Participatory Design provide rich sources, ranging from lab studies of particular products [22] over in-depth studies in the workplace [20] to action-research projects in Scandinavia [10].

\section{DISCUSSION}

It appears that the current state of art in user interface history shares a good number of features wih history of computing twenty years ago. It is therefore interesting to look at the cuttent state of art in history of computing as an indication of the state of art in user interface history twent years from now. Mahoney wrote: "The major problem is that we have lots of answers but very few questions, lots of stories but no history ... simply put, we don't yet know what the history of computing is really about." [25]. So in spite of twenty years of progress there is still a long way to go - useful to keep in mind in user interface history being two decades after history of computing.

\section{REFERENCES}

[1] Bardini, Thierry (2000): Bootstrapping: Douglas Engelbart, Coevolution, and the Origins of Personal Computing. Stanford University Press.

[2] Barnes, Susan B. (2007): Alan Kay: Transforming the Computer Into a Communication Medium. Annals of the History of Computing, vol 29, no 2, 18-30.

[3] Campbell-Kelly, Martin and Aspray, William (1996): Computer: A History of the Information Machine. Westview Press.

[4] Ceruzzi, Paul E. (1998): A History of Modern Computing. MIT Press.

[5] Cringeley, Robert X. (1992): Accidental Empires. How the Boys of Silicon Valley Make Their Millions, Battle Foreign Competition, and Still Can't Get a Date. Addison-Wesley

[6] Dijkstra, E. W. (1980): A Programmer's Early Memoirs. In Metropolis, N. et al (Eds): A History of Computing in the Twentieth Century. Academic Press, 563-573.

[7] Fogg, Brian (2002): Persuasive Computing: Using Technology to Change Attitudes and Behaviors. Morgan Kaufmann.

[8] Friedberg, Anne (2006): The virtual window - from Alberti to Microsoft. MIT Press.

[9] Goldstine, H (1972): The computer from Pascal to von Neumann. Princeton, New Jersey: Princeton Univ. Press

[10] Greenbaum, J. and Kyng, M. (Eds) (1991): Design at work - cooperative design of computer systems. Lawrence Erlbaum.

[11] Grudin, Jonathan (2005): Three faces of HumanComputer Interaction. Annals of the History of Computing, vol 2 no 4, 2-18. 
[12] Grudin, J. (2008): A Moving Target: The evolution of Human-computer Interaction. In Sears, A. and Jacko, J.A. (Eds): The Human-Computer Interaction Handbook - Fundamentals, Evolving Technologies, and Emerging Applications, 2nd ed. Erlbaum, 1-24.

[13]Hiltzik, Michael (1999): Dealers of Lightening: Xerox PARC and the Dawn of the Computer Age. Harper Collins.

[14] Johnson, J., Roberts, T.L., Irby, C.H., \& Beard, M. (1989): The Xerox Star: A Retrospective. IEEE Computer, Sep. 1989, pp. 11-28.

[15] Johnson, S. (1997). Interface Culture. How new technology transforms the way we create and communicate. Basic Books.

[16] Jørgensen, Anker Helms (2008): Taking Stock of User Interface History. Proc. NordiCHI 2008, Lund, Sweden, 20-22 Oct. 2008.

[17] Jørgensen, Anker Helms (2009): Context and Driving Forces in the Development of the Early Computer Game Nimbi. IEEE Annals of the History of Computing, vol. 31, no. 3, July-Sep. 2009, 44-53.

[18]Kay, Alan (2003): The History of the Personal Workstation. In Wardrip-Fruin, Noah and Montfort, Nick (Eds): The New Media Reader. MIT Press.

[19] Landauer, Thomas K. (1995): The Trouble with Computers - Usefulness, Usability, and Productivity. MIT Press.

[20]Long, J., Hammond, N.V., Barnard, P., Morton, J. and Clark, I.A. (1983) Introducing the interactive computer at work: The users' views. Behaviour and Information Technology, vol. 2, 39-106.

[21] Lundstrom, David E. (1987): A Few Good Men from Univac. MIT Press.

[22] Mack, R.L,. Lewis, C.H. and Carroll, J.M. (1983): Learning to use word processors: problems and prospects. ACM Trans. Office Information Systems, vol. 1 , no 3, 254-271.
[23] Mahoney, Michael S. (1988), The History of Computing in the History of Technology, Annals of the History of Computing, vol 10, 113-125.

[24] Mahoney, Michael S. (1996): Issues in the History of Computing. In Thomas J. Bergin and Rick G. Gibson (Eds.), History of Programming Languages II. New York, 772-81.

[25] Mahoney, Michael S. (2005): The histories of computing(s). Interdisciplinary Science Review, vol. $30,2$.

[26] Manovich, L. (2000). The language of New Media. MIT Press.

[27] Myers, B.A. (1998): A brief history of humancomputer interaction technology. Interactions, (5) 2, 44-54.

[28] Nielsen, J. (1993). Usability Engineering. Academic Press Inc.

[29] Norman, D. (2004). Emotional design: Why we love (or hate) everyday things. New York: Basic Books.

[30] Nyce, J.M. \& Kahn, P. (Eds) (1991): From Memex to Hypertext: Vannevar Bush and the Mind's Machine. Academic Press.

[31] Pew, R.W. (2003): Evolution of Human-Computer Interaction: From Memex to Bluetooth and beyond. In Jacko, J. and Sears, A. (Eds.), Handbook for Human-Computer Interaction in Interactive Systems. Erlbaum, 1-17.

[32] Sammet, Jean E. (1969): Programming Languages: History and Fundamentals. Prentice-Hall.

[33] Shackel, B. (1997): Human-Computer Interaction whence and whither. Journal of the American Society for Information Science, vol. 48, no. 11, 970-986.

[34] Waldrop, Mitch (2001): The Dream Machine: JCR Licklider and the Revolution that Made Computing Personal. Viking Penguin

[35] Wilkes, M. (1985) Memoirs of a Computer Pioneer. MIT Press. 


\title{
Wild Rabbits in Living Lab Skagen
}

\author{
Anne Marie Kanstrup \\ Department of Communication \\ Aalborg University \\ Kroghstræde 3, 9220 Aalborg DK \\ +4599409077 \\ kanstrup@hum.aau.dk
}

\begin{abstract}
The paper present results from the living lab Skagen 2009. Living lab Skagen is a central activity in the maXi-project for exploring design of ict to support everyday living with diabetes. The Living Lab 09 focused on how to support diabetics and their families in building an information web to support networking about daily problems and ideas. A web- and iPhone application was set up and explored in a weekend of semi-organized activities in co-operation with 9 diabetes families, seven service providers (restaurants, bakeries, supermarket and tourist office), and a team of researches and engineers organizing the technical and organizational set-up. The paper present the background for the prototype - the wild rabbit metaphor, and present the prototype, living lab exploration and a summary of results.
\end{abstract}

\section{Keywords}

Living Lab, diabetes, iPhone applications.

\section{Vi blev fodt i hatten}

Vi kender alle Jeres tricks

Men vi blev født om natten

I regner os for nul og nix.

Vi er de vilde kaniner med meget lange $\phi$ rer

Alt hvad I hvisker og siger kan vi høre

Vi er de vilde kaniner

...graver grøfter mellem фst og vest

Og vi forbinder sфerne

Nord og syd og dig og mig...

(Gnags: Vilde kaniner lyrics)

\section{INTRODUCTION}

Since 2007 the maXi-project (www.maxi-projektet.dk) has worked with design of information and communication technology (ict) to support everyday living with diabetes. After three years of research central lessons learned about diabetics, their everyday living and design for this setting are:

- Diabetics are experts of their everyday life with diabetes. Clinical models are difficult to transfer to everyday living but diabetics and their relatives knows all the tricks

- Despite this knowledge diabetics are rarely participating actively in design for ict for their everyday life. Additionally, several of the problems they face in their everyday life are so basic that it is clear that they are not regarded as important - if so they would be fixed.

- Diabetics are aware of the general discourse about their illness. They watch the news and see the photos of overweight people who turns up on the TV screen and they hear the discussions about the costs that their illness puts on society.

- For this, and other, reasons diabetics prefer to blend in, rather than stand out with their illness. They have been trained in self management and they to so while supporting each other in a network of collaborations.

This knowledge have inspired me to use the metaphor of wild rabbits, from the song and lyrics of the Danish rock band Gnags, to describe diabetics and the prototype that we have designed and explored for this years living lab in the city of Skagen. Diabetics know all the tricks. However, they are rarely taken into account in design processes and face basic problems while e.g. grocery shopping, going to cafés and restaurants, and going on trips that would be fixed if they were taken serious. Diabetics hear the general discourse about diabetes and can feel stigmatization and for this reason prefer to blend in and support each other via their own networking and knowledge sharing.

The 2008 living lab [1] provided knowledge about basic barriers and opportunities for design of ict to support everyday living with diabetes (table 1). Consequently, the 2009 maXi living lab was based on the idea of supporting resources found in the diabetes community via prototypes 
supporting networking and knowledge sharing between diabetics on products, services, and service providers.

\begin{tabular}{|c|c|}
\hline Barriers & Opportunities \\
\hline $\begin{array}{l}\text { Regulations, especially for } \\
\text { food declaration, are a } \\
\text { barrier for service providers } \\
\text { making it difficult and } \\
\text { costly to carry out } \\
\text { measurements in order to } \\
\text { provide information } \\
\text { services. }\end{array}$ & $\begin{array}{l}\text { Diabetics are not calling for } \\
\text { precise information but hints } \\
\text { for estimations and } \\
\text { informed guessing, sharing } \\
\text { of experiences, ideas and } \\
\text { tips. }\end{array}$ \\
\hline $\begin{array}{l}\text { Small and medium size } \\
\text { service providers do not } \\
\text { have many resources for } \\
\text { information update required } \\
\text { by information services. }\end{array}$ & $\begin{array}{l}\text { Diabetics have a strong } \\
\text { network used for especially } \\
\text { motivation and knowledge } \\
\text { sharing about everyday } \\
\text { management carried out } \\
\text { primarily in local face to } \\
\text { face groups. }\end{array}$ \\
\hline
\end{tabular}

Table 1: basic difficulties and opportunities identified in the 2008 maXi Living Lab in Skagen.

\section{LIVING LAB SKAGEN 2009}

The 2009 maXi prototype is designed with inputs from user experience based on results from the 2008 living lab. The overall goal is to create a prototype allowing users to share and exchange information concerning daily life situations like shopping at bakeries and supermarkets, and visiting restaurants. The system consists of a central server running a web server with access to a database where all information concerning foods, shops, users and comments are stored. The database structure and content is designed with inspiration from information provided by restaurants, the supermarket, food declarations and user inputs from the 2008 maXi living lab.

The server provides a website from where users can share knowledge and information. The users are able to view and share information provided by the maXi database. The users are able to modify and add new information like food declarations,add own experience and knowledge in terms of tips and comments that are updated on the maXi server and exchanged between users. The website is accessible using the internet from a portable wireless computer and has been used in the supermarket and restaurants allowing families in the Skagen lab to comment on the restaurant experience and adding new food products to the database.

Besides the website, it was decided with inputs from the user workshops in the 2008 living lab to provide the users with a mobile device. The device provides the means to view and search information anywhere at anytime. The iPhone was chosen as mobile device due to the feature rich, user-friendly design and support for many wireless communication standards and the possibility to develop customized applications. The maXi iPhone prototype application that has been developed provides a very easy to use application. It allows the user to view and search for information on foods, bakeries, restaurants, comments and hints from other users. The iPhone application regularly updates a local database using a wireless internet access to the maXi server.

The website provides the user with information about foods, restaurants, bakeries and tours. The website provides access to view, add and modify information stored in the database on the maXi server. The iPhone prototype application provides only the user with information and does not allow him to add or change anything. This limitation was to simplify development of the prototype. However, the living lab explorations have shown that it would have been beneficial for the user to be able to correct food information and add temporary comments in the real life situation whenever he needs it, and then being able to correct the information later by using the portable wireless computer. The following sections briefly describe the website and iPhone application content and user interface used for the 2009 living lab.

\section{Food and shopping}

The database contains information about foods covering barcode, producer, dealer, amount, category and user rating. More than 400 food products were entered in the database and used in the Skagen living lab exploration. The food declaration contains basic information about energy, protein, fat and carbohydrate. In addition to the standard food declaration information that is important for a diabetic like gluten, fat, sugar free and organic food have been added. The user is allowed to change the information by selecting modify product using the website at any time.

Information about foods can be found by searching on food categories, names, favorites, history, barcodes or a personal profile that can be setup on the iPhone covering foods that have low fat, sugar free, gluten free or organic. On the iPhone an overview and a detailed food declaration can be viewed to give quick information to advice the user in a given shopping situation. A smiley is presented to the user to indicate if the food fits his profile. Other users rating on a food product are displayed as a star with a number. A graphic representation for the contents of fat, protein and carbohydrate is shown to give an overview of the basic food contents. Figure 1.

\section{Restaurants and Bakeries}

A general description of the restaurant and bakeries are presented with user rating and user comments on the website and iPhone. After a restaurant or bakery visit the user can share his experience and knowledge by adding comments and rating on the website. Detailed restaurant menus and bakery recipes provided by the service provider can be viewed helping the diabetic in his decision on 
ordering and obtaining of the insulin dose. Besides telephone and address information about restaurants and bakeries the GPS functionality of the iPhone has been used allowing the user to find the location using a map. This is one of the many nice features of the iPhone development kit with internet access. Information has been collected and used from two bakeries and four restaurants in the Skagen living lab set up.

The figure 2 below shows how general information, comments and menus are displayed on the iPhone application. This is the same information that has been entered on the website see figure above. Links (URL) to the service providers own website is accessible from the iPhone application to get more information provided by the restaurants or bakeries.
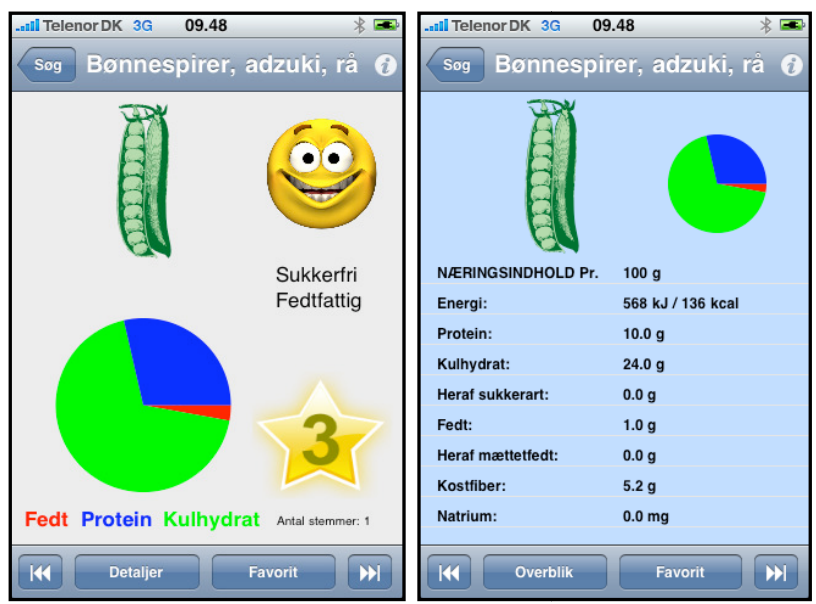

Figure 1: Maxi iPhone - food information
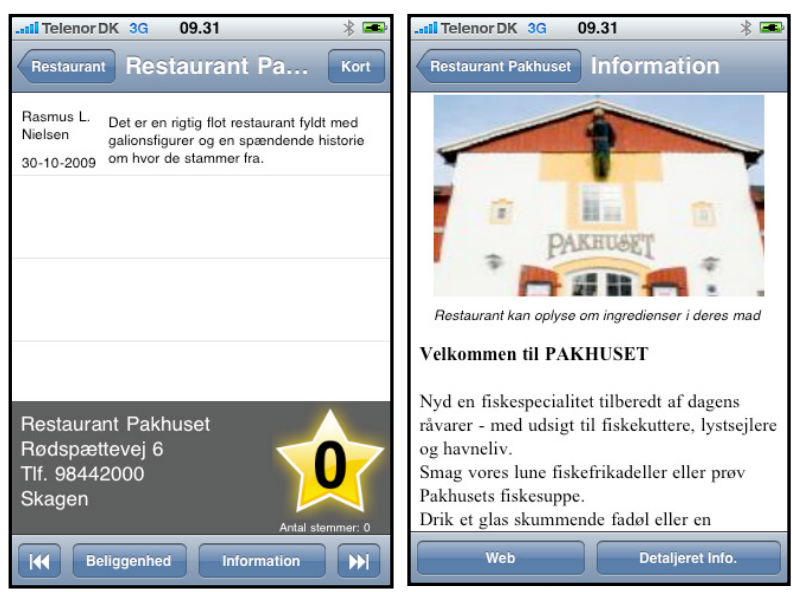

Figure 2: Maxi iPhone - restaurant information

\section{Explorations}

The maXi living lab 2009 was scaled up from the previous year [1] to involving one supermarket, two bakeries, four restaurants and a tourist office. The prototype was explored in scheduled activities organized to support everyday life situations and knowledge sharing about these service providers. The service providers had made a variety of information available depending on their resources - some just offered general information about their shops while others offered detailed information e.g. about ingredients, photos and sugar in products.

Prompting the families to share information and to relate to shared information was organized by scheduling restaurant and bakery visits at one day giving experience with the service provider and requiring sharing of these experiences in the maXi application. The following day the participants were asked to choose restaurants and bakeries based on the user generated information.

Prompting reflections on wiki-like databases for declared food in the supermarket was organized by a shopping list which the participants should choose from in their grocery shopping securing discussion about general information and specific detailed product information. Additionally we explored interaction techniques for both accessing and entering data to the database using the iPhone camera to perform barcode scanning and regular website input via computer terminals set up at the supermarket.

Tour information was organized as a social activity with a family quiz tour as possibility among tourist tours. Explorations on the tour were primarily supported by use of an existing application "run keeper" (http://runkeeper.com/doc/iphone/GetStartedTutorial.html) However, the families primarily used the map function designed in the maXi application.

The living lab provided a positive basis for further development of Wikipedia like services for diabetics and health and wellness on specific everyday health information. As soon as the participants started commenting and sharing information the application became alive and interesting and generated a sense of being together and supporting network community. The exploration revealed a true interest in the other. In getting to know the other and in sharing and connecting to others. For example, when exploring information sharing at restaurants the primary quote was that "I am really looking forward to reading what the others have written" (adult diabetic).

However, a clear response from the exploration was also that when designing for networking and community support you need to go the whole way, not half way as in the explored prototype. Networking to the participants meant meeting others, experiencing with others or sharing experience in a broad sense. Consequently, the main part of the participating families (seven out of nine) miss more contact with the other participants and more opportunities for meetings, getting to know each other, sharing experiences in a broad sense - not only in the narrow quite focused exchange of food information and the like supported by the prototype. One even express that "I miss more contact with the other participants, we have had no 
opportunities at all to exchange experiences with each other" (adult diabetic). One suggest a facebook and other extending the prototype with a more social space.

When the networking started the participants became the foreground and the application and the illness the background. It was clear that we were not designing for diabetics. We were designing for parents, grandparents, children, teenagers, those who fancy Italian food etc. The comments that were shared e.g. about restaurants were comments about highchairs, bathrooms additional to comments on the menu. And the decisions taken on what restaurant or bakery to choose were based on these individual preferences. This highlights that it is dangerous to regard people as rational in relation to health and design ict to support a health rationality.

The ability to blend in with the mobile phone was pointed out as an important design criteria making it possible not only to be supported in everyday living but to act like, look like a normal person with a mobile phone (vs. a diabetic with a medical devise):

"I really like that the phone is super discrete that I can sit with my phone at the table or on the lap and no one can see if I am sending an sms to a friend or looking up information relevant to diabetes" (teen diabetic).

This highlight the importance of not designing yet another medical devise but rather focus on design of applications for general information and communication technologies like the www, mobile phones and the like.

The concern for inaccurate information was withdrawn by the participants' honest concern for each other and related friends. "It is the most honest you can get I will say. You will get a broad range of opinions and attitudes and from this what is most true" (adult diabetic). This emphasize the importance of taking diabetics into account as knowledgeable resources in design projects and not least as knowledge resources who can support each other in their everyday life with diabetes.

\section{CONCLUSIONS}

The living lab Skagen 2009 have explored the opportunity of designing for, and gaining from, the power and resources found within the diabetes community designing for wild rabbits networking and supporting each other. The results have been positive and actually so positive that the major critique is that there is not enough room for networking and cooperation in the explored prototype. On this basis it is concluded that community technologies are a design opportunity for support of everyday living with diabetes which should be pursued both in terms of further design and research on how to support wild rabbits in their cooperation.

\section{ACKNOWLEDGMENTS}

I acknowledge the work of the colleagues who have participated actively in the 2009 living lab explorations: Pernille Bertelsen, Christian Nøhr, Marie Glasemann, Lone Stub Petersen and students Casper Knudsen, and Pernille Victoria Andersen all from Aalborg University. Ole Nielsby, Søren Bach Christiansen, Rasmus Lindstrøm Nielsen and Kim Bjerge from the Danish Technical Insitute have designed the iPhone application in co-operation with Brian Møller Svendsen from Aalborg University who designed the database and website and co-operated on the iPhone application. Marie Glasemann from Aalborg University has been a support in technology explorations.

\section{REFERENCES}

1. Kanstrup, A. M. Living Lab Skagen 2008. Proceedings from the Danish Hci Research Symposium 2008, Aalborg, Demark, November 2008. 


\title{
Methodological Reflections on Working with Young Children
}

\author{
Matthias Korn \\ Aarhus University \\ Department of Computer Science \\ IT-huset, Åbogade 34 \\ mkorn@cs.au.dk
}

\begin{abstract}
This paper provides methodological reflections on an evolutionary and participatory software development process for designing interactive systems with children of very young age. The approach was put into practice for the design of a software environment for self-directed project management in intercultural computer clubs in Germany. Both, the process itself and insights gathered are described.
\end{abstract}

\section{Keywords}

Methodology, Participatory Design, Young Children, Software Development Process

\section{INTRODUCTION}

Doing participatory design with young children at the age of 6 to 12 years poses challenges that are different from those with teenagers or adults. Children in their early stages of cognitive development have difficulties in understanding complex and abstract concepts. They are much more sensitive to good evaluation design. Also, the cognitive development can vary greatly between children who are just one year apart or are even of the same age. On the other hand, they can be very refreshing and have a more creative and exploratory approach than teenagers or adults.

Druin and others already address many of the challenges and opportunities in her seminal book on designing technology with children [3]. This paper tries to enrich these with deeper insights gathered from a recent design activity with children in a computer club in a German elementary school. It especially highlights experiences with children of very young age.

The system being designed and evaluated (the process from which the following results are drawn from) helps children and other participants in the computer clubs to maintain an overview of their work and artifacts and to maintain a flow in their project-based collaborative activities. The system is proposed as a self-directed project management system. Early ideas can be found in [7]. The complete study of the system design and development is contained in [6].
First, the paper lays out context and setting of the study. Subsequently, the two phases of the development process, i.e. the pre-study and the actual co-development process are presented and relevant experiences with the both are discussed.

\section{SETTING}

The study takes place in two intercultural computer clubs for children and their parents (called come_IN) in Bonn and Siegen, Germany. The come_IN computer clubs are modeled after the Computer Cubhouses in the U.S. [8]. The concept has been adapted to the specific context in Germany. The focus of the project lies on integration of different cultures through shared practices and learning [10].

Since 2004 and 2006 respectively, the clubs in Bonn and Siegen meet for 2 hours each school week in the local elementary schools. Participants take part voluntarily and are usually students of the respective school. The children come from families of very diverse backgrounds: families of German decent or with migration backgrounds, from different economic and educational backgrounds. Some of the participants are relatively new to the club and others already participate for several months and up to two years.

Normal activities in the clubs are generally group-oriented project work and encompass the creation of personally meaningful artifacts in the form of photo stories,

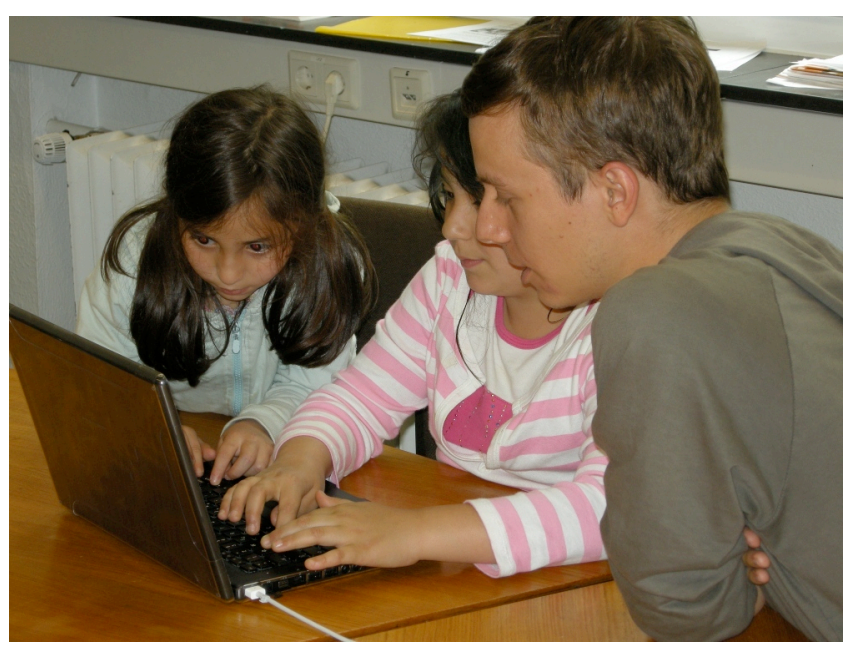

Figure 1. An evaluation session with two participants. 
animations, videos, games and other types of digital selfexpression.

The study comprises 18 evaluation sessions of a software prototype being further developed during 9 club sessions over a period of two months in May and June 2009. The evaluations took place during regular club hours in the clubs' localities. First, single participants and later small groups of two or more participants were, together with a research assistant, involved in each evaluation session (see Figure 1). The participants were 13 elementary school children at the age of 7 to 10 . Nine of them were male and four female. Seven out of the 13 participants have a migration background. Some of the participants took part in more than one evaluation session. Each evaluation session was documented as a screen cast with audio and video of the participants and video of the actual computer screen.

\section{PRE-STUDY}

A pre-study gathered first insights into the field and identified problems and peculiarities of the clubs. From these findings early requirements were derived and an initial, non-functional prototype proposed. This prototype is subsequently being evaluated and further developed in the next phase.

The pre-study is based on participatory action research [5] and encompasses participatory observation and note taking, informal as well as semi structured interviews and video analyses. Notes taken from memory supplemented the insitu notes.

The pre-study took place in three consecutive club sessions in March and April 2008. Around 5 to 10 children and 1 to 3 parents were present at these sessions. At least 3 research assistants in each session took the role as tutors and observed the club activities and held interviews with participants.

The pre-study helped to get a better understanding of the field and identify first requirements, which were used as a starting point for the following phase.

\section{EVOLUTIONARY, PARTICIPATORY S/W DEVELOPMENT}

The non-functional prototype from the pre-study is now evaluated and further developed in an evolutionary (iterative development of individual functionalities or modules) and participatory (involvement of the children in each cycle) development process.

The software is deeply rooted in the everyday practices of the children. So it is crucial to include them and their views and opinions in the software development process. In terms of participatory design, the usage of the prototypes resembles a form of cooperative prototyping [1], where it is aimed to establish a shared understanding of the problem and solution space between designers and users through a co-learning process through iterative prototypes. The development process itself is derived from the spiral model [2] and the STEPS model [4], with the latter emphasizing the context in which the software is used.
Scaife and Rogers [9] give cause for concern that the imbalance of power between children and adults may have negative effects on the success of participatory design methods. On the other hand they report positive results when doing evaluation in pairs instead of one child alone, where two children encourage and build on the ideas of each other. A direct implementation of the design ideas of the children engaged them even more in the process.

\section{GATHERED EXPERIENCE}

Iteration of the prototypes proofed to be very fruitful. But it should be paid close attention that a meaningful sequential order is used to introduce the modules to the users. In this study, a login module was introduced before a registration module, which seemed logical to the author, as the registration would have been done only once per user and the login would be done each and every time they use the system. Still, although they had rarely any experience with software that had individual user accounts, children felt they first had to say who they are before they could choose themselves from a list.

According to cooperative prototyping breakdown situations should lead to in-situ modifications of the system with or with the help of the user. This is hardly possible within the provided context. Young children have a very short attention span and the busy surroundings of the clubs also hinder any concentrated efforts. A more low-tech and hands-on approach to prototyping (e.g. paper, scissors and other utensils to tinker) could be able to alleviate this problem.

In order to engage in free exploration of a new system, children need quite some context information on the idea and use of the system. They would not know what to make out of it otherwise. Additionally, many obvious opportunities to tinker with the system ought to be provided to make any exploration happen at all.

Scenarios were used to evaluate the software, which posed problems that children faced with the existing practices. Although it was often difficult for them to transfer the problems onto the prototype it generally helped to draw a comparison between existing practice and the new prototype. A group of two children had just experienced problems with finding their previously created artifacts. Quickly, the task was to similarly search for an artifact with the prototype. This way several strategies for searching became apparent which could be included in later versions of the prototype. Still, constructing meaningful scenarios was hindered by the fact that the early functionalities of the prototype were quite removed from the existing practices in the current work environment.

It is useful though to incorporate artifacts into the evaluation that have been created by the children themselves in previous sessions. This way they can better relate to the software and feel home. They are more confident in the evaluation situation. 
At first, evaluation sessions were carried out with individual children. Together with the researcher they tried out the software prototype and gave moderate feedback on it. The evaluation situation often seemed a bit tense and directed by the researcher. In the second half of the study, the software was now evaluated in groups of two or three children, i.e. together with friends or siblings. This resulted in a more relaxed, playful and exploratory use of the software. The children incited each other and they became more engaged in the process.

It was of high importance that it has to be made clear to the children, that their opinion and feedback is highly valued. As equal design partners their ideas should be acknowledged and if possible directly implemented to see where this might go and that they are taken seriously. Children should be asked, "Can you help me?" instead of "Can I show you something?"

In summary, it is a challenge to integrate the evaluation of the software in the normal workflow of the children. The differences between the proposed software and the existing practices can be too far apart for the children to make a meaningful comparison of the two. The same applies to the scenarios as discussed above, which are difficult to create as the software in early iterations is not yet as powerful as the current work environment. Asking children directly about their opinion (e.g. problems or ideas for improvement) normally yields few results. Implications have to be drawn from observations and reading between the lines. The inferior visual design of the prototype and small bugs in the interaction did not seem to distract the children much from the actual evaluation. Also, drifting off in unimportant details could not be observed during evaluation. In regard to results, mainly problems pertaining usability of the software could be discovered fast and easily. In contrast to that, it was quite difficult to draw conclusions on the understanding of the underlying concepts and ideas behind the software from the children. They could only be interpreted very tentatively from the observations and conversations. The young age and their limited comprehension of abstract concepts as well as the distance to the existing practices are primarily made responsible for this.

\section{CONCLUSION}

Special methodological considerations have to be taken into account when designing software systems with children of young age in a participatory fashion.

Pairing children yields far better results than evaluating individually with one child. Consider low-tech prototyping in early phases or the development of new modules. Free exploration is not for free. Include many obvious opportunities to tinker with in your system. It should be absolutely clear what your system could be used for. Make clear and even better demonstrate that their opinion is valuable for you and that they are taken seriously.

\section{ACKNOWLEDGMENTS}

The work presented here was conducted as part of the author's Master's thesis at the group of Volker Wulf at the University of Siegen.

\section{REFERENCES}

1. Bødker, S. and Grønbæk, K. 1991. Cooperative prototyping: Users and designers in mutual activity. International Journal of Man-Machine Studies, 34(3): 453-478.

2. Boehm, B. W. 1988. A spiral model of software development and enhancement. Computer, 21(5): 61-72.

3. Druin, A. (ed.). 1998. The design of children's technology. San Francisco: Morgan Kaufmann Publishers.

4. Floyd, C., Reisin, F.-M., and Schmidt, G. 1989. STEPS to software development with users. In Proc. of ESEC 1989, University of Warwick, Coventry, UK, p. 48-64.

5. Kemmis, S. and McTaggart, R. 2005. Participatory action research: Communicative action and the public sphere. In N. K. Denzin \& Y. S. Lincoln (eds.), Handbook of qualitative research $\left(3^{\text {rd }}\right.$ edition., p. 559604). Thousand Oaks, CA: Sage Publications.

6. Korn, M. 2009. Splatch 2: Projektmanagement für gruppenorientierte Projektarbeit in interkulturellen Computerclubs. Unpublished Master's thesis, University of Siegen.

7. Korn, M. and Veith, M. 2009. Learning support through scaffolding collaborative project work. In A. Dimitracopoulou, C. O'Malley, D. Suthers \& P. Reimann (eds.), CSCL 2009 community events proceedings. Rhodes, Greece: ISLS, p. 73-75.

8. Resnick, M. and Rusk, N. 1996. The computer clubhouse: Preparing for life in a digital world. IBM Systems Journal, 35(3 \& 4): 431-439.

9. Scaife, M. and Rogers, Y. 1998. Kids as informants: Telling us what we didn't know or confirming what we knew already? In A. Druin (ed.), The design of children's technology (p. 27-50). San Francisco: Morgan Kaufmann Publishers.

10.Stevens, G., Veith, M., and Wulf, V. 2005. Bridging among ethnic communities by cross-cultural communities of practice. In Proc. of C\&T, Milano, Italy, p. 377-396. 


\title{
How to design security
}

\author{
Niels Raabjerg Mathiasen \\ Department of Computer Science, Aarhus University \\ Aabogade 34 \\ 8000 Aarhus C, Denmark \\ +4589425687 \\ nielsm@cs.au.dk
}

\begin{abstract}
Discussions on how to deal with IT security are emerging. The pivotal issue is the relationship between people and technology. Descriptions of use situations, breakdowns and hacker attacks are brought forward as basis for pointing out big challenges and possible approaches. There seems to be a shift from focus on actual designs towards a focus on the design process and the underlying assumptions. In this paper I discuss a multidimensional design process, how users can be involved, aspects prototyping and the underlying theoretical assumptions.
\end{abstract}

\section{Keywords}

Experience, Security, Prototyping, Multidimensional work.

The emerging discussion of new challenges to the domain of IT security is actualised by a number of articles in Communications of the ACM and Interactions $[2,3,6]$. Susan Landau, whom is a well-known figure in the area of IT-security calls for a multidimensional approach with professionals from areas as diverse as business, anthropology and engineering [3]. While giving credit to breakthroughs done in the technical facets of IT security she calls for results that are more multifaceted. Don Norman takes up the ongoing discussion of how users treat existing security mechanism and how they for instance work around these mechanisms to actually get some work done [6]. He describes how even IT security professionals bypass a lock on a door at a conference. According to Norman IT security dependent systems should be easy to use, however the actual security mechanisms can be reasonably inconvenient if the users understand better the underlying conceptual model. To Butler Lampson the relationship between IT systems and users when it comes to security is all about rules, regulations and policies [2]. $\mathrm{He}$ as well criticises the underlying models of security for being too complex and by model he means policy. He mentions the poor state of usability in IT security mechanisms and put forward the challenge of finding the model that users will be able to use and understand.

I appreciate that these matters are being discussed but I am worried for the intended role for the users. Landau's multidimensional approach calls for a whole range of stakeholders to be included in the design process, however the users are not mentioned. Norman takes up the interesting and important discussion of how today's users workaround IT security mechanisms. He describe how a user deny every time an application suggest to download updates from the Internet because downloading is considered dangerous and how IT security professionals themselves work-around the lock of a door. Even though he presents curious and complex use situations, his suggestion of how to include users in the design process is through modelling their behaviour and desires in a better a way. Lampson's approach is even further in this direction. The big challenge is to come up with a (or a number of) simple and understandable policy(ies) so that even users can understand the underlying concepts of IT security.

I doubt that the big challenge of IT Security is a big hunt for the proper policy or the understandable model. I further suspect that the role intended for the users is the reason why this 
aim is proposed. The problem with policies and conceptual models is that they are fixed at design time. If one models the users desires, behaviours and things later on change problems will surely arise. Even policies that can be changed by system administrators or local security professionals is suffering from being fixed at one time and enforce at another. This leads to that users work-around security. Instead I investigate if users can be more involved in specifying what should be protected, in what sense, and how. John McCarthy and Peter Wright look at how people make sense of technology based on a pragmatist approach [4]. There is an ongoing dialog where people try to find meaning and make sense of their experiences. Moreover people conserve and cumulate their experiences and utilise them in the later on for sense making of new experiences. Therefore any in encounter with technology hereunder also security dependent technology is a new encounter. If one subscribe to a dialectic or dialogic relationship between people and technology one will acknowledge the problems with models and policies.

This approach to IT security is not new [1]. However as the actual discussion $[2,3,6]$ shows it is not commonly accepted. The main reason for this the lack of actual breakthroughs in how to design for an ongoing sense-making dialog. When Norman describes how security professionals tries to "negotiate security with a door lock" by working around it, it seems like a paradox that commonly accepted approaches do not support negotiation, foster dialog or assume a dialectic relationship between people and technology.

The big challenge is then how we, in a multifaceted way, can design for and with users when it comes to security. A starting point is to include users more actively in the design process. Users need to participate as stakeholders and as users encountering prototypes. However still acknowledging Landau's multidimensional approach we may deal with diverse views of what we call users in HCI. In a business context they are customers, in an engineering context they are end-users, and from a security staff perspective they may end up playing the roles as enemies. Likewise different traditions of how to involve these people are present. Moreover the motives for building prototypes can be proof of concept, get to know the domain better, benchmarking, or to involve users and exploring their sense making of the designed artefacts.

In the IT Security for Citizens project at computer science department at Aarhus University, we carry out design in a multidimensional way by bringing together competencies in cryptography, mobile technologies and HCI. The case I been working on is a mobile and usable way of utilising a digital signature for signing, paying and proof of identity that fit everyday life. To ensure that users have access to their digital signature where it is necessary and to still ensure the security we placed half of signature on users cell phones and the other on some trusted server. Through out the design process we build prototypes. We built prototypes for bench marking how fast a signing could be done on a cell phone including a Bluetooth communication. We built prototypes to investigate what interactions step that was necessary in the handling of cell phones. We built prototypes to investigate how the ad hoc communication could be setup. The results of these investigations have shown to work as proof of concept prototypes. I collected user stories early in the process through cultural probing [5] to get a rich picture of what the future use situations. Here we saw several examples where prior experiences was utilised in the sense making of some security mechanism. In two participatory design workshops future users sketched and presented how they imagined a user interface and the interaction. Here simplicity was considered not as important as for instance getting the right feeling of what was going on. Currently we are constructing a prototype that should be robust enough to meet users in a realistic context. However in a multidimensional group of people there is significant gaps in the understanding of why prototypes are build and when they are ready to hand over to users. The idea is to build a prototype that can serve as an 
explorative prototype. Users are invited to participate in scenarios at the municipal offices, in a café, in the street, or attending a web browser on their own PC. I expect to get insights into how users make sense of digital signatures, of the use of their cell phones, and of the use situations in general. In order to capture the sense making I plan observation, video recordings and semistructured post interviews. The interactions with prototype takes not that much time so in order to see how users might interact with the prototype in a new way their taking through series task where they have to utilise the prototype. Then changes in the interaction or uttering may reveal parts of the ongoing sense-making dialog or utilisations of prior experiences.

\section{CONCLUSIONS}

How to work with IT security is a big challenge. People with competencies from diverse areas have to be brought together and design in cooperation with users. In this paper I presented my experiences with a multidimensional design process where we built prototypes of digital signatures in the ITSCI-project. I discussed possible approaches and suggested a pragmatist perspective on user experience as the theoretical basis. Moreover I stated that design activities that aim at capturing the sense-making processes of future use situations are important and that prototyping should be made with purpose of involving users in an explorative way, not only for benchmarking or as proof of concept.

\section{ACKNOWLEDGMENTS}

I thank Susanne Bødker, Pär-Ola Zander, and Clemens Nylandsted Klokmose for valuable discussions and insightful comments.

\section{REFERENCES}

1. de Paula, R., Ding, X., Dourish, P., Nies, K., Pillet, B., Redmiles, D., Ren, J., Rode, J., and Filho, R. S. 2005. Two experiences designing for effective security. In Proceedings of the 2005 Symposium on Usable Privacy and Security (Pittsburgh, Pennsylvania, July 06 08, 2005). SOUPS '05, vol. 93. ACM, New York, NY, 25-34. DOI= http://doi.acm.org/10.1145/1073001.1073004

2. Lampson, B. 2009. Privacy and security. Usable security: how to get it. Commun. ACM 52, 11 (Nov. 2009), 25-27. DOI= http://doi.acm.org/10.1145/1592761.1592773

3. Landau, S. 2008. Privacy and security A multidimensional problem. Communications. ACM 51, 11 (Nov. 2008), 25-26. DOI= http://doi.acm.org/10.1145/1400214.1400223

4. McCarthy, J. and Wright P. (2004) Technology as Experience. MIT Press.

5. Mathiasen, N., \& Bødker, S. (2008). Threats or threads: from usable security to secure experience? NordiCHI '08: Proceedings of the 5 th Nordic conference on Human-computer interaction: building bridges.

6. Norman, D. A. 2009. The Way I See It: When security gets in the way. interactions 16,6 (Nov. 2009), 60-63. DOI= http://doi.acm.org/10.1145/1620693.1620708 


\title{
ClickDrop - a fast interaction technique on large touch displays
}

\author{
Thomas Riisgaard Hansen \\ Cetrea $\mathrm{A} / \mathrm{S}$ \\ Finlandsgade 10 \\ 8200 Århus N, Denmark \\ http://www.cetrea.com \\ thomasr@cetrea.com
}

\begin{abstract}
Interacting with large touch displays requires different interaction techniques compared to desktop systems. In this paper, the problems and challenges around using drag-anddrop on touch displays are introduced. To accommodate these problems the ClickDrop interaction technique is introduced. The ClickDrop technique introduces a special mode in which objects can easily be picked up and dropped using only two touches. The paper briefly discusses how the technique is being used in two commercial applications and some of the strengths and challenges with the proposed interaction technique.
\end{abstract}

\section{Keywords}

Touch displays, interaction techniques, ClickDrop, large displays, drag and drop, multiple displays.

\section{INTRODUCTION}

One of the fundamental interaction techniques behind direct manipulation is drag and drop. Drag and drop is used to combining elements or to combine a command with an element. Drag and drop is typically carried out with the use of a mouse. However, on large touch displays drag-anddrop is less suited for interaction purposes.

First, drag-and-drop on a touch display requires the user to hold down the finger during the entire drag. Missing the contact with the surface for just a short while will either cancel the drag or result in the element being dragged to the wrong location. Losing touch with the surface can both be due to the user losing touch with the surface or inaccuracy in the tracking hardware. In both cases the interaction is either canceled or error prone.

Second, dragging on large touch displays results in having to move the finger over longer distances while keeping touch with the surface. Depending on the surface of the touch screen, the friction between the surface and the finger will eventually result in skin burns and smaller abrasions.

Third, dragging on a large display will often take seconds making it a relatively slow way of interacting with the display compared to other interaction techniques. The challenge is further strengthen if the application spans multiple displays.

Combined, these drawbacks make drag-and-drop a less obvious choice for applications that uses touch displays. However, touch applications still need a way to quickly combining elements or pair a command with an object.

In this paper we present a technique called ClickDrop ${ }^{1}$ for combining elements on large touch displays. The technique has been used in several of Cetrea's products and based on the initial experiences with the technique the technique is briefly discussed.

\section{RELATED WORK}

Pick and drop is an interaction technique introduced by Rekimoto and it is used to move item between devices by picking up an item on one device and dropping it on another [5]. The technique uses a pen to pick up the objects from either a display or a PDA. A similar technique for moving objects between displays is take-and-put where digital objects can be associated with physical objects and move to other displays [4]. Both techniques are directed at distributed display environment where objects need to be moved between displays and devices, but they do not solve the problem about how to use drag-and-drop on large touch displays.

Another type of interaction techniques are directed large displays and deal with different ways of overcoming distances. One approach is to use a throwing metaphor for allowing the user to select distant targets by providing a mini-map of the large display and using this mini map to direct the throw [3]. Another technique called drag-and-pop draws distant target closer to the icon you are currently dragging [1]. Finally, Collomb et al combines the two techniques in a technique called push-and-pop and they show how all three techniques are faster than drag-and-drop on large wall displays [2].

The ClickDrop interaction technique extends the above presented techniques by allowing a fast way to move objects while keeping the element on the display in place.

\section{THE CLICK-DROP INTERACTION TECHNIQUE}

The idea behind ClickDrop is to introduce a special mode called ClickDrop mode. While the display is in ClickDrop mode the application switches between two states. In

\footnotetext{
${ }^{1}$ ClickDrop ${ }^{\circledR}$ is a registered trademark for Cetrea $\mathrm{A} / \mathrm{S}$.
} 
picking up state the application waits for the user to select an object. Selecting an object will switch the display into dropping state. In dropping state the current selected object and all objects that are able to receive the current object is highlight. Clicking on the selected object will drop the object and return the application to the picking up state. Clicking on a highlighted target will issue the associated command and move the display back into the picking up state. Figure 1 shows how objects can be selected in the picking up state and how the selected object and the potential targets are highlighted.

a) Picking up state

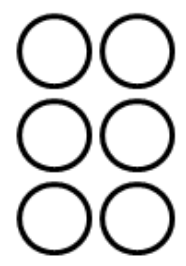

\section{b) Dropping state}

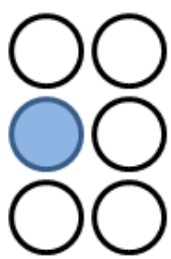

In Cetrea Surgical the ClickDrop technique is used to move surgeries between operating room and to move surgeries in time in the calendar (moving), to associate personnel with a surgery (combining) and associate personnel with an operation room (cloning). The ClickDrop interaction technique is implemented in an updated version of the product and replaced a system where menus were used for providing the same functionality. Without having performed detailed performance studies of the two techniques the ClickDrop technique seems to be substantially faster, especially when objects are moved on the same display. Figure 2 shows a picture of Cetrea Surgical running at a surgical ward.

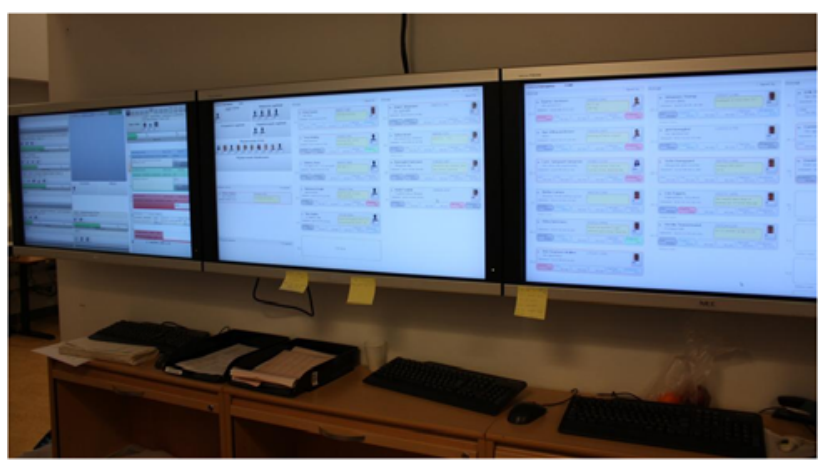

Figure 3. A coordinating room in the Emergency Department running Cetrea Emergency

The technique is also used in Cetrea Emergency for moving patients between beds (moving), associating nurses and doctors with the different treatment tasks around the patient (combining) and for selecting the role of different key personnel (cloning). Also in this application the technique performs substantially faster than the menus previously applied. However, a detailed performance study is future work. Figure 3 shows Cetrea Emergency running on three large displays in the emergency department.

Both applications are currently used by a number of hospitals. In some of the installation the application run on up to four large displays.

To facilitate ClickDrop interaction between multiple displays a new concept called a SwapBoard is introduced. The SwapBoard is shared between all four displays and the SwapBoard is able to hold a reference to all the different objects being picked up. Hence, to ClickDrop an object between displays the user will first have to click on an object and dropping it on the SwapBoard. As soon as an object is dropped on the SwapBoard the object becomes visible on the other displays SwapBoard. The user can following on another display pick the object up from the SwapBoard and drop it at the correct target. While it takes four clicks to move an object between displays, using the SwapBoard has the advantage of allowing other users to use the other displays while the ClickDrop technique is used on one of the displays.

Figure 2. The coordinating central in an operation ward using Cetrea Surgical 


\section{DISCUSSION}

The ClickDrop Technique has proven to be an intuitive and fast way of moving objects, but is not without its drawbacks.

First, while the technique is really fast for moving objects on one display, it is slower when the user has to move objects between several large displays. This is partly due to the extra clicks associated with the SwapBoard and partly due to the user having to move physically to another display to drop the object. This might be overcome by using some of the techniques for throwing or dragging distant target closer (see related work). However, these techniques still have drawbacks when being used on many large displays and are more complex to use.

Second, the technique relies on the interface being in a ClickDrop mode. The problem with introducing modes is that the user manually has to switch into the ClickDrop mode and switch back again after the interaction has been completed. This is especially a drawback if objects often are moved one at a time. However, if several objects are moved shortly after each other, the time used on switching modes is reduced.

Despite these challenges the technique in the current phase has proven to be really intuitive and fast to use. However, future work will look at how the technique can be used without having to enter a specific mode.

\section{CONCLUSION}

Using large touch displays requires different interaction techniques compared to desktop computers using keyboard and mouse. One challenge is to provide similar functionality to drag-and-drop without having to deal with the problems of dragging with the finger on a touch displays.

In this paper the ClickDrop technique is introduced and the initial experiences with using the technique points to the technique providing an intuitive and fast way of interacting with touch displays. We are currently working on improving the technique and quantifying some of the performance issues gained by using this technique.

\section{ACKNOWLEDGEMENT}

I would like to thank the talented people at Cetrea who have worked on developing and refining the presented technique and bringing it into commercial products.

\section{REFERENCES}

[1] Baudisch, P., Cutrell, E., Robbins, D., Czerwinski, M., Tandler, P. Bederson, B., and Zierlinger, A. Dragand-Pop and Drag-and-Pick: Techniques for Accessing Remote Screen Content on Touch and Penoperated Systems. In Proc Interact'03, pp. 57-64.

[2] Collomb, M., Hascoët, M., Baudisch, P., and Lee, B. 2005. Improving drag-and-drop on wall-size displays. In Proceedings of Graphics interface 2005 (Victoria, British Columbia, May 09 - 11, 2005). GI, vol. 112. Canadian Human-Computer Communications Society, School of Computer Science, University of Waterloo, Waterloo, Ontario, 25-32.

[3] Hascoët, M. (2003). Throwing models for large displays. In Proc. HCI'03, pp. 73-77.

[4] Prante, T., Streitz, N., and Tandler, P. 2004. Roomware: Computers Disappear and Interaction Evolves. Computer 37, 12 (Dec. 2004), 47-54. DOI= http://dx.doi.org/10.1109/MC.2004.255

[5] Rekimoto, J. 1997. Pick-and-drop: a direct manipulation technique for multiple computer environments. In Proceedings of the 10th Annual ACM Symposium on User interface Software and Technology (Banff, Alberta, Canada, October 14 - 17, 1997). UIST '97. ACM, New York, NY, 31-39. DOI= http://doi.acm.org/10.1145/263407.263505 


\title{
Use of Sense-Making Methodology in a Requirement Process
}

\author{
Georg Strom \\ Gormsvej 1 \\ DK-4320 Lejre, Denmark \\ +4540181272 \\ strom@georg.dk
}

\begin{abstract}
This paper describes a field study where Sense-Making Methodology was used in an actual IT-project to elicit user needs that were transformed into requirements. It shows how it was possible to create a complete set of requirements, where the background and need of each requirement clearly could be traced, and how it in particular was possible to transform the elicited user needs into requirements in a rapid and reliable manner.
\end{abstract}

\section{Keywords}

Interviews, Sense-Making Methodology, Requirements

\section{INTRODUCTION}

The most important activity in a project is to define the outcome that is required of it. Only then can it be decided whether the project is necessary and feasible and ensured that the results of the project are beneficial or creates value.

Koen [5] presents the following heuristic: Allocate resources as long as the costs of not knowing exceed the costs of finding out. This means that the definition of the required outcomes of a project shall continue, until the cost of continuing is higher than the expected value of the additional insight into the required outcome.

However, it requires some knowledge of the required outcomes to identify any lack of information and the possible value of acquiring it, so it may be difficult to argue for requirement work before at least part of it is done.

The first part of the definition of the required outcomes consists of collecting information about the needs of the organisation and future users. If the results of that part are not valid and reliable, the resulting requirements may be misleading. One particular problem is that users may forget to mention existing valuable functions or routines that they have become accustomed to.

The second part consists of the transformation of the collected information into formats that may be used in the project. This is more complex than it may seem, because the information may be needed for different purposes:

- It may be needed to guide a further investigation, as it becomes clear which additional information that is required.

- The required outcomes may be used as basis for a business case or of other evaluations of the possible benefits of the project.

- The required outcomes may be used to evaluate whether the project is feasible, for instance whether any available software can support them.

- Part of the required outcomes may be included in a contract between a supplier and the customer and used as a legal document.

- A supplier may uses part of the collected information as input to design a system that fits the precise needs and situations of use.

- The collected information may be used to evaluate the value of different outcomes of the project, if it is necessary to prioritize the requirements.

\section{SENSE-MAKING METHODOLOGY}

In this study, I have investigated how Sense-Making Methodology (SMM) developed by Dervin and other [3] could be used to collect and process information about the required outcomes of a project.

I have used SMM in earlier projects [7, 8, 9], and found that it offers several advantages. One of them is, that it is based on a number of explicit assumptions so it is easier to discuss its suitability in a particular project.

The following description of the assumptions is based on a paper that for now is the most complete description of the methodology [2].

SMM [2] is based on the assumption that humans may work inside, outside or against the structures surrounding them. A person may for instance use a system as it is supposed to, decide not to use it, or use it in an unplanned and unforeseen manner, depending on his or her actual goals and ideas. This makes it possible to analyse conflicts between how a user is supposed to do a task and how he or 
she does it, or between the organisation's and the user's personal goals for a task.

Another of the assumptions is that humans in general move step by step through time and actively try to solve the problems that block their progress [2]. SMM focuses on the thinking and problem solving that are part of an activity, and makes it possible to describe the large range of tasks where users adapt their use of an IT-system to a specific task and situation. This encourages a better understanding of how the user's work can be supported, than when using contextual enquiry [1] which aims at documenting fixed procedures that are done repeatedly.

A core part of SMM is a theory of the interview with its own set of assumptions [2]. This makes it possible to get valid and reliable information about how specific users think and act when solving specific problems. It is a major advantage compared to Weick [10], who has a similar focus on mental activities in his Sense-Making. However, he does not have a way to study the mental activities, so his descriptions appear often to be post-hoc rationalisations similar to "The person did this, so he had probably thought that".

During the interview, the problems and how they are solved are seen from the perspective of the participant, without trying to restrict them to the perspectives of the interviewer or the planners of the study [2]. Even though the interviewer and the planners need information for designing a new IT-system, the participant is encouraged to tell about the whole work situation, and not only about his or her experiences using existing IT-systems. I have seen in my previous studies [9] how that inspired new creative solutions, because it made it easy to identify unfulfilled needs. I also found [9] that it tended to make the interviews highly effective. In most cases the participants told first what they felt were the most serious problems, so I got an almost prioritised list of problems from the interviews.

In addition, it is in accordance with the democratic and equalitarian ideals of many Danish workplaces, to see the problems from the perspective of the participant, and not the interviewer.

SMM [2] is based on the assumption that all communication is designed, no matter whether the design is done spontaneously or consciously. The interviews are therefore explicitly structured in a manner that helps the participant to articulate an insight in the problems he or she experiences. I have experienced during my previous use of SMM, that such a structure is similar to the sort of active listening we expect in a normal conversation, so it feels natural and encourages the participant to talk.

The participant [2] is invited to go over the same experience several times, so he or she gradually reveals more aspects of it. During my previous use of SMM I found this offered an additional advantage: As interviewer I could get an early overview of a number of different topics that the participant wanted to tell me about, so I later could bring them up and avoid that the interview got stuck in the details of one of them.

\section{METHOD}

The study was done in the municipality of Copenhagen. It is the largest municipality in Denmark, with more than 14,000 estimated computer users. The municipality has established a Koncernservice with about 200 employees. It is clearly a professional and capable organisation and responsible for acquiring and operating most of the municipality's IT-systems.

During the study I used SMM to collect information about the needs of the intended users of a future IT-system and transformed the information into formats that could be used for evaluating and preparing acquisition of the system. I acted throughout as a participant-observer [4] without having any special influence on whether or how the results of my work were going to be used.

I wrote equal to 21 typewritten pages of continuous notes during the study. They captured the progress of my work and my experiences during the study, and I have used them as a basis when reporting the results in this paper.

\section{RESULTS}

I had earlier been in contact with Koncernservice. They had become interested in what I told about SMM, and I was invited to discuss possible consultancy work.

They were evaluating the value of and preparing to invite proposals for a system to simplify users' access to the range of IT-systems used in the municipality. The background was anecdotal evidence that some users had to handle different user-ids and passwords to more than twenty ITsystems, and that they spend a considerable part of their workday logging in and out of them.

A major part of the evaluation and preparations was a proof-of-concept test where two competing access systems should be used for a period in actual work situations. The project group had planned to do workshops or focus groups to collect requirements, but I understood that it might be difficult to find time for the workshops when all required participants would be available. So one argument for my work was that individual interviews were easier to arrange than work-shops.

We decided I should interview a number of technicians in the IT-support, to ensure that the access system would be easy to maintain for them. We also decided that I should interview users from three groups: The so-called citizen service centres, where the employees had to log into and use a larger number of systems than any other user group, and where they had to provide direct service to citizens while using the different systems; The city-planning department whose employees had highly varied tasks that required processing power and a number of special applications; Finally a number of nursing homes that had a 
large number of intermittent users with limited computer skills.

I decided to use so-called micro-moment time-line interviews from SMM [2], where each participant is guided to tell about a situation where a problem has occurred, the actual problem, how it was overcome, and what the outcome was. During the first interviews I found that I had to divide the last point into two: What the participant found might make it easier to solve the problem - that was often valuable to know when defining a requirement to the access system - and the consequences of the problem, for instance whether the problem had delayed the work or made it more cumbersome. The consequences would often be crucial for deciding how serious the problem was for the organisation.

I prepared checklists for the interviews, where I first asked general questions about problems in the work and then with the IT-systems, and after that asked specifically about for instance problems when logging on to systems or when handling passwords. That was done in order to ensure that all relevant topics were covered with each participant.

During the interviews I often found that most topics were covered when I asked the more general questions. However, the more specific questions made it possible to ensure that any remaining problems were included. I also found that one of the specific questions did not generate any response from the first three participants, and then an extremely interesting one from the following. If in doubt, it seems better to keep than to omit a question.

In addition to exploring the problems the access system should solve, it was also necessary to explore the functions it should support. I asked about a number of these and used micro-moment time-line interviews to explore the problems to be solved by each function, and the situations when it was needed.

I had prepared separate checklists for each of the four groups to be interviewed, to take into account the specific problems of each group. Even then I found, in particular in the nursing homes, that it was essential to be open and see the world from the perspective of the participants. If I had been more focused on getting useful results or on discussing IT-systems, I would have missed some serious and unexpected problems they experienced.

In total I interviewed 22 persons at seven different locations, with each interview lasting about 30 minutes. I made notes during the interviews and typed them up with some additional explanations and expansions of abbreviations shortly after I had completed each day of interviews. That was done in order to make the results accessible when the details of the interviews were no longer present in my memory.

I had discussed with other members of the project, which formats of the results that would be most useful, and we decided I should make two documents. The first document was for use when writing the actual requirements, and it was highly structured. I sorted the results of the interviews according to the reported problems, so it was possible to see the different situations when each problem had occurred, the different ways it had been solved and what the consequences had been in each case. In total the document gave information on about 90 different problems.

The micro-moment time-line interviews had produced results that all were structured in a similar manner, so it was easier to process the results than results from other unstructured or semi-structured interviews.

The second document was written for decision makers. It was much shorter and started by describing the seven most essential requirements, followed by a brief background of the study, brief details about the requirements and four brief human-centered stories [7] or vivid scenarios [6] that described two current situations of use and two possible usage situations with the access system.

This first part of the work took in total 90 hours in June 2009. After my vacation and the proof-of concept test, I was invited back in late August and September to write the functional requirements for the system. I found that one additional and fairly important function had been identified during the proof-of-concept, when users had complained that it was not available in the system they tested.

I made a note about the additional function, and started to write the requirements based on my first document. A number of reported problems were outside the scope of the present project, so they were omitted from the further work. (They are still preserved in the structured description of the problems, and may for instance be used as a basis for improving work routines.)

Based on the remaining problems I wrote 77 requirements in less than 32 hours, in most cases by transforming one or a few problems into one or a few requirement to be fulfilled by the IT-system. This systematic approach meant that the risk of errors was reduced, and that it was easy to trace each requirement back to specific problems and their consequences. To most of the requirements I added a description of the problem to be solved and its consequences to explain the need of the requirement.

The writing of requirements generated a few additional questions that had to be answered, in particular about the handling of software updates and licensees. It was expected to save money on software updates and licenses, and I realized during the writing, that there were no requirements for tools to handle them.

The participants in the project appeared to be satisfied maybe even impressed - by the speed and results of my work. One indication was that both documents describing the problems experienced by the users were included in the information used to brief the decision makers.

\section{DISCUSSION AND CONCLUSION}

The circumstances of the study make it possible to give a valid evaluation of the general value of using SMM in a 
requirement process. The only aspect that can be argued is whether my own skills are so outstanding, that other practitioners cannot produce a similar result. I do not believe that is the case. (But for personal reasons I will not argue strongly against it.)

In earlier software projects where I have used SMM [7, 9] the goal was only to suggest improvements to the software, whereas the goal in the present project vas to supply a complete set of functional requirements. It appears that this goal could be fulfilled. At the end it was possible to identify the additional information that was needed to complete the requirements.

However, the identification of existing valuable functions and features was not done in an optimal manner. One such function was discovered almost by accident during the proof-of-concept test. It may be advantageous to use the micro-moment time-line interview to explore, which of the capabilities of the existing system users find particularly valuable, so they are not left out by accident.

It may be advantageous to reverse engineer an existing system to create more complete lists of existing functions and features, and to interview users about situations when each of them are used. In particular by using micro-moment time-line interviews or another type of interviews, that encourage participants to provide background information that makes it possible to evaluate the need of each function and feature. Otherwise, all capabilities of an existing system may be included in a new system, just to be on the safe side.

Similar to my previous studies, I found that the interviews felt natural and encouraged the participants to talk freely; that the interviews were very time-effective because the participants first told about the problem they considered most important; that the users' perspective on the work resulted in new valuable and unexpected information; and that the background information made it possible to evaluate the validity of the results and the importance of each of the needs expressed by the participants.

This study demonstrated the value of continuously discussing the work with other members of the project, for instance which users to be interviewed, topics to be covered and the contents and formats of the results. That was in particular necessary in a project as the present, with several ongoing parallel activities, where it is worthwhile to make continuous adjustments.

It is necessary to take into account that most users do not know or focus on the organisational goals of the project. These have to be clarified through the organisation's management. If I had involved myself more in these including discussions of the business case - it is possible that the need for tools for handling software updates and licenses had been identified earlier.

One particular positive experience was, that the results of the interviews rapidly and reliably could be transformed into formats that could be used in the project, and in a manner where it was easy to trace arguments for each requirement back to specific parts of the interviews.

\section{LITERATURE}

1. Beyer, H. \& K. Holzblatt. Contextual design. Morgan Kaufmann Publishers, USA 1998

2. Dervin, B.: Interviewing as dialectical practice: SenseMaking Methodology as exemplar. Presented to audience section International Association for Media and Communication Research (IAMCR), IAMCR 2008 Annual Meeting

3. Dervin, B. From, the minds eye of the user, The SenseMaking Qualitative-Quantitative methodology (1992), in Sense-making Methodology Reader ed. by Brenda Dervin and Lois foreman-Wernet, Hampton Press, USA, 2003

4. Kristiansen, S. and H. K. Krogstrup. Deltagende observation, introduktion til en forskningsmetodik, Hans Reitzels Forlag, Denmark 1999

5. Koen, B. V.: Discussion of the method. Oxford University Press 2003

6. Lauesen, S.: Software requirements, Styles and Techniques. Addison-Wesley 2002

7. Strom, G.: Stories with Emotions and Conflicts Drive Development of Better Interactions in Industrial Software Projects. Proc. Ozchi 07, Australasian Computer-Human Interaction Conference 2007

8. Strom, G.: Power Distance and User-Centred Design in a Traditional Culture. Proc. DHRS 07 - Seventh Danish HCI Research Symposium ed. by Anker Helms Jørgensen, Morten Borup Harning. IT-U kompendier, 2007

9. Strom, Georg: Sense-Making Methodology: Learn What Users Understand is Important. Proc. Sixth Danish HCI Research Symposium, Aarhus, Denmark November 15, 2006, ed. by O.W. Bertelsen, M. Brynskov, P. Dalsgaard, O. S. Iversen, M. G. Petersen, M. Wetterstrand, University of Aarhus 2006

10. Weick, K.E. Sensemaking in Organizations, Thousand Oaks: Sage, USA 1995 


\title{
Designing technology for spectator experiences - Beyond the passive spectator
}

\author{
Rune Veerasawmy \\ Aarhus University \\ Helsingforsgade 14 \\ DK-8000 Aarhus C \\ imvrvn@hum.au.dk
}

\begin{abstract}
In this paper I will argue that if we are to design technology for engaging spectator experiences at sporting events in sports arenas, we need to focus beyond the spectators fascination of the sport. We also need to embrace the social elements of the spectator experience and the sporting event itself in order to design meaningful technology for engaging spectator experiences. Today, most technological systems at sporting events aim at augmenting the activities in the game on large displays. But, as I will argue, if we are to design technology for engaging spectator experiences at sporting events, we must acknowledge the spectators as active participants and present technology-mediated opportunities that allow spectators to share and express their collective and social experience of the sport and sporting event. My argument will be based on a series of ethnographically inspired field studies, conducted at football and handball games, as well as on a participatory design workshop with sports fans.
\end{abstract}

\section{Keywords}

Spectator experiences, interaction design, social interaction, ethnographic field studies.

\section{INTRODUCTION}

Spectator experiences at sports arenas are often explored in the paradigm of the spectators' fascination of the sport. This has also often been the case when designing technology for spectator experience. The aim has been how to enhance and strengthen the spectators' experience of the sport by providing more detailed views of the sport itself on large display presenting video replays, detailed views, and statistic and additional information about the sport (see figure 1 and [1]). This use of technology to enrich the spectator experiences contributes to the paradigm of the spectators' fascination of the sport at the sporting event. The academic field of interaction design is gradually acknowledging that the spectators are not passive observers of the sporting event, but active spectators whom not only intellectual engage in the sporting activities but also in the spectator event itself. Designers should therefore take the spectators experience of the sporting event into account when designing technological systems [2, 3]. Academic work has recently contributed to the understanding of technology that moves beyond a task-tool towards providing interactions wherein meaningful and engaging experiences can unfold [4-6]. Furthermore, have work been done in the field of technology-mediated experiences evolving in social contexts $[5$, 7, 8]. [5] stresses that technology can provide the users with the opportunity to express, reject, and reciprocate their experiences among one another. This shared attention, interpretation, and meaning elaboration lifts up the experiences to, what they state as, a co-experience. This paper builds upon this notion of experience, co-experience, and contributes to an understanding of the social aspects of spectator experience.

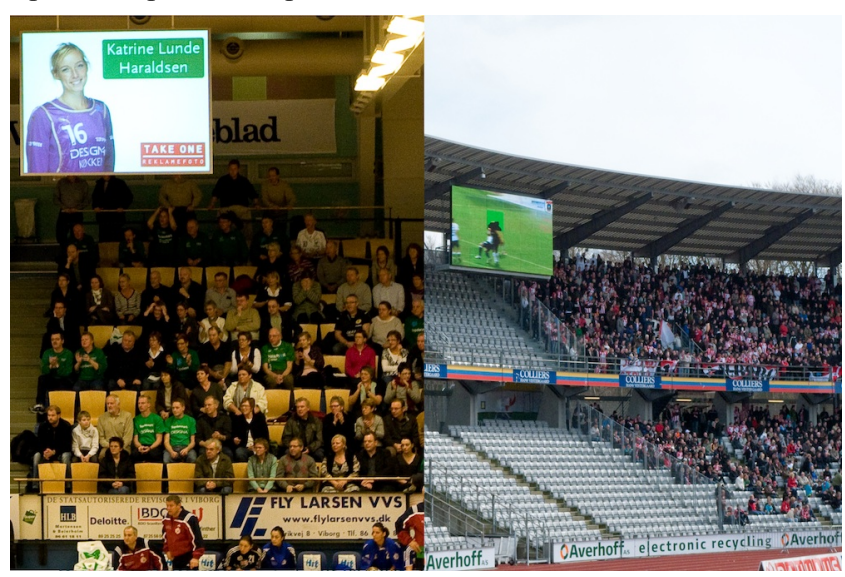

Figure 1. Left: Display at a handball arena viewing name and picture of the scoring players. Right: Display at a football arena showing replays of the game.

In this paper, I argue that we need to focus beyond the fascination of the sports activities if we are to understand the complex matters of engaging spectator experiences. Based on field studies and a user workshop, I will also argue that we need to acknowledge the social aspects of spectators, the sporting event itself, and the sports activities in order to understand the notion of shared spectator experiences of sporting events at sports arenas. The scope of this paper solely contributes to the understanding of spectator experiences at sporting events at sports arenas. Thus this paper refers to spectator experiences in the context of sporting events in sports arenas.

\section{STUDIES OF SPECTATOR EXPERIENCES}

These studies have been a part of a three-year research project entitled 'iSport' at the Center for Interactive Spaces, which is an interdisciplinary research center, designing technological systems for non-working domains. The aim of the 'iSport' project was to explore spectator experiences at sporting events through development of experimental prototypes for spectator experience at sports arenas. This study were based on a series of ethnographically inspired field studies and a user workshop designed with inspiration from the Scandinavian participatory design approach $[9,10]$. In the following sections, the case studies and findings of the 'iSport' project will be described.

The field study data was collected by participating observations [11]. This was done both to achieve a first-hand experience and rich insights into the field of spectator experiences. The field studies were conducted in a range of games in the Danish Premier 
League of handball for men, the Champions League of handball for women, and in the Danish Premier League of football for men. The purpose of the user workshop carried out in the research project was, in collaboration with spectators, to create a vocabulary of the core elements of spectator experiences.

In the following sections, I will present the findings from the field studies and the user workshop in order to discuss design of technology for engaging spectator experiences. Each section will present a synopsis of these findings under three main headings: the social aspect of spectator experience, the role of the sporting event itself, and the fascination of the sport.

\subsection{The social aspect of spectator experiences}

Both the ethnographically inspired field studies and the design material, gained from the user workshop, stress the particular importance of the social aspect of spectator experiences. The social aspect unfolds in a variety of ways. First of all, the majority of the spectators arrive at the game in company with others, whether it is with neighbours, colleagues, friends, or families. Because of this the sporting arena functions as a social place where spectators meet and socialize. Some spectators even expand the event by eating dinner together before or after the game. Furthermore, a large number of spectators attend the game on a regular basis, which contributes to a very loyal and social atmosphere at the sports arena.

The spectators' use of merchandise, such as clothes, flags, and scarves (see figure 2), is a visible manifestation of their sense of belongingness to and social relationship with the other spectators. By acquiring a variety of merchandise, the spectators confirm their support of and loyalty to the team, which makes them a part of a loyal collective of spectators.

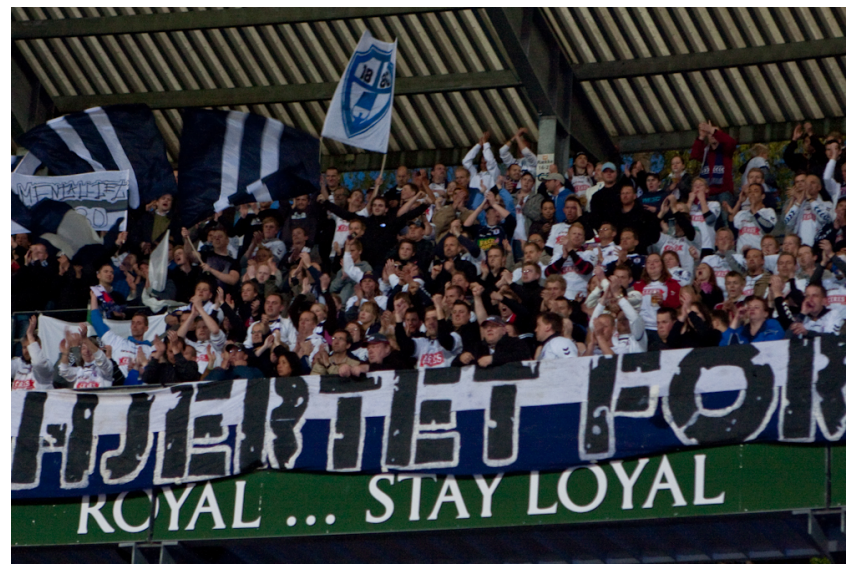

Figure 2. Spectators use merchandise, such as clothes, flags, and scarves, to manifest their support and sense of belongingness to their favourite team.

Another way the spectators manifest their sense of belongingness to the team and the other spectators is by cheering. Knowledge gained from the field studies and the user workshop shows that cheering has two primary purposes. First, the spectators cheer to support their favourite team, thereby encouraging them to perform better. At the user workshop, the spectators explicitly stated that they were convinced that their cheering had a direct influence on the teams' performance. The supporting cheering presents opportunities for spectators to express their experience of the game. This type of cheering is illustrated in figure 3 , where the spectator in the left photo expresses his excitement of a goal scored by his favourite team. He expresses and communicates his experience by jumping up and raising his hands and scarf into the air. In the right photo, the same spectator chides the referee for what he considers a bad judgment by showing his clenched fist.

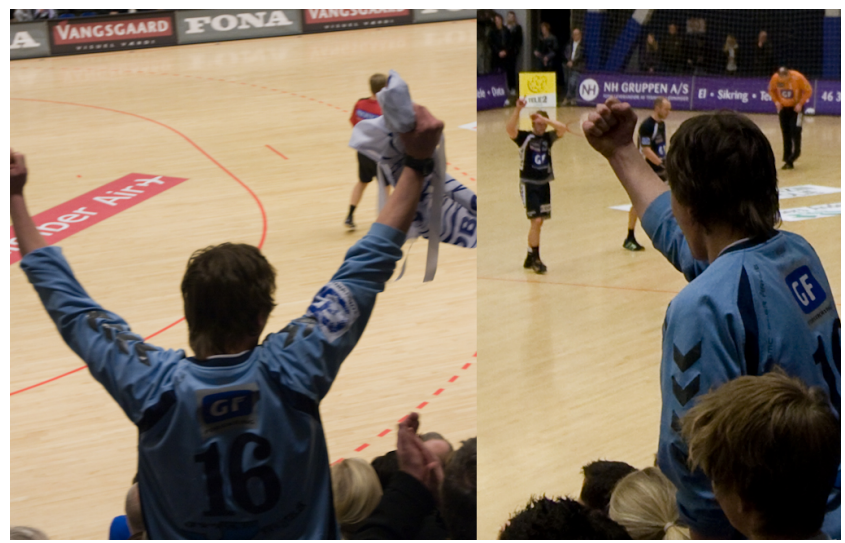

Figure 3. Left: Spectator celebrating a goal. Right: The spectator chides the referee for a bad judgment.

The second type of cheering is centred on an ongoing battle between the rival teams' spectators. The aim of this battle is to be the most dominating and engaging spectators in the sports arena. The spectators use a variety of marching instruments, like drums and whistles (see figure 4), to create loud noises and rhythms to assist their cheering and singing. The cheering songs are often offensive to the other team and its spectators and are about how unskilled, bad, or stupid the rivals are. This type of cheering strengthens the social and loyal atmosphere among each teams' spectators.

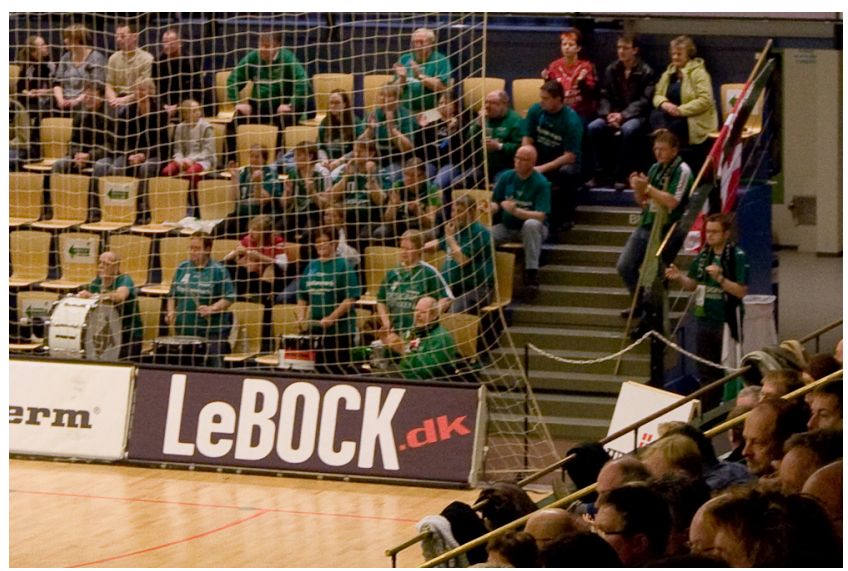

Figure 4. Spectators at a handball game using march instruments to assist their cheering and songs.

One of the differences worth noticing is how and where the two types of cheering are directed. The first type of cheering is directed at and relates to the sports activities progressing in the game, as illustrated in figure 3 . Which is in contrast to the second type of cheering that is directed at the activities taking place among the spectators in the stands. This type of cheering is independent of the sports activities on the game court. Furthermore, does this type of cheering not only take places during the game but throughout the whole event, including before and after the game. 


\subsection{The event}

The social aspect does not solely constitute the spectator experience. At the user workshop the participating sports fans stressed the significance of the event itself. Some elements of the social aspect of spectator experience seems hard to separate from the event itself. The social aspect and the event itself are tightly connected and depended on each other. So even though it can be hard to categorise these elements I will in this section present what the spectators stressed as especially significant of the event.

The sporting event is enveloped in a variety of traditions and ritual actions performed by the spectators. Often these ritual actions start at the spectators' home when they dress up in merchandise cloths. The sports fans expressed that they wear special merchandise cloths at the games in order to bring luck to their team. This can be a special hat, scarf, or t-shirt that they sense will bring them and their team luck, maybe because they wore that particular object last time their team defeated the rival team. The sporting event itself is also surrounded by a lot of traditions. The spectators often sit in the exactly same seat or area in the stands. This tradition means a lot to them because they always end up seating next to other spectators they know. During the game the spectators perform a lot of traditional or scripted actions. This especially unfolds at the standard situations in the game, like corner and penalty kick in football, where the spectators gather and cheer together to build up tension before the player kicks the ball. These actions during the sporting event are tightly connected and scripted to the sporting activities in the game.

Another element of the sporting event that constitutes the spectator experience is the food and drinks served at the event. Many of the spectators arrive at the sporting arena hours before the game to meet and share stories with other spectators while drinking and eating at the bar area outside the arena as a way of expanding the event and the spectator experience.

\subsection{The fascination of the sport}

Besides the social aspect and the event itself, is the fascination of the sport of cause significant for the spectator experience. This is manifested in the spectators' knowledge about the game, the strategic game play of the teams, the athletic performance of the players, and knowledge about the team history. With this knowledge about the sports the spectators have a very broad but yet complex understanding of the games influence not just on the current game, but on the teams seasonal performance and previous history. This advanced sport knowledge influence and engage the spectators' experience because they not just experiencing the experience of wining or loosing the single game but the experience reaches out to embrace the broader perspective of the teams performance. With this knowledge they engage in the sporting event by analyzing the game with their fellow spectators and discussing needs for substitutions of players, change in the team tactic, and so fourth. This engagement is very important because it lets the spectators not just to engage in the game on a social level, or in the event itself, but intellectual engage in the spectator experience by analyzing the sport.

\section{THE SPECTATOR EXPERIENCE}

In order to design meaningful interactive technology for engaging spectator experiences at sporting events is it necessary to understand the elements that constitutes spectator experiences. As presented in the field study description above, engaging spectator experiences go beyond the core fascination of the sports activities taking place on the game court. Spectator experiences are complex, rich, and multifaceted and involve; a fascination of the sporting activities, the social aspect of the experience, and the core event itself. I will in the following section elaborate over the findings and challenges presented, when we are to design technology for engaging spectator experiences that accommodate their richness and complexity.

The case studies illustrated that three main aspects seem to be significant in constituting the spectator experience.

First, the social aspect of spectating where the spectators engage in the sporting event in company with others, and by being a part of a large group supporting their favourite team is a very essential element of the experience. Furthermore the self-representational element, which is manifested in the spectators' use of merchandise, their battle with the other spectators to be the most dominating spectators, and their opportunity to express their experiences and relations to the team and other. The social aspect constitutes the frame wherein the self-representational aspect evolves and creates meaning. These aspects are essential for the spectator experience as they provide spectators with the opportunity to express their experience in a social context. [5] argues that experiences emerging in shared attention have the property of "lifting up" the experience. The collective negotiation and interpretation of the experience have the potential to increase sense making among the spectators.

Second, the event is enveloped in a variety of rituals and traditions. And the extension of the event to both includes ritual and social activities before and after the game.

Third, the spectators intellectual engagement in the sports activities stresses that spectator experiences is both addressing the physical activities in cheering and expressing the experience, and address the intellectual element of statistic and historical knowledge about the sport.

Figure 5 aims at mapping the constituting elements of the spectator experiences concluded from the studies and created in collaboration with the sport fans in the user workshop.

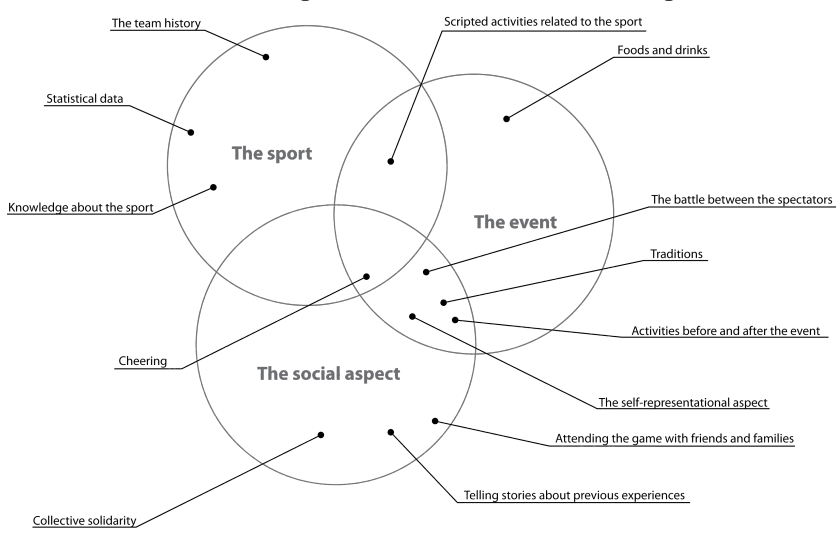

Figure 5. Constituting elements of spectator experiences at sporting events.

When mapping such complex matters as spectator experiences at sporting events will most likely result in a reduction of the rich complexity of the experience. Likewise is figure 5 a reduction of the rich complexity of spectator experiences at sporting events, but the aim of figure 5 is to illustrate the variety in the elements of the three main categories. It does not make sense to only focus on one single element if we are to understand spectator experiences. 
Spectator experiences at sporting events go beyond the fascination of the sport. Nor is it a question of solely addressing the social aspect of the experience or elements relating to the event itself. Instead, we need to acknowledge the variety and simultaneous interplay of the elements in figure 5. There was for example a constant changeover in the two types of cheering among the spectators. When the activities on the court became trivial, the spectators started battling each other, and when the game again turned interesting they started cheering at their teams again. This illustrates the variety and constant interplay between elements in the three categories. We therefore need to acknowledge that spectating is an activity in itself of the sporting event where the spectators are active participants in the event. But we also need to consider both spectating and the sport as an integrated whole. If we are to understand the core of spectator experience, we need to focus on how the spectators express themselves, their relations, and social experiences at the sporting event. Furthermore we also need to focus on the event that is extended beyond the game itself and consist of traditions and rituals, before, during, and after the game. Lastly, we need to focus on how to let spectators engage intellectual in the sport. By exploring this we might understand the core elements of what constitutes engaging spectator experiences at sporting events at sporting arenas.

\section{FUTURE WORK}

These studies described here are preliminary studies and in the near future more qualitative studies and design activities in collaboration with spectators will be carried out in order to get even more detailed data. But what can be drawn from these studies and figure 5 is that spectator experiences at sporting events are constituted by more elements that just the ones augmenting to the sport activities. As illustrated in figure 5, the majority of the constituting elements of the spectator experience are located in the intersection between the social aspect and the event.

So we need to go beyond the examples presented in the introduction, where many of the technological systems at sporting events today are solely focusing on the fascination of the sport. When we are to design technological systems for engaging spectator experiences there is a unexplored potential in creating technology that not only focus on the sport but also embrace the constituting elements of the social aspect and the event in it self. The challenge is therefore in my forthcoming studies to operationalise these findings by designing technology that aims to go beyond the core fascination of the sport.

\section{ACKNOWLEGDEMENTS}

I would like to thank Christian Dindler who took part in the field studies. This work has been supported by ISIS Katrinebjerg, Center for Interactive Spaces - The iSport project.

\section{REFERENCE}

[1] Kansascityfrontpage.com Royals Fans to Watch Highlights and Replays on World's Largest HD Display. Kansas City Front Page, City, 2007.

[2] Beusekom, M. v., Bignert, J. and Taşar, Ö. SoMo: An automatic sound \& motion sensitive audience voting system. In Proceedings of the CHI '04 extended abstracts on Human factors in computing systems (Vienna, Austria, April 24-29, 2004, 2004). ACM.

[3] Esbjörnsson, M., Brown, B., Juhlin, O., Normark, D., Östergren, M. and Laurier, E. Watching the cars go round and round: designing for active spectating. In Proceedings of the Proceedings of the SIGCHI conference on Human Factors in computing systems (Montréal, Québec, Canada, 2006). ACM.

[4] McCarthy, J. and Wright, P. Technology as Experience. The MIT Press, 2004.

[5] Forlizzi, J. and Battarbee, K. Understanding experience in interactive systems. In Proceedings of the Proceedings of the 5th conference on Designing interactive systems: processes, practices, methods, and techniques (Cambridge, MA, USA, 2004). ACM.

[6] Petersen, M. G., Iversen, O. S., Krogh, P. G. and Ludvigsen, M. Aesthetic interaction: a pragmatist's aesthetics of interactive systems. In Proceedings of the Proceedings of the 5th conference on Designing interactive systems: processes, practices, methods, and techniques (Cambridge, MA, USA, 2004). ACM.

[7] Battarbee, K. Co-experience: the social user experience. In Proceedings of the CHI '03 extended abstracts on Human factors in computing systems (Ft. Lauderdale, Florida, USA, 2003). ACM.

[8] Forlizzi, J. and Shannon, F. The building blocks of experience: an early framework for interaction designers. In Proceedings of the Proceedings of the $3 r d$ conference on Designing interactive systems: processes, practices, methods, and techniques (New York City, New York, United States, 2000). ACM.

[9] Ehn, P. and Kyng, M. Cardboard computers: Mocking-it-up or hands-on the future. Lawrence Erlbaum Associates, Inc., 1991.

[10] Ehn, P. Work-Oriented Design of Computer Artifacts. L. Erlbaum Associates Inc., 1988.

[11] Blomberg, J., Giacomi, J., Mosher, A. and Swenton-Wall, P. Ethnographic field methods and their relation to design. Lawrence Erlbaum Associates, Inc., 1993. 


\title{
Utilizing Social Network Services for Enhanced Communication with Elderly Living at Home
}

\author{
Stefan Wagner \\ Aarhus School of Engineering \\ University of Aarhus \\ Aarhus, DK8000 Denmark \\ +4523325571 \\ sw@iha.dk
}

\begin{abstract}
This paper discusses whether social network services, like Facebook and Twitter, may be used by elderly living in their own homes to enhance communication with their relatives and friends. It introduces a prototype solution based on the iRobot Roomba 560, iRobot, USA, robot vacuum cleaner, which has been enhanced with Facebook and Twitter communication capabilities. The paper points out a number of other relevant applications where the use of social network services may provide better communication for ambient assisted living solutions and intelligent environments.
\end{abstract}

\section{Keywords}

Social network services, communication, elderly, robot, vacuum cleaner, ubiquitous computing, $\mathrm{HCI}$

\section{INTRODUCTION}

In the western world, many elderly are living alone in their homes, having only limited contact with relatives, neighbors and friends. This is especially a problem for elderly with certain chronic disabilities, including hearing and seeing disabilities, often combined with a certain degree of cognitive impairment such as light dementia.

These disabilities, individual or combined, make it harder for the elderly to communicate using typical communication platforms, including phones, cell phones, email or even posted mail. In many western countries relatives are living far away, and close family members are either working or studying. In Denmark, most families have both parents working full time, and children attending education. Following this, not much time is left to visit elderly family members at a regular interval, deferring care and social visits to weekends, leaving the elderly unattended most of the time, or with caretaking staff. As the elderly might not be able to communicate using standard communication technologies such as telephones, email or text messages, they might easily experience a varying degree of social isolation. Besides the psychological stress this might incur, also the physical wellbeing of the elderly might be threatened. For example insufficient cleaning might heighten the risk of allergic reactions and infections. Poor medical compliance (have the elderly taken the prescribed medication or not) might worsen symptoms. Lack of regular blood-pressure monitoring or other physiological sensordevices might be dangerous not to react upon, in case of a lack of communication. These events might have a huge influence on the overall health condition and well-being of the elderly. Relatives and friends might thus be interested in getting this information communicated to them in their native social environments (including their social network services of choice), to stay as updated as possible.

At the same time, demographic projections indicate a severe lack of care personal in the near future[1,2], leaving the elderly to fend off their problems for themselves, including emptying the robot vacuum cleaner when it is full, fixing it when it gets stuck or breaks down, etc.

To increase the communication levels we suggest utilizing the concept of social network services $[3,4]$, to enhance communication between the elderly and their friends and relatives. Social network services include popular services like Facebook, Twitter, MySpace, LinkedIn, and many others, by providing regular information on every-day and non-critical or life threatening events and occurrences. For instance, every time the vacuum-cleaner robot has performed a cleaning run, or the robot reports that it is full, this might be updated on the elderly's Facebook or Twitter profile.

In social networks like Twitter and Facebook, this means that all trusted "friends" will be able to see the updates on their social network web sites. Many people might not want this kind of information in their email or as a cell phone text SMS (Short Message Service), as this might be too intrusive for everyday operation. However, the social 
network services are conceived for an alternative type of non-intrusive, ambient status updates, which might help connect relatives and friends closer to the elderly by utilizing these systems in a non-invasive way.

Boyd and Ellison [3] defines social network sites as "webbased services that allow individuals to (1) construct a public or semi-public profile within a bounded system, (2) articulate a list of other users with whom they share a connection, and (3) view and traverse their list of connections and those made by others within the system. The nature and nomenclature of these connections may vary from site to site."

While most elderly may not be expected to be online themselves and active on Facebook or another social home of the elderly home, requiring relatives to interact with the touch screen of the base station in order to learn more about the cleaning history. This paper suggests that this might be handled in a much more ambient way, by simply utilizing a Facebook or Twitter status update. In short, every time the robot has finished vacuum-cleaning, it might update the status profile on Facebook, informing friends and relatives, that "Grandmother Karen has just gotten her floor vacuum-cleaned" or "Grandmother Karens vacuum-cleaner is stuck and not in operation, please come and help.". While this information might just as easily have been send by email or text message (SMS), the social network services are much more non-intrusive, and intended for exactly this purpose. This paper suggests that this might help strengthening the ambient relations and communication with relatives and friends.

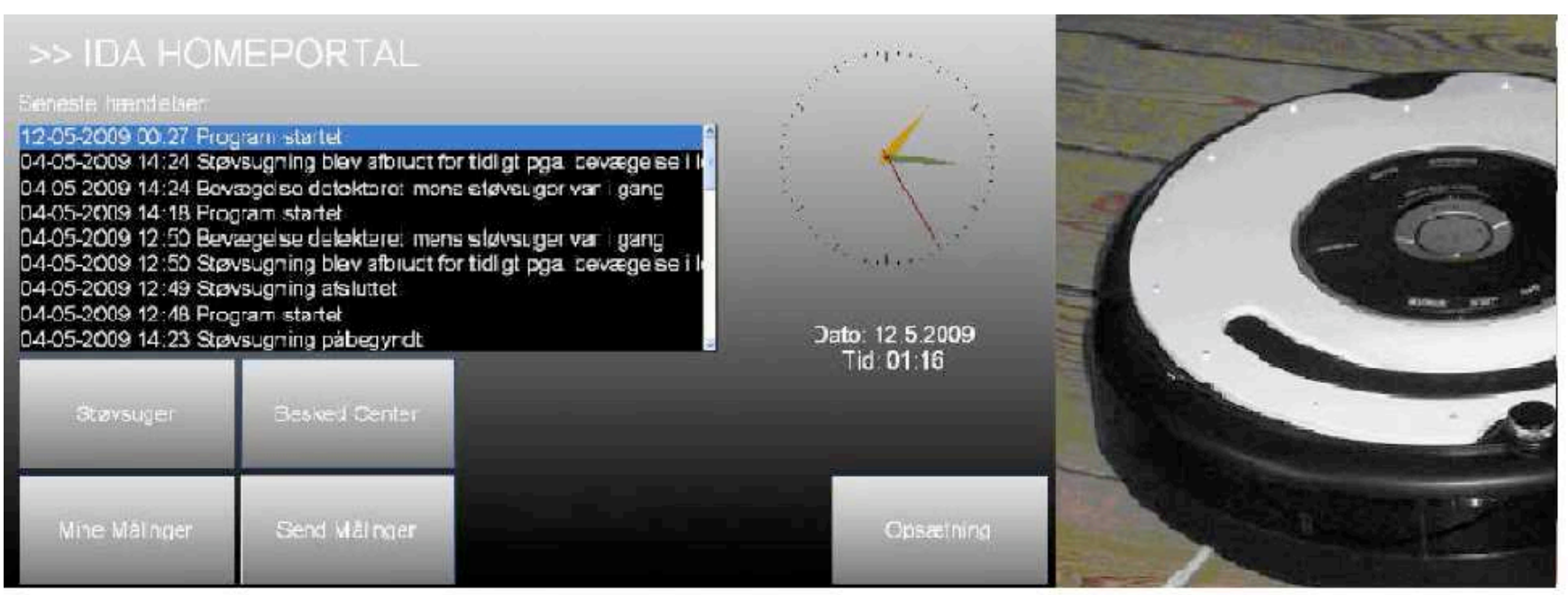

Fig. 1. Left: OpenCare HomePortal base-station user interface, adapted for special usage in the eldercare sector of Denmark. Right: The robot vacuum cleaner: OpenCare Cleaner (OCC) [5]. It is wirelessly connected to the HomePortal base station, and via this, to Facebook and Twitter. It can up date on starting and finishing of the device, and on "needs emptying".

network service (though they might be), this paper suggests that we might instead use automated services to upload relevant status updates to the social network services, not intended for the elderly themselves, but for their friends and relatives, in order for them to heighten awareness and strengthening the ambient social interaction.

This paper presents the case of the remote controlled, auditable and social network services-enabled vacuum cleaner: OpenCare Cleaner (OCC) (figure 1). Most existing robot vacuum cleaners available today are not equipped with auditing features, in the sense, that it is not possible to check the cleaning frequency, and how often it has, or has not worked as specified. This leaves most relatives as to guessing when the home of the elderly was vacuum-cleaned the last time, or whether it has been done at all. The OCCdevice is fully auditable as it is storing all operational data on the base-station. In the first version of the OCC-device however, the data was only stored on the base-station in the

\section{MATERIALS AND METHODS}

In order to illustrate and validate our suggested solution, the following steps were deemed necessary:

Surveying and selecting a suitable robot vacuum-cleaner

1) Adapting robot vacuum-cleaner hardware and software for the purpose of this study

2) Creating an infrastructure allowing the robot vacuum-cleaner to interface with the social network services application programming interfaces (API)

3) Surveying and selecting suitable social network services, including API's for accessing these 
Relative to 1: The iRobot Roomba 560 iRrobot, USA, robot vacuum cleaner was found suitable for this. While other vacuum-cleaners exists, the Roomba was the only which was accessible for hardware modifications.

Relative to 2: The Roomba needed to be modified and equipped with a Bluetooth remote control module, enabling us to remote control the device from another Bluetooth enabled device. Other wireless protocols than Bluetooth might have been chosen, including WiFi, ZWave, ZigBee or a proprietary protocol. Bluetooth has the advantage of being standard on many commercial off-the-shelves devices, including personal computers and cell phones.

To enable a command and control module for providing an infrastructure for auditing and communication, the existing OpenCare Project base-station, HomePortal was chosen (see figure 1). This platform is open source, and equipped with many relevant features, including SMS and email messaging, storage facilities and more. It would have to be altered to be able to communicate with the Roomba, as well as communicating using social network services.

Relative to 3: A prime concern was to identify suitable social network services, as well as finding and testing suitable application programming interfaces. Of the many, Twitter and Facebook was deemed the most relevant. A short introduction to these are given in the next section.

\section{Twitter}

Twitter is a free social networking and micro-blogging service that enables its users to send and read other users' updates. This is known as tweets. Tweets are text-based posts of up to 140 characters in length which are displayed on the user's profile page, and delivered to other users who have subscribed to them. Senders can restrict delivery to friends or allow anybody to access them. The latter are known as followers. Users can send and receive tweets via the different sources, including the Twitter website, SMS text messages or external applications, like e.g. the HomePortal.

There are several API's available for communicating with [6]. This project selected the Twitterizer API [7], which is open source.

\section{Facebook}

Facebook is a free social networking website that is operated and privately owned by Facebook Inc. Users can join networks to connect and interact with other people. People can also add friends and send them messages and update their personal profiles to notify friends about themselves and their current activities (including when to vacuum-clean). Facebook appears more closed than e.g. Twitter, but has a greater number of users. For programming Facebook application several API's are available, including the Facebook Application Programming Interface $[8,9]$.

\section{RESULTS}

We have designed and implemented the OpenCare Cleaner (OCC), which is a modified standard iRobot Roomba 560 robot vacuum-cleaner. The OCC-device is able to communicate with a base-station computer using Bluetooth for safe and auditable operation. Its features includes amongst others intelligence that allows it to only start a cleaning task once it is safe to commence (e.g. no elderly in the vicinity that might fall over the device). It may also give spoken and visual warnings whenever it detects movement (using PIR motion detectors), while also being able to send the device back to its docking station if movement is detected. Finally, it is possible to audit the device, including providing updates on performance for interested stakeholders.

We have also managed to implement a Facebook application, which will plug-in to the Facebook web site, and integrate this with the HomePortal base-station software and thus Facebook enabled the device as proposed. Finally, we have also integrated it with Twitter, all using the standard available programming APIs.

\section{DISCUSSION}

This study has indicated that it is possible to utilize social network services for non-intrusive ambient information sharing between the elderly and their relatives and friends. This also implies that information such as a non-critical events of a vacuum-cleaner that is not working, or healthcare related issues such as minor delays in the elderly's medication compliance (if the elderly is forgetting to take the medication at the prescribed time), or the elderly forgetting to measure their blood-pressure at the prescribed interval, could all be shared using these services.

Several ethical questions need to be addressed on this topic. Will the users even know they are being surveyed in such manner, and how may they object to this surveillance?

Whether users would actually want this type of non-critical information served in an ambient manner as proposed in this paper, or rather might prefer a more intrusive type of notification, such as an email or SMS text message. Or whether they might in fact prefer not to be bothered by this type of information at all, and would rather choose to stay uninformed instead, remains open for discussion and further user studies.

Minor scale qualitative user studies have been planned to commence in the near future to collect further data on this issue, once testing in the lab-setting for validation of functionality and durability in daily use have been completed. One of the challenges at present is finding a suitable methodology for clinical testing; including 
uncovering exactly which results we are actually hoping to obtain from the clinical studies. Also, we plan on integrating more non-critical sensor data into Twitter and Facebook, including overall activity data (how much is the user moving, how long is the user staying in bed etc. using accelerometers and pressure-sensors), medicine compliance (through the use of the Automatic Medicine Dispenser device, blood-pressure usage, logged visitor information and more [1].

In the case of critical events, social networks might not be the most obvious. Critical events needs media that supports the urgency. Here SMS and email might not be much better suited, as these technologies are also asynchronous by nature.

Finally, it might be added, that these types of services might also raise several concerns with regards to security and privacy. Might these data be captured by insurance companies, burglars and other potential criminals with malicious intensions? Security and safety is a huge topic, which needs to be discussed further, including how to deploy a solution, and which users should be invited to share information.

\section{REFERENCES}

1.Wagner, S. (2008). Towards an open and easily extendible home care system infrastructure. In: Proceedings of the 2nd International Conference on
Pervasive Computing Technologies for Healthcare, Tampere, Finland.

2. OpenCare Project. (1.4.2009) Online available at: http://opencareproject.com

3.Boyd, D., Ellison, N. (2007). Social Network Sites: Definition, History, and Scholarship. In: Journal of Computer-Mediated Communication, volume 13, issue 1, November 2007.

4. Kumar, R., Novak, J., \& Tomkins, A. (2006). In: Structure and evolution of online social networks. Proceedings of 12th International Conference on Knowledge Discovery in Data Mining (pp.611-617).New York: ACM Press.

5. OpenCare Project. (1.4.2009). Online available at: http://opencareproject.com

6. Twitter Libraries. (1.4.2009). Online available at: http://apiwiki.twitter.com/Libraries

7. Twitterizer Library. (1.4.2009). Online available at: http://code.google.com/p/twitterizer/

8. Facebook Application Programming Interface. (1.4.2009). Online available at: http://wiki.developers.facebook.com/index.php/Main_Pag e.

9.NET Facebook API Client. (1.4.2009). Online available at: http://facebook.codeplex.com/ 


\section{Experiencing Democracy - a Research Proposal}

\author{
Pär-Ola Zander \\ Aarhus University \\ Department of Computer Science \\ IT-huset, Åbogade 34 \\ poz@cs.au.dk
}

\begin{abstract}
This paper presents a literaure study, which results in a research idea within the field of HCI and e-governance: Digital mediation of municipal land use planning, with focus on mobility and experience. Related literature, in particular public participation GIS (PP-GIS) and participatory urban planning, is presented, followed by an argument for why the research idea can contribute. The key theories that can be used in understanding the design space are presented, in order to make the project idea concrete enough to be possible to inspect critically.
\end{abstract}

\section{Keywords}

Web 2.0, e-governance, user experience, map-based communication, democracy

\section{INTRODUCTION}

The web 2.0 trend [10] continues to spread over the Internet. Increasingly, the public sector tries to learn from the trend, but it is still unclear how many of the web 2.0 ideas that work in the voluntary sector or in business will manifest in a public sector setting. Our project, eGOV+, tries to address this challenge.

This paper presents a research idea within the field of HCI and e-governance, which is to be realized during 2010 , concerning the digital mediation of municipal land use planning. One of the most important documents in the governance of municipalities is the municipality plan (Danish: "Kommuneplan"). These municipality plans are constructed in a process that takes several years from start to publication. Once published, it is a static document that is used to create local plans (Danish: Lokalplaner), which may be dynamic. While the existing plan is still valid, the complex process of creating its successor plan is started. Municipality plan making can be metaphorically thought of as cross-country skiing. - there are limits for how far the new plan can distance itself from the currently operating plan.

This paper discusses how this process can be supported by information technology (IT) in ways that can yield interesting research results to the HCI community and its supporting disciplines. The first step is a short introduction

\author{
Morten Bohøj \\ Alexandra Institute \\ IT-huset, Åbogade 34 \\ bohoej@cs.au.dk
}

to the practice of municipality plan-making. Secondly, we review literature relevant to this field, and are probing for a gap where it is feasible to contribute. When the gap is identified, a possible approach is sketched, without presupposing more than the limited context knowledge allows.

\section{MUNICIPALITY PLANS}

It is built into the democratic constitution of how municipalities are operating that municipality plans should not be the pure work of bureaucrats, but created in cooperation between citizens and municipality. What this means exactly has been interpreted in various ways. A common strategy is first to make the internal negotiation between political parties and experts within the municipality, until a compromise early version of the plan is created. Only then are the citizens involved in "hearings" where they can provide feedback. On the practical level, a central problem is that few citizens choose to get involved in these hearings. This is a problem for researchers within the field of urban planning as well, there is no known master solution.

\section{RELATED WORK}

One side of the problem is the practice of making plans in a public sector context. This is of course a type of activity that has been carried out long before office work and communication begun to be digitalized, and is generally known as land use planning, and sometimes as urban planning (although the setting may be more rural than urban).

It is well-established that ICT can be used in order to facilitate urban planning $[3,9,12,14]$ recommend that researchers engage in development of versatile web mapping technologies truly founded on web 2.0.

\section{The Technical Side of the Plan-making}

The content of municipality plans are to a large degree map-based, or consists of text that makes reference to maps. Some of the content is not related to maps (for instance it can also consist of manifests and visions of the childcare quality), but it is the exception rather than the rule. Therefore, geographical information systems (GIS) are an almost necessary component, both the more interface-related questions of how to present and interact 
with the maps, but also integration with systems that can populate these maps with data overlays.

Many GIS systems are built for specialists, but over time a vibrant research community that engages with questions of public participation has emerged, the so-called PP-GIS community (see www.ppgis.net). The research interest here is not exclusively HCI, but it is an integral part all since 1963[11]! Contemporary work includes for instance PPGIS and usability engineering, and case studies on Land use planning of forests. Actually, over 500 published studies on PPGIS in local communities have been carried out! [7]. Somewhat surprisingly, a large portion of these has been carried out in the third world. A recent example and interesting example on a study in Scandinavian settings is Nuoja \& Kuutti [9]. It is an attempt to support for acquisition of local knowledge, and is based on web 2.0 principles, where participants had the opportunity to discuss map issues on web-based maps, and support maps with images. Amongst other findings, [9] report that the citizen suggested things that were too general for the planners to incorporate in a revised version of the land use plan. The authors conclude that when mobile phones with integrated camera and GPS will become common among citizens it is an area for future research.

Mobile GIS has of course been massively investigated, not the least since the advent of Google Maps, which fits well into the Web 2.0 paradigm by supporting mashups. When searching, it is important to distinguish between mobile phones and GPS. Many PPGIS with GPS has included semi-professional teams that have went by car and brought laptop equipment, a setting that is quite different from a focus where interaction with the municipality is more adhoc and integrated in everyday life. Map annotation and collaboration over mobile phones is also an investigated area; on the technical side we have found HyCon [2] interesting, and in particular the possibilities to collaboratively annotate maps and handle GPS coordinates as context.

The Danish municipality Hedensted in 2007 tried to use interactive maps on the municipal website to get information from the citizens about dangerous places in the traffic. In collaboration with the consulting company Grontmij Carl Bro, the municipality developed a webservice where citizens could draw directly on a map where they thought there was a dangerous place and leave a comment on why they thought this place was dangerous. The information collected this way was then taken into account when developing the future plan for traffic improvement. Although not explicitly incorporated in the municipality plan, we think of it as an inspiring example of what can be done from a technical perspective (teknisk afdeling, 2007 [5] .

\section{The Human side of the Plan-making}

When citizens are involved in planning, a common method is focus groups. One of the biggest alleged advantages of this approach is that its feedback results have less representational flaws than many other approaches.

When broad calls for commenting on the municipality plans are made, public meetings are arranged. The drawback of this approach is that these meetings favour extrovert, courageus, and quick-witted persons.

Another common approach when it is specifically maps that are at focus is so-called transect walks. For instance Shresta's [13] planning processes were carried out through transect walks where experts and locals walked together while discussing data and specific spots, with a common GPS unit. This was combined with feedback opportunities from the community (not in-situ), and finally the definitive plan for the forest area was made.

Citizens' attitudes towards public participation have of course been researched. Westholm [14] reports that citizens prefer focused, selective, and limited local-level involvement. However, also more ambitious approaches have been suggested. Today's municipality plan processes are often quite top-down-oriented in their approach. It may be instructive to think about alternatives of pure bottom-up approaches [4]. If steered from the municipality, they may superimpose some directives or biases, either involuntarily or deliberately.

The bottom-up perspective is also weakly present in other aspects. [9] argues that even if local knowledge has been acquired in some projects, there is a total lack of studies of the impact on the decision processes. It would be worthwhile if a study could see any propagation of change from the "acquisition" to the actual content of the municipality plan.

Another challenge is that the municipality and its planners sometimes have a problematic conception of citizen participation. They see it not as a way to get the perspectives of others (indeed, sometimes the only way to get the participation of others) - instead they see it as a (often poor) way of delegating their work, e.g. taking illustrative pictures [9].

The processes of sense making of municipality plans have not been that well understood. Let us assume that socially, a municipality is constituted by local communities. When individuals act in the context of these communities, the community culture, history and collective memory shape the interpretative frames through which each potential municipality plan participant derives meanings for their actions. The support for such sense making is however severely limited in interaction with contemporary PGIS applications [6].

\section{OUR PROPOSED IDEA}

We have not found a single study that reports the combined setting of PP-GIS, mobile phones, GPS and a governmental context. The closest we have found is Shresta [13], who is mentioning an ongoing such project (however in Nepal), but it is yet to be reported. So from a context perspective, 
we feel confident that we will be able to report accounts that are novel in some sense. There will probably be some technical challenges as well that might be worthy to address.

HCI research clearly has a role to fulfill in the development of PP-GIS. We are troubled by propositions like the journal article [6] from 2009 which discussed the future of PP-GIS for local communities only noted that now it is possible to use web-based GIS also on the mobile phones, just as the applications were to be used in the same way as at the office. We rather assume that mobile use now and in the foreseeable future is qualitatively different - when it comes to user experience, when it comes to what works and what does not in interface design, and in interaction ecology.

Despite the fact that experience-based approaches has become very popular in HCI, and that pragmatic/experiental and phenomenological approaches to social science has been popular for decades, we have not been able to find any research on the experiences of democratic actions. Political science has limited itself to investigations of attitude, and has always imposed an external order of democracy from historical or philosophical conceptions, rather than trying to describe the local meanings of democracy [1]. Even less, have they studied the experiences of local democratic acts, such as giving feedback to the municipality. Furthermore, we make the assumption that citizens in general, when faced with the choice to participate in municipality plan writing, do not give that plan a strong connection to their personal meaning in everyday life, nor do they get a concrete sense for what a municipality plan is. A focus of experience may provide an understanding of why the connection between plan and life is not there - or explain how it is there and invalidate our assumption. Furthermore it may provide design alternatives that enable a richer experience of democratic actions.

In theorizing experience, we find McCarthy \& Wright [8] and their pragmatist aesthetics a promising approach. Although not being the only approach to understanding experience, there is a reason for why it is particularly appealing. The first is that one of the main influences, John Dewey, is not only a pragmatist but also a thinker who not only believed in democracy but also put it at the center of his philosophical writings. It is therefore remarkable that no one has cared to describe the experiences of democracy from a Dewyian standpoint.

Since there is little knowledge about these crucial aspects, it seems suitable to make more studies of context. Our eGov+ project has conducted several participatory designoriented design research in other domains, and we see no reason to why this approach should be less feasible here. Our long-term research goal in this aspect is to understand how PD methods work in the context of web 2.0. An adequate way to get design-relevant descriptions of experience is via interviews [8]. We will try to establish a partnership with some NGO concerned with development within the municipality, in order not to get citizens that are much more involved and enmeshed in the municipality workers' networks than most citizens. We do deliberately hold back from conceiving more concrete design solutions before the field studies has begun to yield results.

The municipality that we are cooperating with is about to launch a series of hearings for their municipality plan. Observing the interaction patterns in these meetings seem to be a promising source of inspiration. In parallel with these user-oriented activities, we will design mockups and running prototypes. They will serve as crystallizations of our present design knowledge and enable us to refine it in dialog within the research team but also with citizens and municipality. In our prototyping process, we will also look into ways of combining the mobile and the web platform, and shed light on some of the considerations that the municipality should have when providing this kind of service.

Our eGov+ project has the explicit goal of combining democracy and efficiency. A prototype should strengthen the participation of the municipality plan AND create a more efficient municipality plan process, although it is not our ambition to intervene in all stages. Another explicit goal is to increase the knowledge of how visualizations can be utilized in e-governance, and the uses of maps for visualization are almost infinite in alternatives, some better than others. Consider a working hypothesis we have (and which we thorugh the use of visualization hope to substantiate our understanding of underway:

Citizens have unrealistic expectations of how complicated society is and do not understand the process from feedback to integration in municipal practice is; it is a black box from their point of view. The citizens who act may have naïve expectations of the flexibility of the system, and when they act, little happens due to the complexity of actors and artifacts. Our hypothesis is that it results in that the citizen gets alienated from the political processes. This is important to pay attention to in several ways. Firstly, because we may design for transparancy and thereby sidestep the problem. Secondly, in order to avoid to make it worse. By providing the citizens with more options for influencing municipality decisions, we risk to contribute to the heightening of these expectations and may in turn end up disappointing the citizen due to his or her unrealistic expectations. With a design focus on visualization and experience, we hope that we can keep the processes more transparent.

\section{CONCLUSIONS}

The literature review on PP-GIS, the literature on democracy and e-democracy does leave a relatively unstudied gap in the intersection between PP-GIS, mobile technology and support for local democratic acts. Furthermore, the literature demonstrates a neglect of the experience of such acts. We investigate if this area seems feasible for a PD research process with Web 2.0-inspired prototyping, and find it potentially fruitful. The next step in 
our eGov + project is to start design activity with our municipality partner. Follow our progress on www.egovplus.dk.

\section{REFERENCES}

1. Bishop, J. 2004. Locating democracy: Meanings and intersections in the Czech Republic. In White, C. \& Openshaw, R. (eds): Democracy at the crossroads: International perspectives on critical global citizenship education. Lexington Books: Lanham, USA.

2. Bouvin, N. O., Christensen, B. G., Grønbæk, K., and Hansen, F. A. (2003). HyCon: A framework for context-aware mobile hypermedia. The New Review of Hypermedia and Multimedia, 9:59-88.

3. Craig, J., W. 1998. How and why community groups use maps and geographic information. In Cartography and Geographic Information Systems 25 (2): 5-104.

4. Elwood, S. 2006. Negotiating knowledge production: The everyday inclusions, exclusions, and contradictions of participatory GIS research. The Professional Geographer, 58/2:197.

5. Hedensted Kommune. 2007. Internetundersøgelse udpeger nye pletter. Retrieved 2009-11-30 http://www.hedensted.dk/page27868.aspx

6. Kyem, P., Saku, J. 2009. Web-based GIS and the future of participatory GIS applications within local and indingenous communities. In Electronical Journal on Information Systems in Developing Countries, 38(7): pp. 1-16.
7. McCall, M. 2004. Can Participatory GIS strengthen local level planning? Suggestions for better practice. Paper presented at GISDECO2004, Malaysia.

8. McCarthy, J. and P. Wright (2004). Technology as experience. Cambridge, Mass., MIT Press.

9. Nuoja, J., Kuutti, K. Communication based web mapping: A new approach for acquistion of local knowledge for urban planning. In MindTrek'08, Tampere, Finland.

10. O'Reilly. (2005). "What is Web 2.0? Design Patterns and Business Models for the Next Generation of Software." Retrieved 30/11, 2009, from http://oreilly.com/web2/archive/what-is-web-20.html.

11. Pivar, M., Fredkin, E., and Stommel, H. 1963. Computer-compiled oceaographic atlas: An experiment in man-machine interaction. Proceedings of the national academy of science, p. 396-398.

12. Sawicki, D. \& Craig, W. 1996. Democratization of data: Bridging the gap between community groups. In Planner's Notebook, Journal of the American Planning Association, 62 (4): p. 512-523

13. Shresta, H., L. 2006. Using global positioning systems (GPS) and geographic information systems (GIS) in participatory mapping of community forest in Nepal. In The Electronic Journal on Information Systems in Developing Countries. Vol 25, pp. 1-11.

14. Westholm, H. 2002. E-democracy goes ahead. The internet as a tool for improving deliberative politics? Lecture Notes in Computer Science, 2456/2002, p. 240-247. Springer Verlag. 
